Digitized by the Internet Archive in 2008 with funding from Microsoft Corporation 


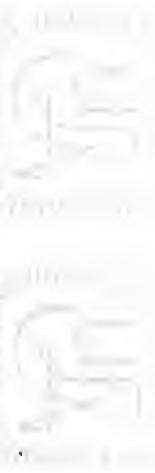





\section{THE \\ COMMUNITY hEALTH PROBLEM}




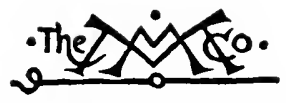

THE MaCMILLAN COMPANY

MEW YOEX - BOSTON - CHICAGO - DALLAS ATHANTA - SAN TRANCISCO

MACMILLAN \& CO., LiMited

LONDON - BOMBAY - CALCUTTA

MELBOURNB

THE YACMILLAN CO. OF CANADA, ITD. тоzokro 


\section{The Community Health Problem}

By

ATHEL CAMPBELL BURNHAM, M.D.

HEALTH SERVICE, ATLANTIC DIVISION, AMERICAN RED CROSS; ATTENDING SURGEON, VOLUNTEER HOSPITAL, NEW YORK CITY; LIEUTENANT COLONEL, MEDICAL RESERVE CORPS, U. S. ARMY; FELLOW NEW YORK ACADEMIY OF MEDICINE

\section{Antw Tark THE MACMILLAN COMPANY 1920}

All Rights Reserved 
Copyright, 1920

By THE MACMILLAN COMPANY

Set up and electrotyped. Published October, 1920 


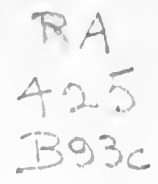

\section{PREFACE}

The various requests the writer has received for references to health literature dealing with what has come to be known as the community health movement, have indicated the desirability of a brief treatise upon the community health problem in its relation to the modern conception of social medicine.

The wclfare worker who is called upon to meet, from a practical standpoint, health conditions as she finds them either in the crowded tenement districts of the larger cities or scattered over a large territory in a rural community, often fails to accomplish maximum results because of a hazy and fragmentary understanding of the health problem and very $c$ indefinite ideas as to its solution. Public health nurses and C? practising physicians, who because of routine duties have been $\Rightarrow$ unable to follow the recent health literature, are sometimes handicapped in their work because of a lack of understanding of the modern movement toward the socialization of medicine. For such, and for all others interested in the improvement of health conditions as part of a community welfare movement, this work is intended.

The attempt has been made briefly to outline the health problem as it exists, and to indicate the most important of the measures which are being suggested for its solution, in order to permit the reader to secure in one small volume a fairly comprehensive understanding of social medicine in its relation to community health.

New York City. 


\section{TABLE OF CONTENTS}

Preface

CHAPTER I

The Health of the Community $\ldots \ldots \ldots \ldots \ldots \ldots$. 3

CHAPTER II

Sickness as a Cause of Ponerty $\ldots \ldots \ldots \ldots \ldots \ldots .15$

CHAPTER III

The Private Phisician and Community Health... 23

CHAPTER IV

Health Departments and Community Health.... 30

CHAPTER V

The Public Health Nurse .............. 38

CHAPTER VI

The Campaign for Better Health .......... 54

CHAPTER VII

Workmen's Compensation InsUrance $\ldots \ldots \ldots \ldots 67$

CHAPTER VIII

Compulsory Health Insurance $\ldots \ldots \ldots \ldots \ldots \ldots$ \% 75

CHAPTER IX

Industrial Medicine $\ldots \ldots \ldots \ldots \ldots \ldots \ldots \ldots . \ldots 4$

CHAPTER $\mathrm{X}$

State Medicine $\ldots \ldots \ldots \ldots \ldots \ldots \ldots \ldots \ldots .92$

CHAPTER XI

Health Centers . . . . . . . . . . . . . 99

CHAPTER XIT

The Social Unit Experiment ............ 108 
Tuberculosis $\ldots \ldots \ldots \ldots \ldots \ldots \ldots \ldots \ldots \ldots \ldots \ldots \ldots \ldots$

\section{CHAPTER XIV}

Social Hrgieyf in its Relation to Community Healtil ........................ 122

\section{CHAPTER XT}

Pemabilitation of the Disabled .......... 128 CHAPTER XVI

Exdowed Healtir Demonstrations .......... 139

References to Recent Poblications ........... 150 


\section{THE COMMUNITY HEALTH PROBLEM}

\section{CHAPTER I}

\section{THE HEALTH OF THE COMMUNITY}

The public liealth problem of today is a community problem. It is no longer possible to separate the health of the individual from the health of the community at large. Conditions of work, play, education, food supplies and transportation, which were at one time largely the personal concern of the indiridual have today become community problems and must be solved as such. The health of the individual, influenced largely by man's environment, presents a similar problem.

\section{THE RESPONSIBILITY FOR SICKNESS}

Responsibility for accident and disease is no longer considered merely as a personal problem, it is a community problem as well. Just as we insist that every American shall have the benefits of public education so should we insist upon the inherent right of every American to the possession of a body free from the handicap of preventable disease.

The causes of disease are found in individual, industrial and community conditions, many of which are under public supervision. These conditions must be studied and corrected by the community before any appreciable decrease in preventable disease can be attained. For example, in order to protect the growing child from infection with bovine tuberculosis the state health authorities may inspect and condemn infected cattle hundreds of miles away-cors which neither the child, nor his parents, nor eren his physician have ever seen. The community recognizes its responsibility in the case 
of borine tuberculosis but in the case of human tuberculosis the responsibility is less clearly defined. Some communities make fairly adequate provision for the eare of the tuberculous, others undertake the care of charity cases only and some make little or no provision for the treatment of patients suffering from this disease.

Until comparatively recently the problem of public health las been almost entirely one of prevention in the case of acute infectious disease. Small-pox, typhus and plague hare been all but completely wiped out. Scarlet fever and diphtheria have been greatly diminished. During the last few years there has been a praiseworthy stimulation of interest in the prevention of disease, with a consequent steady progression toward better health. The movement at present is, notwithstanding the rapid progress already made or, possibly beeause of the very rapid growth of the movement, somewhat inco-ordinate and characterized by a certain amount of duplication of effort and waste of energy which is, from the nature of things, unavoidable during the early stage of a movement of this sort.

\section{DISABILITI DISCOVERED BI THE DRAFT}

Examination of the records of nearly five million drafted men las focused attention upon the fact that there is in the United States a health problem which has been erally disregarded. Not entirely so, because during recent years many exhaustive health surveys have brought to light a tremendous amount of untreated illness, but such statistics have been read by comparatively few and have not made the same impression upon the popular imagination as have the more striking figures which resulted from the draft board examinations.

There is in every community, if we accept the figures of the Surgeon-General, a comparatively large amount of prerentable disease among young men between the ages of 18 and 31. The figures vary somewhat in different parts of the 
country and there is a rariation between the urban and rural population, but the figures taken as a whole represent an approximately accurate cross section of the country.

The following figures furnished by the Surgeon-General* of the U. S. Army, indicate the percentage of disability found in the examination of approximately 5,000,000 drafted men :

SOME IMPORTANT DEFECTS REVEALED BY THE DRAFT

Per Cent.

1. Defects of feet (flat-foot 11 per cent.)........ 13 .

2. Venereal disease-

During first period of draft.......... 2.9

In later period of draft ............ 5.7

3. Hernia and enlarged inguinal rings ....... 4.

4. Defective vision (largely errors of refraction).. 3.5

5. Defective physical development, including underweight and under-height ............. 3.5

6. Organic diseases of the heart........... 3 .

7. Deformities or loss of extremities.......... 3 .

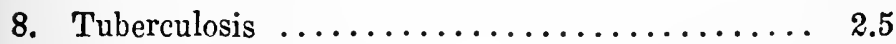

9. Hypertrophy of tonsils .............. 2.33

10. Defective and deficient teeth ............ 1.33

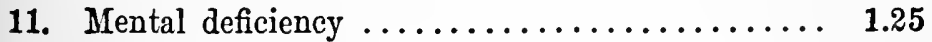

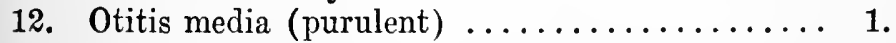

13. Hemorrhoids, varicocele, varicose veins....... 1.

14. Goitre (simple and exophthalmic) ........ 0.75

15. Deformities of the hand.............. 0.75

16. Cardiac arrythmias and tachycardia........ 0.50

17. Asthma ....................... 0.25

According to figures obtained from various sources the number of men disqualified for military service was found to vary between 21 and 34 per cent., depending upon the

-Ireland, Merritte W.; Physical \& Hygienic Benefits of Military TrainIng as Demonstrated by the War. Journal A. M. A., Vol. $i 4$; No. 18 , Feb. 21, 1920. 
statistics quoted. The records of the Surgeon-General show that 29 per cent. had some form of disability. Other records show a slightly higher figure. Suffice it to say that approximately one-third of the young men of the country were physically unable to perform full military duty. In the later examinations 14.5 per cent. were rejected by local boards as unfit for service and about 7 per cent. were rejected by military boards after having been sent to camp. Only fifty-three per cent. were accepted as fully meeting the military standard with no defects recorded.

If preventable illness (and physical disability which results from preventable illness) is found to such a great extent among young men during a period when the highest degree of physical development is expected, is it not natural to suppose that preventable illness exists in a proportionate amount in other members of the community?

This number errs on the side of conservatism for in the haste of mobilization many minor disabilities were overlooked and many men were taken into the Army as "physically fit" only to be found disqualified at a later date. It is safe to say that over one-half of the young men of military age show some form of physical defect.*

\section{SICKNESS SURVEYS}

So much for the military. Without attempting to determine whether adequate treatment had been available for the average drafted man and whether such treatment might have modified the findings, let us examine the status of the civilian population. In general, no such complete figures are available for civilians, but in recent years a number of health surveys have been carried out in rarious parts of the country with most striking results, which indicated that general conditions were at least as bad as those discovered in the draft.

- A report pnblished in the Journal of the American Medical Association (A pril 10, 1220), states that according to recent figures only 23 per cent. of the drafted men were qualified according to pre-war standards. 
Just what is a health survey and how is it carried out? As ordinarily understood a health survey is the examination of the health conditions in a given community especially with reference to disability due to injury and disease. In some cases only meagre details are furnished and include only a report of those seriously ill and unable to work. In other surveys every member of the community is carefully examined and a notation made of non-disabling conditions such as defective teeth, adenoids, varicose veins, and other similar conditions. As a consequence of the varying conditions under which health surveys are carried out, it is very difficult to compare figures given in different surveys without clearly understanding the methods adopted by the examiners.

Surveys are made difficult because of the fact that most adults object to a physical examination by a physician unless they are seriously ill. There are those who resent what they consider to be an intrusion into their private affairs and others who, while not actively antagonistic, show little inclination to supply information required to complete the survey.

For this reason, and others which are self evident, it has been much easier to make a health survey among children of school age than among either infants or adults. Consequently we are much better informed as regards the health conditions of children of school age than of other members of society. After making due allowance for those children who are crippled or too ill to attend school, the results of so-called "school examinations" offer reasonably accurate figures upon which to base an estimate of the general health of the community.

\section{EXAMINATIONS OF SCHOOL CHILDREN}

For some years Now York State has had a fairly comprehensive law requiring the examination of school children. During the year 1918 over 700,000 school children were examined and over 500,000 were found to have physical defects. In New York City defects were found in 77 per cent. of the children examined. In rural districts and villages 
the percentages were somewhat lower. The New York State Reconstruction Commission, in discussing these findings, suggests that the smaller percentages in rural communities are due to "the varying degree of thoroughness in examinations."

PHYSICAL CONDITION OF SCHOOL CHILDREN 1918 ₹20,176 Children Examined in N. Y. State

\begin{tabular}{|c|c|c|c|}
\hline Defects & $\begin{array}{l}\text { New York } \\
\text { City } \\
\text { Number }\end{array}$ & $\begin{array}{l}\text { Cities and } \\
\text { Villages } \\
\text { Number }\end{array}$ & $\begin{array}{l}\text { Rural } \\
\text { Schools } \\
\text { Number }\end{array}$ \\
\hline 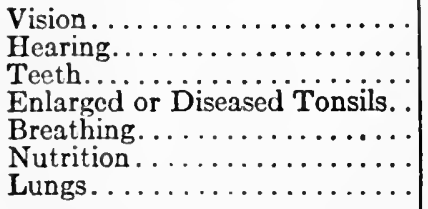 & $\begin{array}{r}23,362 \\
1,214 \\
161,686 \\
33,475 \\
25,168 \\
35,225 \\
742\end{array}$ & $\begin{array}{r}15,692 \\
2,511 \\
63,925 \\
29,756 \\
10,203 \\
4,578 \\
642\end{array}$ & $\begin{array}{r}18,591 \\
4,699 \\
70,561 \\
42,202 \\
17,455 \\
3,859 \\
834\end{array}$ \\
\hline $\begin{array}{l}\text { Total Number of Defective } \\
\text { Children.............. }\end{array}$ & $\begin{array}{c}190,898 \\
(77 \%)\end{array}$ & $\begin{array}{c}138,093 \\
(57 \%)\end{array}$ & $\begin{array}{c}177,063 \\
(63 \%)\end{array}$ \\
\hline
\end{tabular}

During recent years the Bureau of Child-Hygiene of Nerr York City has made a careful study of the subject of malnutrition in school children.* Ignorance of the nutritive value of foods, the high cost of food, carelessness in its preparation, and the use of food substitutes all play a part in the causation of mal-nutrition. Many cases were found to be secondary to physical defects such as enlarged tonsils, defective teeth, etc.

In a nutritive survey of school children an arbitrary standard, known as the Dumferline Scale, has been adopted for convenience of classification. This consists of four classes as follows:

Class 1. Excellent-the child is well nourished.

Class 2. Good-nutrition falls short of excellent.

Class 3. The child requires supervision-borderline.

Class 4. Nutrition seriously impaired-requires medical treatment.

- Report of the Public Realtb Committee on Reconstruction. IEw Yors \&tate, Oct. 24, 1919. 
During 1918 nearly 200,000 school children were examined and graded for nutrition with the following result:

\section{EXAMINATION OF SCHOOL CHILDREN, 1918} City of New York

\section{Public Parochial}

Schools Schools

Class $1 \ldots \ldots \ldots \ldots \ldots \ldots 35,606$

5,372

Total

Class $2 \ldots \ldots \ldots \ldots \ldots \ldots .92,588$

15,702

3,908

40,978

Class $3 \ldots \ldots \ldots \ldots \ldots \ldots 25,346$

Class $4 \ldots \ldots \ldots \ldots \ldots \ldots, 5,205$

Totals ...........158,745

$\frac{647}{25,629} \quad \frac{5,852}{184,374}$

It is estimated that the number of children in Class 4 has increased during 1919, since the cost of milk and butter has risen so high that many families have economized by cutting down on the daily supply, substituting other less nutritious foods.

Of the children requiring medical treatment probably only a comparatively small number actually are receiving medical attention. Some are under the care of private plissicians and others are being treated by welfare associations and dispensaries, but a large number are neglected and will continue to be neglected unless treatment is insisted upon by school authorities or by welfare organizations.

\section{COMMONITY HEALTH SURVEYS}

Among adults there are few surveys which indicate physical disability with the same anount of detail as is found in the draft board and school reports. As has been noted, adults are apt to object to physical examination and consequently most of the surveys include only personal statements as to actual disability.

In six surveys made by the Metropolitan Life Insurance Company covering a total of 637,000 persons holding policies, 
it was found that there were 12,114 , or 1.9 per cent., who were sulfering from an illness severe enough to prevent them from going to work. In addition to this number about 1200 were sick but were still able to work. No attempt was made to discover those suffering from light illness and non-incapacitating disability. In the Chelsea surrey the figures were $\mathbf{1 . 5}$ per cent. sick, and 1.4 per cent. disabled. In North Carolina the figures were 2.85 per cent. sick, and 2.3 per cent. disabled.

Information as to adult sick rates may be secured in another way, that is, by considering the number of days sick per year for each member as shown by the records of sickness and death benefit societies. Such records compiled by the Bureau of Labor Statistics show that, for all ages, there was a disability rate (per insured person) of 6.6 days per year. This figure is approximately 5 days per year for insured persons under 35 years of age and gradually increases to 15 days per year for members 70 and over.

In time of epidemic the amount of sickness may be greatly increased. During the epidemic of influenza in 1918 it was shown that in a total of 148,245 persons canvassed* in various parts of the United States, 43,580 suffered from an attack of influenza. This is a case rate of 29.4 per cent.

\section{FRAMINGHAM HEALTH DEMONSTRATION}

In the Framingham Community Health and Tuberculosis Demonstration a careful health survey was made of the entire community.** Every individual who would permit examination was systematically examined by a physician trained in this work. In all, 4,473 persons were examined during a period of several days.

Minor ailments such as colds and defective teeth were included with the result that 3,456 or 77 per cent. were found to show plysical disability of some sort. This is an enormous

- Annual Report U. S. Public Health Service, Washlngton, 1919.

- Armstrong, Donald B.: Framingham Monograph No. 4; Community Eealth Station, Framingham, Mass, November, 1918. 
figure, and, as might be expected, represents largely "minor ills." These may be classified as follows:

MINOR ILLS IN EXAMINATION OF 4,473 PERSONS

Defective teeth ................,

Enlarged tonsils ................ 563

Colds, coryza, ete. .............. 132

Bronchial pulmonary aflection (undiagnosed) 265

Glandular system ................ 277

Miscellaneous .................. 100

2,443

Of the major ills there was a total number of 1,113 of which 96 were pulmonary tuberculosis. The number seriously ill represented 25 per cent. of the total examined.

The result of these examinations shows the large amount of illness usually disregarded. In this same group a census taken before the examinations showed only 6.2 per cent. who reported any illness. Compare this number with 77 per cent. as found by the medical examinations or even with 25 per cent. which represented those having "major ills."

Of the total number of affections found, both minor and serious, Doctor Armstrong estimates that 61 per cent. are either "theoretically preventable or easily remediable," while about 15 per cent. are non-preventable. The balance are classed as "doubtfully preventable."

\section{HEALTH IN THE ARMY}

If we turn now to the report of the Surgeon-General, U. S. Army, for 1918, we find that among picked men (remember a large number were not accepted for the Army because of physical disabilities) there is always a fairly constant sick rate. This is called the non-effective rate, meaning thereby that among a given number of men a certain number per hundred are "non-effective" or unfit for duty. The non-effective 
rate for 1917 among enlisted men was 22.21 per 1,000 in the United States. In Europe it was slightly less and in the Philippines considerably more. Over a series of years the Army non-effective rate runs pretty regularly between 2 and 3 per cent. There are sereral factors which tend to make the rate lower in the Army than in civilian life, chief of which is the fact that soldiers are carefully picked young men presumably able to do full duty when enlisted. In addition, when soldiers develop chronic diseases they are discharged so that such diseases as tuberculosis and chronic nephritis play a comparatirely small part in the non-effective rates.

\section{THE SICK IN THE COMMONITY}

If the figures already giren are carefully considered it will be seen that while there is abundant evidence of illness in a given community, it is rather difficult to state exactly any figure which would fairly represent the total number requiring treatment at any one time, but by a consideration of the facts we may judge rather closely the number seriously ill.

If we start, for example, with a consideration of those who are too ill to work we will find that, excluding the number, who have a permanent disability unsuitable for treatmentsuch as an amputated leg or deformed liand-there is a fairly definitely fixed percentage which represents those incapacitated. This figure is as a rule between 2 and 3 per cent. At times it may drop below this figure and during epidemics it may rise as high as eight or ten per cent. or even higher.

Of this 2 per cent. probably at least one-half should be under hospital treatment so that in any given community there should be at least one hospital bed for every hundred persons. As a matter of fact this number is very conservative, it being claimed by many that two hospital beds for every hundred persons is the least number consistent with adequate treatment. In military camps where there are no accommodations for "home treatment" this number should be increased to at least 5 per cent. in time of peace and considerably more during war. 
In addition to those unable to work because of illness there is a certain percentage who feel the effects of illness but continue to work (among these are eases of chronic heart disease, tuberculosis, kidney disease, chronic bronchitis and many minor ailments). This is usually estimated as about 2 to 4 per cent., so that the figure for the total acknowledged illness will usually average pretty elose to 6 per cent.* That is to say, that if one physician should undertake the care of a typical community of a thousand persons he would have about 60 patients at all times. This does not mean that such a physician would see 60 patients a day. Many would be at work, reporting for treatment weekly or monthly, or possibly even less frequently.

If we accept the figure of 6 per cent. as representing the number in a community who admit illness and acknowledge the necessity for treatment, we still have a considerable discrepancy between this figure and the figures obtained from the draft boards, school surveys and the Framingham survey quoted above. Part of the discrepancy is due to those who suffer from a permanent disability such as a deformed hand or amputated finger and do not consider that they are ill; part is due to the ignorance of the symptoms of disease; and a large part is due to minor ills which for economic reasons have been untreated and are consequently disregarded.

However the exact percentage of sickness in a given locality is of less importance than is the fact that, in each and every community, there are constantly found some persons seriously sick, some ill but not incapacitated, and a large number of others suffering from minor ills of more or less consequence. The efficiency of the methods adopted in dealing with these conditions has a direct, influence on the social and economic life of the community.

Every community should examine closely into the preparation it makes for care of its citizens' health. Do the sick receive adequate treatment? Are there sufficient hospital beds?

-In Dr. Armstrong's health census the number who said they wero sick represented 6.6 per cent. of the total surveyed. 
Are proper measures being taken to educate the mother in the care of her child and is every effort being made to decrease prerentable disease and to diminish remediable ills?

It is not enough to increase wages and to expect the indiridual to secure medical treatment. Erery patient suffering from an infectious disease is a menace to his neighbors, and every case of disability is an economic drain on the community as a mhole. Education of the medical profession has decreased illness but not sufficiently to wipe out certain easily prerentable diseases; public education has not, up to the present, sufficiently influenced physical health

Neither increased wealth nor advances in medical science will develop the full resources of the youth of the nation unless directed by a well-planned concerted effort to apply the lessons taught by medical science to the every-day problems of public health. 


\section{CHAPTER II}

\section{SICKNESS AS A CAUSE OF POVERTY}

In the struggle between capital and labor the pecuniary rewards of the workman have steadily increased, and this was true even before the World War upset all pre-war standards. The recent rapid increase of wages combined with a diminished supply of labor has tended to decrease the ordinary evidences of poverty. Bread-lines are strikingly short; municipal lodging houses have few guests; and unemployment is at the minimum rate for many years.

There is, however, still considerable poverty due to disease. The increased income has not, as might be expected, been hoarded against the proverbial rainy day but has been expended for luxuries of a temporary character. The workman receiving an unprecedented high wage is living better than erer before. More automobiles, more phonographs, and more fine clothes have been purchased by wage earners than ever before. Moving picture theatres are flourishing, candy and soda-water is sold in enormous quantities, and silk has become the daily raiment of the skilled worker. This is perhaps as it should be. Certainly labor has waited a long time for the coming of the day of high wages and is entitled to a few of the luxuries of life, but it is certain that the average wage earner is not saving any considerable portion of his wage as an insurance against loss duc to illness. There is today, in every large city, an enormous number of persons entirely dependent upon charity as a direct result of sickness and there will be more when the present boom hegins to diminish, and still more when really hard times arrive.

Prosperity during and after the war tended in one way to decrease poverty due to physical disability. In every com- 
munity there is always a certain number of crippled and subnormal individuals who are unable to secure any sort of remunerative employment during periods when supply of labor exceeds the demand. In the prosperity which followed the World War most of these individuals secured employment at a living mage. Others, however, who are actually too ill to work are less fortunate. The increased cost of living and the diminished purchasing power of the dollar makes their plight doubly difficult and throws an increased burden upon the resources of charity. When sickness occurs it is found that the cost of medicine has increased, medical attention is considerably more expensive than during the pre-war period and rents and household expenses have more than doubled.

So that we find that, even with high wages, illness of the bread-winner of the family, for an extended period, often results in economic distress. This is true in the calse of the wage earner so frequently as to be considered the rule. Those who are especially wasteful are almost immediately plunged into poverty; those who have greater means do not feel the pinch of want until later; while a few of the more provident may pass through a fairly long illness without actual distress.

Edward T. Devine of the Charity Organization Society of New York City says in his book "Misery and its Causes": "Ill health is perhaps the most constant of the attendants of porerty. It has been customary to say that 25 per cent. of the distress known to charitable societies is due to sickness. An inquiry into the physical condition of the members of the families that ask for aid, without taking any other complication into account, clearly indicates that whether it be the first cause or merely a complication from the effect of other causes, physical disability is at any rate a very serious disabling condition at the time of application of three-fourths-not onefourth - of all the families that come under the care of the Charity Organization Society."

Sickness acts as a double cause of poverty. There is, first the direct loss due to the cessation of regular income and, 
second, the loss of savings due to expenses for doctors' and nurses' fees and for medical supplies.

The loss due to idleness has been estimated to be equal to an average of nine days' wages per year. The Pennsylvania Health Insurance Commission estimated that in that state alone employees are losing more than $\$ 39,000,000$ annually because of sickness. In the Kensington Survey the wage loss was reported in 367 cases and averaged $\$ 78.53$ per case. In only a small percentage of employees are wages continued during sickness, probably not more tlan five or six per cent. Illness may act further to increase poverty through its results. Frequently after an attack of rheumatism or typhoid or other disease, the body is left so shattered from the effeets of the illness, that the former occupation is beyond the strength of the individual. Consequently a new and lighter occupation must be chosen which results in diminished earning power.

The expenditure for sickness varies considerably in different families and in various localities. Many of the poorer families spend as much, or more, for patent medicines (self-medication) as they do for medicines prescribed by physicians. In a number of families studied in Philadelphia, the average expenditure for this purpose was over $\$ 5.00$ a year. In a survey by the United States Bureau of Labor Statistics the expenditures for medical relief of families with varying income was studied with the following findings: 
YEARLY EXPENDITURES FOR SICKNESS

Washington, D. C., 1916

\begin{tabular}{|c|c|c|c|}
\hline Income & & $\begin{array}{l}\text { Number } \\
\text { of } \\
\text { Families }\end{array}$ & $\begin{array}{c}\text { Yearly } \\
\text { Expenditures }\end{array}$ \\
\hline Under $\$ 600 \ldots \ldots \ldots \ldots$ & $\begin{array}{r}\text { Total ........ } \\
\text { Whites.... } \\
\text { Colored... }\end{array}$ & $\begin{array}{l}65 \\
45 \\
19\end{array}$ & $\begin{array}{l}\$ 12.01 \\
12.83 \\
10.03\end{array}$ \\
\hline$\$ 600-\$ 900 \ldots \ldots \ldots \ldots$ & $\begin{array}{r}\text { Total ........ } \\
\text { Whites.... } \\
\text { Colored... }\end{array}$ & $\begin{array}{l}235 \\
115 \\
118\end{array}$ & $\begin{array}{l}20.81 \\
25.52 \\
16.20\end{array}$ \\
\hline$\$ 900-\$ 1,200 \ldots \ldots \ldots \ldots$ & $\begin{array}{r}\text { Total ........ } \\
\text { Whites.... } \\
\text { Colored.... }\end{array}$ & $\begin{array}{r}215 \\
167 \\
48\end{array}$ & $\begin{array}{l}40.19 \\
42.31 \\
32.81\end{array}$ \\
\hline$\$ 1,200-\$ 1,500 \ldots \ldots \ldots$. & $\begin{array}{r}\text { Total ........ } \\
\text { Whites.... } \\
\text { Colored.... }\end{array}$ & $\begin{array}{r}209 \\
195 \\
11\end{array}$ & $\begin{array}{l}42.42 \\
43.16 \\
28.95\end{array}$ \\
\hline Over $\$ 1,500 \ldots \ldots \ldots \ldots$ & $\begin{array}{r}\text { Total ........ } \\
\text { Whites.... } \\
\text { Colored... }\end{array}$ & $\begin{array}{r}198 \\
191 \\
7\end{array}$ & $\begin{array}{l}58.71 \\
59.57 \\
35.21\end{array}$ \\
\hline Average, all incomes.... & $\begin{array}{r}\text { Total ........ } \\
\text { Whites.... } \\
\text { Colored... }\end{array}$ & $\begin{array}{l}922 \\
692 \\
230\end{array}$ & $\begin{array}{l}37.75 \\
43.59 \\
20.19\end{array}$ \\
\hline
\end{tabular}

This of course does not include the free treatment at charitable institutions, such as hospitals and dispensaries, which would amount to considerably more. Therefore it is safe to say that medical attention and medical supplies cost each family at least $\$ 40$ per year under conditions such as exist in large cities. In rural districts it is possible that the expenditure is a little less.

Thongh this expenditure is not large, it should, if it were expended scientifically and efficiently, purchase a fairly satisfactory medical service. However, under our present system 
the money is to a large extent not well spent. In the first place it is spent almost entirely after illness has oceurred. Only a small amount is devoted to the prevention of disease. Compared with the amount spent for the cure of illness the community spends only a comparatively insignificant amount for prevention, possibly from one to three dollars, ${ }^{*}$ per capita, yearly in cities and very much less in most rural communities. In the next place the care of illness is left largely to the patient himself. When he decides he needs medicine he proceeds to buy patent medicine; when he thinks he needs a doctor he secures the services of one, if he can afford the expense, only when he is convinced that there is no other alternative. In many cases this is too late to securc the best results. The physician, being paid to cure disease and not to prevent it, devotes most of his energies to curative medicine and very little to prevention.

The experience of the Rockefeller Foundation in certain southern communities has thrown considerable light upon this point. In certain eases they have found that by expenditures directed toward the prevention of malaria they were able to reduce malaria almost to the vanishing point and this at $a$ cost of less than had previously been spent for treatment of the disease.

In an experiment carried on by the Foundation in Arkansas an attempt was made to rid four towns in the state of malarial infections by means of well recognized measures for the extermination of the mosquito. Pools were drained or filled, sluggish streams were ditched and oil was applied to surface water which could not be otherwise dealt with. In other words the atiempt was made to make these towns unhealthy places for the disease-carrying mosquito.

The results were measured by the number of visits made by physicians to patients suffering from malaria. In 1916, before the experiment, the number of calls made in the town of Ham-

The expenditures of the New York City Department of Health is abont 65 cents per capita. This amount is increased by State and Federal expenditures and by voluntary donations. 
burg, Arkansas, was 2,312; in 1917, the year of the experiment, the calls dropped to 259, and in 1918 to 59.*

In this town of only a few orer a thousand inhabitants the per capita cost of the conquest of malaria was $\$ 1.45$ in 1917 and 44 cents in 1918 .

Similar results could not be secured in erery community, but there are many towns and villages in the United States where comparable results might be obtained.

The element of charity in free medical treatment, whether provided from the public purse or by charitable organizations, has prevented a certain portion of the community from accepting free treatment even when it is offered. There is a certain portion of the population, perilously near the porerty line which resents the implication that it is unable to pay for medical care. This follows closely on the experience of the early days of education. The "free school" was for the very poor, the pay school for the well-to-do and nothing for the middle class. Many children were denied the benefits of education because their parents refused to send them to the free school. It is the same today with regard to medical care. Free medical care is available to a limited extent but self respecting wage earners often prefer to do without treatment rather than to deprivo others who may be more in need of help.

It is easy to determine for yourself the effect of prolonged illness as a cause of poverty and want. Examine a given number of wage earners, say twenty or thirty, and find out how many of them could stand the financial strain of a disability lasting six months or longer. Such a disability might easily occur as a result of a broken thigh or an attack of nephritis and yet only a few have enough moncy in bank to begin to pay the necessary expenses of such a long illness. Yet scattered over the entire population such a period of disability occurs comparatively seldom and could be easily met by some form of insurance.

- Review of the Work of the Rockefeller Foundation for 1918 . PubUshed by the Rockefeller Foundation, New York, 1919. 
The adrocates of health insurance, believing in the principles of insurance and in its application to the distribution of economic loss due to disease, contend that the enactment of a health insurance bill will diminish poverty which may arise because of ill health. They point to the experiences of Germany, where poverty, in the sense in which we see it in our larger cities, was practically unknown before the war, as an example of what health insurance can accomplish for the economic regencration of the communties. Because of the high overlead charges of any form of voluntary insurance, and because of the fact that in commercial voluntary health insurance, policies are seldom taken out except by the "dangerous risks" thus greatly increasing the premium, it is claimed that if health insurance is to be successful it must be made compulsory and administered by the state.

The opponents of health insurance, while admitting the value of insurance in general, claim that the word "compulsory" is objectionable, that the idea of compulsion is un-American and that health insurance is impracticable and unfair to the physician and to the individual.

Theoretically, if we accept nine days as correct for the average yearly disability for all workers it would seem that if each worker contributed nine days' wages to a general fund, to be expended in benefits to those disabled by injury or disease, the figures should balance and sickness would cease to act as a cause of poverty.

While the workman has been willing to purchase fire insurance on his home and life insurance on his person he has never taken to sickness insurance and his savings against future sickness are usually entirely inadequate.

There must be found for the benefit of all a workable method which will greatly diminish the economic loss to the individual arising out of serious injury and protracted illness, and the search for such a method constitutes a large part of the community health problem as it is presented to us today. Workmen's compensation insurance, which applies to injuries 
incurred during employment, has done a great deal to diminish part of the poverty arising from injuries, and it is possible that similar measures may be applied to non-industrial injuries and to at least a part of the disability due to disease.

The following is taken from the Report of the Special Committee on Social Insurance of the American Medical Association: "As a result of all investigation covering forty-three cities and over 30,000 charity cases, the United States Immigration Commission found that illness of the bread-winner or other member of the fanily was a factor in 35.3 per cent. of the cases of those seeking aid. In New York City sickness or deformity was present in two-thirds of the 3.000 families assisted by the charity organization in 1916; in Chicago, sickness is reported as the primary factor in 25 per cent. of the cases cared for in 1917 and as a contributory factor in 45 per cent. of the other cases; in San Francisco and Los Angeles, sickness was the primary cause of destitution in 50 per cent. of over 5,000 charitable cases." (Social Insurance Series, Pamphlet No. ¿I, American Medical Association, 1919). 


\section{CHAPTER III}

\section{THE PRIVATE PHYSICIAN AND COMMUNITY HEALTH}

If we accept as true the statement that there is constantly a large number of persons in every community who are seriously ill and that a certain considerable percentage of sickness is either preventable or requires treatment, it becomes necessary to examine the present facilities for prevention of disease and for the treatment of illness when it occurs, in order to determine whether cvery reasonable effort is being made to diminish preventable diseases and whether all cases of illness are receiving adequate medical attention.

Medical practice in the United States is based primarily upon the work of the private physician. The laws of most of the states recognize the responsibilities of the private practitioner and, within certain limits, define the educational requirements which a physician must satisfy in order to practice his professon.

Within these limits, however, medical treatment varies according to the physician employed. In some states various schools of osteopathy, chiropractic, neuropathy, and mental healing all receive recognition and the patient may receive treatment by practitioners of any of these schools. There is often no general supervision of health conditions except in matters of infectious and contagious disease and even in such patients the measures enforced by the community often have to do with quarantine rather than treatment. As a rule, community requirements are satisfied when a patient suffering from acute or chronic illness is under the care of a medical practitioner. In general, only in the case of contagious disease, and then only to a limited extent, does the state attempt to aualify the character of the treatment given. 
The interests of the community are, theoretically, under the care of the state and local departments of health, which as a rule, have an advisory relation to the private physician, and certain police powers affecting both the physician and the public.

It is the purpose at this time to discuss ciniefly the relation of the private physician to sickness in the community, disregarding, for the time being, the limited control by the state and by voluntary associations.

If we cxamine the history of medicine we see that there have been three stages of progress in the practice of medicine. During the first stage it was believed that illness was the work of cril spirits, and that charms and incantations would drive the evil spirits from those afflicted. At a later date disease was thought to be due to various "humors" which might be expelled from the body by the use of various medicaments. Examples of believers in the first stage still exist in the followers of so-called "faith" cures and of the second stage among those who make possible the dividends of the patent medicine manufacturers. Tonies, blood purifiers, and other drugs of a similar nature are sold in tremendous quantities largely as a result of adrertisements in newspapers and lay magazines with a resulting enormous amount of self medication for which there is no scientific basis.

"The third or modern stage," says Dr. William Brend,* is based upon scientific study of disease and the human body. Exact diagnosis of the malady is the first step and efforts are then made to cure it which bear, as far as possible, distinct relation to its cause. For these purposes medicine no longer blindly administers nauseous compounds, but calls to its aid physiology, anatomy, chemistry, physies and other sciences and at the same time studies the constitution of the patient and his surroundings including in its treatment suitable dieting, nursing care and hygienic surroundings."

During the last fifty years there have been vast changes in medical science. The known facts have increased so rapidly

-Erend, William A.: Health and the State, London, 1917, p. 169. 
that it is impossible for any man to master the details of all branches of the profession. The technic of surgery has become so specialized that men spend years mastering the operative technic of a single part of the body such as the eye or ear. As a result specialism has rapidly developed and the importance of the general practitioner has steadily declined.

The private physician practices little or no preventive medicine. He is ordinarily called only when the patient, of his own accord, decides that he is sick and requires medical attention. The physician seldom sees his patients unless they send for him. Except for vaceination against small pox, which is required by law, and advice to persons exposed in cases of infectious disease, his efforts are confined almost entirely to the cure of illness. He has, as a rule, neither the experience nor the time to practice preventive medicine.

For economic reasons preventive medicine as such must depend upon community effort either local or general. In the United States, most preventive measures have been 'undertaken either by the public health authorities or by voluntary organizations working for the public welfare.

Admitting that it is impossible for the private physician to devote much time to preventive medicine, let us examine the present system of medical treatment which is largely under the control of the private practitioner.

Does the present system of medical treatment supply adequate facilities for the care of disease? Does private practice supply modern scientific medical treatment to a reasonable extent for the bulk of the population? If these questions are answered in the affirmative then the community health problem is limited to prevention and to the care of the pauper class only and is much simplified. If the large amount of sickness is unavoidable and is at present receiving every necessary attention then we have only to devote ourselves to the prevention of charlatanism and medical quackery, avoiding so far as possible any interference with the existing order.

However, there is, unfortunately, considerable evidence that the private practice of medicine, except for its function of 
furnishing a livelihood for the doctor, is a partial failure, in that it fails signally to furnish either adequate medical care or modern scientific medicine to a large part of the population.

The arerage plysician practices medicine primarily as a means of livelihood. From the nature of his profession the humanitarian aspect of modern life is seen more clearly than in most other professions but, in the last analysis, he must receive adequate remuneration or cease to exist. Consequently he must either derote a small part of his time to patients financially able to pay large fees, thereby permitting him to give a part of his time to charity patients from whom he obtains his fund of clinical experience; or, he must make a large number of visits upon patients able to pay a sinall or moderate fee. Patients of this latter class are usually unable to bear the additional burden of the expense of specialists and laboratory fees required by modern medicine and are, as a consequence, deprived of the expert service which they often require. As a result they often lose confidence in the medical practitioner and, if unable to pay the fees of the specialist, resort to home remedies or patent medicines. It is among such patients that self medication is most widespread.

In the families of workmen in New York City medical treatment costs from one to three dollars a visit. For ordinary cases this secures good treatment but for complicated cases where laboratory examinations and radiographs are required the additional fee becomes a heavy burden and consequently the necessary examinations are often neglected. This results in unscientific and unsatisfactory medical treatment and often in lasting injury to the patient.

In the sickness surveys made by the Metropolitan Life Insurance Company* from 1915 to $191 \%$, in widely separated communities, from 27 to 39 per cent. of the persons ill were found to be without a physician in attendance, these surreys including only "serious" illnesses. In six surveys covering

\footnotetext{
* Social Insurance: Report of the Special Committee of the American Medical Association for 1919, p. 45.
} 
some 13,000 persons seriously ill, almost 4,000 or about 30 per cent. were having no medical care whatsoever.

In a somewhat similar survey made in Dutchess County, New York, in 1912-13 and covering approximately 10,000 persons, only 76 per cent. of those ill were under the care of a physician. An examination of those siek in Framingham, Mass., showed 81 per cent. under a physieians's care, while in the rural districts surrounding Framingham more than 53 per cent. of those sick were receiving absolutely no medical attention.

Of 1726 dispensary patients studied in Boston, 72 per cent. had had no previous medieal care and, of these, 35 per cent. had been sick more than three months.

It would be possible to continue similar statistics almost indefinitely. While the percentage varies there is regularly a large portion of the population who receive no medical care when ill.

The causes of this failure may be classed under three headings: 1. Economy; 2. Distrust; 3. Ignorance.

Economy is no doubt the most potent factor. Expenses devoted to medical care are seldom foreseen and consequently their burden is doubly hard to bear. Moreover, the working man feels that a charge of two or three dollars represents more than he can afford and he puts off calling the physician as long as possible, trusting that he will escape serious consequences.

Distrust of the physician or of the medical profession in general is a fairly frequent cause of lack of medical care. Some persons, because of a previous disagreeable experience at the hands of an unscrupulous doctor, will delay calling a physician when next they become ill. General distrust such as is fostered by patent medicine interests, and medical cults, also acconnts for a certain number of non-treatment cases.

Ignorance both of the cause and symptoms of disease is a rather potent factor. It is not uncommon to see a patient suffering from pulmonary tuberculosis with a temperature of 102 degrees, or over, who for months attempts to cure his 
condition by exercise under the impression that his symptoms, weakness and loss of weight, are the result of sedentary habits. Under this same heading may be placed the ignorance of the patent medicine adrertisement reader "who knows a lot but knows it wrong." Their partial knowledge of the subject allows them to be made easy dupes of the clerer advertisement writers so that pain in the back, oceasionally an early symptom of tuberculosis of the spine, is treated for months with "Curem's Kidney Remedy" so that when seen by the physician the disease has progressed beyond the favorable stage.

The medical profession derotes an enormous amount of time to the care of charity cases but in spite of this is failing to fulfil its full duty to the community. It fails not because it does not give its best efforts to the sick but beeause it does not, as a whole, appreciate the community problem and has not succeeded in reaching the bulk of the population with any marked degree of success.

Cabot has drawn attention to what was, until recently, the prevailing method of treating heart disease in the best type of metropolitan hospitals. The patient, admitted in bad condition, after several weeks of treatment was usually sufficiently improved to be able to be up and around the ward without shortness of breath or subjective evidence of his leaky valve. He was then discharged from the lospital with the advice to "take things easy." In most cases, howerer, for economic reasons, he was obliged to seek work, and attempting work which was too hard for the weakencd condition of his heart he soon broke down and was obliged to return to the hospital for further treatment. This process was repeated over and over again to the economic loss of theman, the community and the hospital. Recently this has been changed by the follow-up system of after-care introduced in many hospitals which not only provides the subnormal individual with medical advice but actually undertakes the placing of such persons in suitable occupations.

With the advance of medical science the mortality rates of 
most great cities have steadily fallen and the span of human life has generally increased. This is largely the result of the application of what wise physicians and skilled surgeons have taught regarding the cure of disease. Men of science are devoting their lives to the problem of disease and may be expected in the future to develop new methods of prevention and cure. 'Typhoid, small-pox, malaria, and diphtheria are rapidly disappearing. Many other diseases such as tuberculosis and diabetes, are more successfully treated today than ever before. Cancer is only partially conquered by surgical measures, but experimental results obtained give hope that sooner or later a clear understanding of the cause and a rational method of treatment may be discovered.

The community problem today is not concerned with the search of new ways and means for the cure of existing disease, such searcl may well be left to hospitals and scientific institutions. The real problem before the community is that of making proper use of the tools at hand, so that modern scientific methods of treatment may be available to each and every eitizen, whether rich or poor.* To this end the medical service must be reorganized so that the services of the general practitioner, the specialist and the medical laboratory may be secured by the sick in the community at an equable cost. The present system of charging what the traffic will bear must be discarded.

- "The remedy for this situation (labor scarcity due to injury and disease), lies economically in a redistribution of costs, not of adding new costs. but rearranging the present method of expending the costs already being expended. - Improved medical care must come from more co-operative and less purely individualistic care from the medical profession." (Report of Special Committee on Social Insurance, Americal Medical Association, 1919). 


\section{CHAPTER IV}

\section{HEALTH DEPARTMENTS AND COMMUNITY HEALTH}

In the prevention of disease, much depends upon the public health authorities. As ordinarily used the term public health includes all forms of federal, state, county, or municipal activities which may influence the morbidity or mortality rates of a community. A public health officer is usually an employee of the local or state government by which he is paid and from which he receives his authority to act. Under our present system the public health official devotes his time almost entirely to prevention and sanitation.

Until comparatively recently, public health officers were poorly paid and served mainly as police officers to enforce sanitary regulation. In recent years, however, the work of the public health officer has broadened in its scope and is now concerned not only with sanitation in the narrower sense, but also with hygiene, housing, child welfare, and numerous other health measures for the prevention and control of disease.

Professor Winslow, of Yale, has expressed this broader view of public health in an address before the American Association for the Adrancement of Science." "Public health," he says, "is the science and art of preventing disease, prolonging life, and promoting health and efficiency through organized community efforts for sanitation, the control of infection, the education of the individual in the principles of personal hygiene, the organization of the medical and nursing service for the early diagnosis and preventive treatment of disease, and the

-Winslow, C. E. A.: The Untilled Fields of Public Health, Sclence, Jan. 9 , 1920 . 
development of social machinery which will insure to every individual in the community a standard of living adequate for the maintenance of health."

\section{THE UNITED STATES PUBLIC HEALTH SERVICE}

The federal health service has grown rapidly during recent. years, especially during the war period. Originally concerned chiefly with quarantine and the administration of marine hospitals and with an appropriation of less than a million dollars yearly, the service has rapidly increased, so that in 1920 the anuual appropriation was approximately $\$ 18,000,000$.

In 1919 the commissioned personnel of the Public Health Service consisted of a Surgeon-General and 217 medical offcers of various grades. In addition there were 526 commissioned to the reserve of whom 222 were on active service.

Since the war, the work of the service has greatly increased, due largely to the fact that all medical care of discharged soldiers, sailors and marines, made necessary as a result of injuries or diseases incurred in service, was turned over to the medical officers of the Public Health Service. In addition the medical examinations required by the Bureau of War Risk Insurance were made chiefly by commissioned or reserve public health officers.

Space does not permit more than a brief outline of the afterthe-war program planned by the Public Health Service.* The program in brief is as follows:

1. Industrial hygiene:-Health surveys in industry are to be continued and extended and minimum standards are to be established. Co-operation with state and local officers in the sanitation of industrial communitics is to be developed.

2. Rural hygiene:-Federal aid is to be made available for the maintenance of adequate county health organizations. Such aid is not to exceed one-half the expense of intensive rural health work. Investigation and trained assistance is to be given in campaigns for better rural sanitation.

-Anaual Report for 1919, U. \$. Public Health Service, Washington, D. C. 
3. Prevention of the diseases of infancy and childhood:There has been a comprehensive program arranged including pre-natal care, child welfare, physical examination of children and supervision of children during the school age.

4. Water Supplies:- Surveys of water supplies are to bo made and recommendations are to be made to local authorities for the improvement of the local water supply.

5. Milk supplies:-This part of the work includes a campaign for universal pasteurization and adequate inspection of all milk supplies.

6. Sewage disposal:-It is beliered that proper sewage disposal will greatly diminish intestinal diseases such as typhoid fever, dysentery, etc.

7. Malaria:-National development of measures to control malaria is contemplated.

8. Venereal diseases:-A comprehensive campaign against venereal disease is planned.

9. Tuberculosis:-The control of tuberculosis is to be attempted through the stringent provision for reporting cases, adequate instruction for families and patients, and hospitalization of cases wherever practicable.

In addition to the above there is a plan for the development of better railway and municipal sanitation together with the promulgation by the Public Health Service of health standards and other subjects connected with health and sanitation. They also hope to increase the available morbidity reports by records obtained from the industrial group of the population through the appointment of industrial surgeons as special sanitary officers.

It may be seen from the above that the Public Health Service should be an active factor in the solution of the community health problem. Like the Rockefeller Foundation the Public Health Scrvice does not, except in a few cases, attempt the actual care of the individual but attempts to demonstrate to the local community the modern and scientific method of health control. 


\section{STATE IIEALTII DEPARTMENTS}

Public health, under the state system of government, is largely a function of the State. Theoretically the Federal health service has to do only with interstate health problems and the care of employees of the Federal Government. Actually through the control of interstate commerce the United States Government can take a considerable part in shaping the health policies of the various states.

State Departments of Health are ordinarily under the control of a commissioner who is appointed by the Governor. They receive their power from the state legislatures and as a consequence their functions vary considerably in different states. In the more progressive states their powers and functions are broad and their control over community health is considerable. In other states their duties are confined almost entirely to the recording of statistics and more or less perfunctory efforts to control disease. In many states the health boards are notably lax so that statistical data, even in reference to births and deaths, is so incomplete as to be without value.

Until recently it has been very difficult to organize an efficient state health department. There have been several reasons for this. In the first place it has been difficult to get sufficient appropriations so that the department is frequently limited in its activities beeause of lack of funds. In the next place the health laws are often not correlated, the powers of the department being limited, and health functions often divided among several different commissions. And finally it has been difficult to secure efficient health officers beeause positions are frequently under political control and the financial rewards are much less than could be obtained from private practice.

In spite of these difficulties there has been a steady advance in the standing of the state health departments and within the last few years certain states, notably Ohio and North Carolina, have undertaken progressive measures for the statewide improvement of public health. 


\section{LOCAL HEALTI DEPARTMENTS}

In the community, health functions are usually under the control of the municipal or township health board which receives its powers in part from the state and in part from local sources. Such health boards are often very well developed in large vities such as Chicago and New York. In smaller cities the health activities are often very inadequate and in villages and rural communities of some states there is often no community health effort worthy of the name.

An examination into the expenditures for public health in various localities shows great variations. Indeed it is extremely hard to compare the expenses in different cities because of the fact that in one city the expenses of the health department may include such items as removal of garbage, or disposal of sewage, and in another these items are charged to other departments. However, even allowing for these factors there is still a great difference in expenditures for health in different localities.

In some states annual appropriation of the state health department is less than five cents per capita. It is rarely over ten or fifteen cents per capita even in states otherwise most progressive. In the large cities the expense of the health board is considerably higher. In Chicago, for example, the yearly health expenditures amount to over forty-five cents per capita. In some of the smaller cities the amount drops to a few cents per capita and in certain rural communities practically nothing is spent for public health.

Money spent in the prevention of disease should be looked upon as insurance. From statistical studies it is certain that, up to a certain amount, money spent for better health is returned to the community in terms of diminished disability and decreased financial loss due to sickness.

However it is often hard to prove this to the taxpayers principally because the money must be expended largely for personal service and the results are difficult to visualize. Certainly much larger expenditures should be made for public health. 
The total eren of several dollars per capita does not sound excessive viewed in the abstract but when it comes before the state legislature, or local gorernment, for appropriation it appears enormous. The health officer of today must do his best to demonstrate what can be done with small appropriations and trust that public opinion will support him in requests for more funds in the future.

Doctor Hemenway has studied the expenses of some of the eities of Illinois. By a rather elaborate computation he has compared the expenses for health with the estimated losses due to communicable disease. While it is possible to criticize his results because of the difficulty in arriving at a definite figure representing financial losses due to sickness, the figures are accurate within certain limits.

The result of his inquiry is shown by the following table:

TABLE OF PER CAPITA APPROPRIATIONS AND LOSSES*

\begin{tabular}{|c|c|c|c|}
\hline City & $\begin{array}{c}\text { Health } \\
\text { Appropriation }\end{array}$ & $\begin{array}{l}\text { Sickness } \\
\text { Losses }\end{array}$ & $\begin{array}{c}\text { Per Capita } \\
\text { Annual Valuation }\end{array}$ \\
\hline Evanston & $\ldots \$ 0.31$ & $\$ 12.82$ & $\$ 473$. \\
\hline Bloomington & 0.13 & 23.60 & 332. \\
\hline Rockford & 0.80 & 22.74 & 433. \\
\hline Waukegan & 0.08 & 17.45 & $1 \% 4$. \\
\hline North Chicago & . . 0.03 & 41.40 & 216. \\
\hline East St. Louis. & $\therefore 0.13$ & 28.05 & 192. \\
\hline Belleville .... & $\ldots \ldots 0.14$ & 26.83 & 239. \\
\hline Alton & .. 0.08 & 38.41 & 193. \\
\hline Springfield & $\ldots 0.11$ & 24.32 & 251. \\
\hline Decatur ..... & .. 0.177 & 17.48 & 234. \\
\hline Chicago & . $0.45 t$ & 26.21 & 421. \\
\hline
\end{tabular}

While a strict comparison of figures in the abore table is not possible, because so many other elements may effect public health, yet it is apparent that, in general, money appropriated for public health resulted in diminished losses. It is pointed out that Waukegan and North Chicago are contiguous and - Hemenway, Henry Bixby: Economles of Fealth Administration. American Journal of Public Health, February, 1920. 
represent similar communities, yet Waukegan at an expense of 5 cents more per capita shows a loss of only $\$ 17.45$ per capita, \$23.95 less than North Chicago. The table would also indicate that in smaller cities, such as Rockford and Springfield, a smaller expenditure is required than in a large city such as Chicago.

The modern tendency is toward the concentration of public health activities in conmunities large enough to secure the services of a full time medical officer. In Ohio the state health department was reorganized through what is known as the Hughes Act which divided the state into various administrative districts. The village and townslip health officers who were previously paid very small salaries were to have been replaced by district health officers who were to be paid salaries sufficiently large to secure a full time health officer. One or more visiting nurses and a clerk were recommended for each district office. The district supplies a part of the fund and the state aids by a subsidy which raries in amount according to the district appropriation up to a maximum of $\$ 2,000$ yearly. In general the districts follow county lines except that cities usually represent a separate administrative district. Unfortunately just before the Hughes Act went into effect it was amended so that many of the expected benefits were nullified. It is understood that the changes were made because the local communities rebelled at paying the additional taxes required in order to carry out the provisions of the original act.

North Carolina has also made considerable advance along similar lines aided by expert advice and financial assistance from the Rockefeller Foundation. In many rural districts the North Carolina Board of Health has gone out of its way to seek ont school children who are in need of treatment. Traveling free dental clinics and free operative clinics for the removal of tonsils and adenoids have reached an enormous number of children throughout the state. In an editorial in the monthly Health Bulletin* the following statement is

-The Health Bulletin, North Carolina State Board of Health, Norember, 1910. 
made: "The State Board of Health is finding daily what every physician practising in the smaller towns and in the country has always known, and that is the urgent necessity for hospital and medical service which will reach the great majority of the people in time to prevent neglect and suffering especially among children. It is one of the great sociological problems which must be settled."

The new departures in North Carolina and Ohio are breaking a path which must be followed by the health departments of other states. Whether the road leads to state medicine or to health insurance or to some other form of community effort for the prevention of disease is not clear. At all events it is a step in the right direction. 


\section{CHAPTER V.}

\section{PUBLIC HEALTH NURSING}

The development of nursing has led to the classification of trained nurses in three distinct groups; institutional nursesthose working in hospitals, sanitaria and other similar institutions; private nurses-those giving continuous care to private patients; and public health nurses-who are in the main engaged in some form of social work closely related to public health. The work of the last group is classified under the heading "public health nursing" and includes visiting bedside nursing, industrial nursing, infant welfare, school nursing, tuberculosis nursing, social service work and many other similar activities, each closely related to the improvement of public health.

The term public health nurse is usually understood to mean "a graduate nurse who is devoting her time and energies to social work aiming toward the improvement of the health and welfare of the public." Her training as a nurse is essential to the work although actual bedside nursing, as it is ordinarily understood, may represent only a small part of her daily duties. It is impossible to outline definitely all the various forms of work which a public health nurse may engage in. Indeed every year new forms of social health activities are added to the duties of the nurse under the general heading of "public health nursing."

\section{DEVELOPMENT OF PUBLIC HEALTH NORSING}

Some form of what is now known as public health nursing has been in existence for many years, usually in connection with the visitation of the sick by nuns, deaconesses and others, who were, as a rule, almost always under the control of the 
Church. It was not until comparatively recently, however, that public health nursing, in a form approaching the present, has been systematically carried out. In England there are authentic records of visiting nursing under a centralized control as early as $\mathbf{1 8 7 5}$, but in America the movement did not start until considerably later and in the beginning there was little attempt made to co-ordinate the work, every organization or municipality starting the work in its own way and according to its own ideas and ideals.

During the last twenty years, public health nursing has dereloped by leaps and bounds so that in 1919 there were nearly 9,000 trained nurses who devoted their entire time to this type of work. Some idea of the growth of this movement since 1891 may be obtained from the following table:

GROWTH OF POBLIC HEALTH NURSING IN THE UNITED STATES*

\begin{tabular}{|c|c|c|}
\hline Year & Organizations & Nurses \\
\hline 1891 & $\ldots \ldots$ & 130 \\
\hline 1905 & $\ldots \ldots 200$ & 400 \\
\hline 1914 & ...1992 & 5152 \\
\hline 1919 & . . .3094 & $87 \% 0$ \\
\hline
\end{tabular}

During the first decade of this century, this particular kind of nursing was largely developed by local organizations which were known as district, or visiting, nursing associations and the nurses working under such organization were termed risiting, or district, nurses. With the growth of public health nursing, however, the names were outgrown and such associations are now recognized as merely special branches of general public health nursing.

\section{NATIONAL ORGANIZATION FOR PUBLIC HEALTH NORSING}

As the result of the very evident need for some centralized body which might speak with authority on subjects having to do with public health nursing, the National Organization for

-Statistical Department, National Organization for Pablic Health Nursing, 1920. 
Public Health Nursing was formed in June, 1912. This organization does not undertake actual administrative work but acts as an advisory body, collecting and disseminating information, maintaining standards, and stimulating new endeavor. The objects of this association as stated in a circular sent out from the central office are: "to stimulate the extension of public health nursing and eventually to maintain service bureaus employing a staff of secretaries whose services are available to both private and public agencies doing public health nursing work." A magazine "The Public Health Nurse" is published monthly.

\section{RED CROSS PUBLIC HEALTH NORSING}

Before the war the American Red Cross had adopted a comprehensive plan for the development of public health nursing especially in rural districts. While this program was somewhat interfered with, because of the shortage of nurses during the war period, the Red Cross has adopted a peace-time program which includes the extension of public health nursing into local communities. Local initiative and control is encouraged under the Red Cross plan but a certain amount of general supervision and guidance is retained by Division and National Headquarters.

\section{TRAINING}

While it is essential that the public health nurse be a trained nurse, in the sense that she has completed her hospital training, it is also required that she be especially trained in the public health aspects of her work. This may be accomplished at the present time by special field work in connection with her hospital training or by post-graduate studies either at a college or in connection with one of the existing district nursing associations. A few excellent nurses have received their training in this phase of nursing through practical work in the field under the instruction of a trained supervisor, but in general such training is inferior to the combined theoretical 
and practical training courses offered by colleges and schools for public health nursing.

Many of the representative colleges offer courses leading to a certificate in public health nursing. Teachers College, Columbia University, offers a full year's course consisting of eight months' work in the college and four months' training at the Henry Street Settlement, as well as several shorter courses which do not, however, qualify for a certificate. Undergraduate nurses from approved hospitals who are taking the training course at the Henry Street Settlement may be admitted to special classes. Similar courses are offered at the University of Michigan, the University of Pennsylvania, the University of California, and Western Reserve University.

It thus becomes cvident that there is a steady morement to increase the requiremonts while at the same time the work is bcing constantly extended. It is pointed out that while in the hospital the nurse learns to care for the sick, she usually has little experience in the solution of either family or community problems which, in many cases, constitutes a large part of the work of the public health nurse. The present shortage of public health nurses has caused a few to protest against what they consider to be "over-training" but among those who may be expected to speak with authority in public health circles a short period of special training is considered not only desirable but absolutely necessary. Indeed the statement is frequently made that, in this field, a nurse without special training is worse than none.

If we remember that the first district nurses limited their work almost entirely to bedside care, and if we stop for a moment and consider the problems which must have confronted such nurses, we may possibly appreciate more clcarly the necessity for special training in public health nursing. The early district nurses sent out to give medical care only, soon discovered that the giving of medicine had little effect if there were no food in the house; learned that to secure cleanliness required more than an order from the physician or nurse; and that medical treatment and preventive measures 
required not only nursing skill but an immense amount of tact and social understanding. She soon found that she was making a certain number of visits which were entirely social in character and that in order to improve the health of a particular patient her work might require a knowledge of eco. nomic, financial, industrial or social conditions, which carried her a long way from the therapeutic principles she had learned in the hospital.

\section{THE RELATION OF THE VISITING NORSE TO THE PHYSICIAN}

Bedside nursing, as such, should always be carried out under the direction of a physician. The public health nurse who has the welfare of the patient at heart will always insist that, if possible, a physician be secured to prescribe for every individual who appears ill, the nurse devoting her efforts to the training of the patient, or attendants, in simple measures for carrying out the instructions of the attending physician.

It would seem that this service might be considered as interference with the work of the physician, and in certain isolated instances it has been so considered but, in the main, physicians have appreciated the help and co-operation of the district nurse and have not hesitated to say so. Mary Sewall Gardner* states the attitude of the medical profession to visiting nursing as follows: "The finer and more broadminded physician has always recognized the public health nurse as a helpmeet who strengthens his hands and helps him to produce results impossible alone. The poorer and narrowminded members of the profession have regarded her with suspicion and feared her interference at every turn. Men whose minds have been steadily fixed on the welfare of the people, not on circumstances affecting themselves, have from the first gladly given to the nurse a helping hand and with a fine loyalty sought to strengthen her position with the patients. Men occupied chiefly with their own personal careers, who have feared that the public health nurse might jeopardize either their authority or the amount of their work, have per-

- Gardner, Mary Bewall: Pablle Health Nursing, p. 43, New York, 191a 
sistently denied her the loyalty which they so rigorously demanded for themselves."

In any community which contemplates the establishment of a district nursing service there is apt to be a certain amount of antagonism among the local physicians. This can be greatly diminished if the service is started with the co-operation of the profession and if the nurses makc special efforts to observe the ordinary rules of professional ethics. These rules, simply stated, mean merely that the physician and not the nurse is in charge of the case and that the nurse must not take upon herself the duties and responsibilities rightly belonging to the physician.

Miss Gardner interprets the rules of professional ethics to mean, "that she (the public liealth nursc) should not diagnose, should not prescribe, should not recommend a particular doctor or a change of doctors, should not suggest a hospital to a patient without the concurrence of the doctor and should never criticize, by word or unspoken action, any member of the medical prpofession." These rules appear to me too severe and I believe that in time they may be modified so that a nurse will not be compelled to serve under a physician who is palpably ignorant or dangerously careless. In such cases the nurse should report to her immediate superior who, if she is experienced and resourceful, can usually find a way out of the difficulty.

\section{SPECIALIZATION IN PUBLIC HEALTH NURSING}

The anti-tuberculosis campaign required nurses of special training and with a special knowledge of the care and management of the tuberculous, so that there gradually developed nurses who were specialists in this work. About the same time there was an extension of school nursing so that in this field there were also nurses who by virtue of their training had become specialists. In the samc manner various other branches of medicine and a variety of social welfare movements led to a number of other specialties so that at one time it is said to have 
been difficult to find a nurse who was doing ordinary bedside nursing. It has been felt by some that so much specialization is undesirable because it tends to narrow the field of vision and interferes with the broad grasp of the public health problem as a whole.

While specialists are certain to remain and while they, without doubt, fill a distinct place in the public health program the tendency of the recent graduate to specialize should be discouraged. It is far better to limit the work to certain physical boundaries, such as a group of city blocks, or a rural township, than it is to limit the services according to the type of disease under treatment. The public health nurse accomplishes most through personal contact, obtaining thereby the confidence of the family. Cases have been reported where as many as five different nurses were visiting the same family. Such a procedure cannot fail to result in duplication of effort and confusion and should of course be avoided. In this connection it is desired to point out to those doing health work that in dealing with patients it is always much better to arrange the visits so that, in so far as practicable, all instructions are given by the same person. It frequently happens that inconsequential variations in the details of instructions given by two different nurses lead the patient to distrust them both.

Certainly it would appear best if there are to be specialists in the field of public health nursing that they should be limited in number and that they should devote their time largely to research, teaching and supervision, rather than in the more intimate details of social welfare.

\section{TUBERCULOSIS AND PUBLIC HEALTH NURSING}

Among the first of the specialists in public health nursing was the tuberculosis nurse. It has been stated that this work began in New York about 1902 and extended rapidly in New York and to many other cities.

Tuberculosis is a disease which is peculiarly adapted to the work of the public health nurse. It is a chronic disease, 
continuous treatment is required, physicians visits are infrequent (usually once in two weeks or thereabouts), the social problems are numerous, and the field of preventive medicine is almost unlimited.

In such cases the nurse secs that the physician's orders are carried out, aids in the securing of sanitarium treatment for suitable cases, does what she can to prevent contact infection and aids in the economic rehabilitation of the family. She helps children in tuberculous families to secure vacations in the country, tries to influence the working members of the family to secure suitable occupations, insists on the systematic routine medical care of the patient, and teaches the homo attendants simple methods to prevent the spread of the infection.

\section{INDUSTRIAL NURSING}

As the term implies, industrial nurses are nurses employed by mercantile or manufacturing establishments for the benefit of sick or injured employees. The industrial nurse is a specialist but she specializes by limiting her attention to the employees of a certain industry rather than in any limited field of medicine. Her duties vary according to the demands made by the particular industry concerned and the various problems presented by the sick or injured.

Industrial nursing has been greatly stimulated by the introduction of the workmen's compensation principle, although many nurses were employed by industrial establishments before this law went into effect. The work of course varies greatly with the nature of the business and with the requirements of the employer. In some cases it is limited to first aid during business hours at the plant dispensary and in others a complete visiting nursing system available to both cmployees and their families is carried out to the last detail. The value of the services of the nurse in factory first aid rooms has been clearly demonstrated to employers of a thousand or more persons although the need is less evident to those who 
employ a smaller number.* The need of a nurse for the care of the sick and for the prevention of disease is not, however, so generally admitted among employers of labor. While many of the larger plants hare adopted a fairly thorough health service with a public health nurse in charge, there is still a large field in which no effort is made by the employer to improve either personal health or community social conditions. However the industrial nursing movement has had a remarkable stimulus during the post-war period and promises to spread rapidly.

\section{SCHOOL NORSING}

With the development of inspections in schools came the school nurse. It was found that to accomplish definite results personal contact with the parents and follow up efforts were necessary. Few physicians could be found who had the time for this work and few teachers who had either the time or the required training, so that school nurses were required almost from the first. The most striking result of the introduction of nurses in schools was the increased attendance. This was brought about by the fact that the nurses cut down the number of exclusions from school for minor easily curable troubles, such as ring worm, pediculosis, etc. In the next place efforts were directed toward the cure of such simple diseases as enlarged tonsils, dental diseases, and mild coughs and colds, and more recently efforts have been made to overcome under-nutrition and mal-development in children of school age.

The school nurse is sometimes under the direction of the board of education and sometimes under the health authorities. In the broader sense of her duties the nurse is largely concerned with health education rather than actual treatment so that those who insist that her duties are properly a part of the department of education have very strong arguments.

- In states $w$ here compensation laws are in effect, the insurance companies recognize the value of a first aid station with a nurse in charge and make a reduction in the insurance rates to employers adopting this Dlan. 
In many schools there are classes in home hygiene and the care of the sick, dietetics, and first aid, which are taught, in part at least, by the school nurses.

\section{OTHER SPECIALTIES}

There are many other specialties which have become part of public health nursing. Among these are child welfare nursing, maternity nursing, pre-natal nursing, venereal disease nursing, mental hygiene nursing and many others. It will be noted that in some cases the special field takes its name from the special field of medicine with which it deals and in others from the name of the establishment in which the nursing is done, so that it is often difficult to say just where one specialty leaves off and another begins. Thus the school nurse does bedside nursing when she visits a sick child in his home and the industrial nurse invades the field of tuberculosis nursing when the disease occurs in an employee of a particular establishment.

\section{PUBLIC HEALTH NURSING UNDER PUBLIC AUTHORITY}

State or municipal control of public health nursing is considered by many as essential for the wide and thorough development of the nursing program. While there has been considerable opposition to this view the movement is gradually spreading so that the employment of nurses is now considered an essential part of every comprehensive municipal health program. Especially in schools, the employment of nurses has become general and is bound to spread because the need is recognized and, in the end, it is felt that the solution of the problem of child welfare is the duty of the community rather than of certain individuals. This being the case, is not municipal or state control the most practicable method which we have to accomplish tangible and permauent results by means of community effort?

In some cities tuberculosis nursing has been taken over either wholly or in part by the local health department and 
in other localities bedside nursing has been placed under the same control. In New York City as in many other places, during the influenza epidemic of 1920 large numbers of volunteer nurses were employed by the City Department of Health in the effort to control the epidemic.

It is plainly apparent that there is a strong tendency for the state or municipal health authorities to take over certain parts, at least, of the public bealth nursing program, and in some localities this has been opposed on the ground that the work was better done under private control.

However, those who fear that the loss of control by private enterprise will result in a deterioration of the service need not regret the change, for the entire health program is so large that private enterprise may be successfully utilized to its fullest extent in other fields if it can be relieved, in part at least, of the load it is now carrying. Every health movement is of necessity largely limited as to available funds and the broad application of any welfare movement can only take place through the movement becoming part of the local or state government.

\section{THE PUBLIC HEALTH NURSE IN THE COMMONITY}

It is a generally accepted principle that organizations employing public health nurses should be non-sectarian; that association with a church even to the extent of having offices in the church. or parish house, tends to prevent the fullest utilization of the nurses' services. For self-evident reasons the nurse should never interfere with the religious views of her patients. Churches may contribute to the support of the nursing association which should in turn care for the entire community without sectarian limitation.

Limitation of the nurses' services to a certain prescribed district is not open to the same objection. Indeed, in spite of arguments which have been advanced to the contrary, the writer believes that in practically every case the district covered by the nurse should be definitely limited in extent. Occa- 
sionally the work of visiting nurses has been greatly interfered with because of the enormous districts which must be covered, in some cases so great that not more than three or four calls could be made in the course of the day's work. The value of the services of a public health nurse lies, in part at least, in her ability to supply medical supervision at a reasonable cost and this element of cost is greatly increased when a long trip is made to see a single patient.

Before the war the services of a public health nurse were figured at from fifty to seventy cents per visit. With the increase in salaries and the cost of supplies the figure today is increased possibly to the neighborhood of seventy-five cents, or more, for each visit. If the districts are unlimited in area the cost may increase alarmingly.

Of course the geographieal boundary should be based on the population which might be expected to require the nurses' services. The nature of the nurses' work and the ability of inhabitants of a given distriet to employ private nurses, both so greatly influence the population which may be satisfactorily served by a single nurse that one hesitates to give exact figures. It may be safely said, however, that in a community of 3,000 inhabitants representing all classes there will be found sufficient work to require the full time of a public health nurse. In rural districts this number would probably be smaller.

The question of payment is rather a rexatious one. It is ordinarily the custom to charge a fixed fee to patients able to pay-usually fifty cents or thereabouts-scaling the fee down for those less able, in some eases to as low as five cents, eventually treating some cases for nothing. The arguments advanced in favor of this plan are that it avoids the idea of charity to which most people object, and helps pay the nurses' expenses. Others claim that, like education, the nurses' services should be free to all. Possibly the middle ground is best, the nurse giving her services when she is paid by the state or municipality and receiving a fee when she is supported by private organizations. Of course, in industrial 
or insurance nursing, sufficient fees should be charged to corer not only the nurses' time but orerhead expenses as well, but such fees should be paid by the employer or insurance company, rarely, if ever, by the patient.

\section{THE HENRY STREET SETTLEMENT}

Of interest because it represents a large and interesting risiting nursing association, the Henry Street Settlement may profitably be discussed in some detail. Started twenty-six years ago by two nurses it has expanded its activities so that at present nearly two hundred nurses are employed in the work and during a single year 43,946 patients were cared for.

The service was started in the Henry Street district, one of the poorer sections of New York City in which the inhabitants are almost all of foreign birth. It increased so rapidly that, in 1919, there were in operation twelve district branches throughout the city at each of which there were a supervisor and two or more nurses. The service, in the main, consists of general bedside nursing and it is giren chiefly to those who are unable because of economic circumstances to provide adequate attention for their families in time of illness.

The expenses of the organization are met by small fees paid by those treated, by payment for services rendered to employees of industrial corporations and policy holders of insurance companies, and by voluntary contributions.

During the epidemic of influenza in 1920 a total of 30,555 visits were made between January twenty-fourth and February eighteenth. Many cases of pneumonia receired nursing care in their homes with a mortality which, it is claimed, was considerably less than that of the city hospitals. A large proportion of the patients are children, the result being that no small part of the nurses' work is deroted to education of the mother in simple rules for the improrement of the health and welfare of the small sufferers. A maternity center is established in one district which in a single year had a record of 28,982 visits to mothers and babies.* As a result of this

- Erom statistics furnished by the Henry Street Settlement. 
intensive work it was felt that infant mortality was distinctly diminished.

\section{INSORANCE NORSING}

Closely related to industrial nursing is the program instituted by the Metropolitan Life Insurance Company for its industrial policy holders.

This service was started in 1909 in conjunetion with the Henry Street Settlement, Department of Nursing, in New York City, and is limited entirely to industrial policy holders; that is those holding life insurance for small amounts, most of whom are persons employed in industrial occupations. The service increased rapidly in New York and soon spread to other cities so that today it may be said to be applied universally by this company to all industrial policy holders who are ill and require bedside treatment. In some cases, in cities outside of the New York City area, visits are made by company nurses but as a rule it employs the nurses of the local visiting nurses' association. The total cost for the service to the company during the year 1918 was $\$ 810,387.86$ and the average cost per visit was 52.5 cents.*

The average number of visits per patient was 4.9. Based upon the entire number of industrial policies in force the cost per policy was 4.6 cents.

The Metropolitan Company have prepared a table showing the influence of the nursing service and other welfare activities upon the mortality rate.

-Frankel, Lee K.: The Welfare Work of the Metropolitan Life Insuzance Company for its Industrial Policy holders. Report for 1918. 
INDUSTRIAL EXPERIENCE, METROPOLITAN LIFE INSURANCE CO. 1911-1917

Deaths per 1,000

\begin{tabular}{|c|c|c|c|}
\hline ge Period & 1917 & 1911 & Decline \\
\hline All ages & 11.6 & 12.5 . & 7.2 \\
\hline 1 to 4 & 10.5 & 12.8. & 18.0 \\
\hline $1 \ldots$ & 20.4 & 25.2 . & 19.1 \\
\hline 2 & 13.5 & 16. & 18.7 \\
\hline 3 & 7.7 & 9. & 17.2 \\
\hline 4 & 5.6 & 6.6 & 15.2 \\
\hline 5 to 9 & 3.4 . & 2.7 & 3.7 \\
\hline 10 to 14 & 2.6 . & 2.7 & 3.7 \\
\hline 15 to 19 & 4.8. & 4.7 & $* 2.1$ \\
\hline 20 to 24 & 6.6 & 7. & 9.6 \\
\hline 25 to 34 & 8.4 . & 9. & 11.6 \\
\hline 35 to 44 & 12.4 & $13 . \%$ & 9.5 \\
\hline $45 \mathrm{t}$ & 19.6 & 19.8 . & 1.0 \\
\hline $55 \mathrm{t}$ & 35.8 . & 36.0 . & .6 \\
\hline 65 & 76.4 & 74.5 . & $*_{2.6}$ \\
\hline 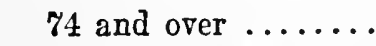 & 10 & 39.5 & *2.4 \\
\hline
\end{tabular}

- Per Cent. increase in seven years.

There is shown by the above table, for all ages, a decline of the mortality rate of over 7 per cent. in seven years. The decline is most marked and most significant during the early ycars, being over 19 per cent. for the first year of life. When the rates for the principal causes of death of policy holders are compared with general death rates for the community at large as obtained from government sources, the results are distinctly in favor of the policy holders. It is fair to assume that a part of the decline in mortality, and improvement in general health, was due to the program of visiting nursing established in 1909.

EFFECT OF THE VISITING NORSE ON PUBLIC HEALTH

It has been pointed out that approximately only one-tenth of all illness is treated in the hospital, the remainder being 
cared for in the patient's home. Consequently in order to reach every sick individual, nine-tenths of the sick must receive medical care in the home. Such visits may be made either by physicians or public health nurses or by both. In acute ilmess, and to diagnose disease and outline treatment, the services of a physician cannot be dispensed with, but for the routine care of chronic illness and for prevention of disease there is at present no one better qualified than the public health nurse.

The medical problems connected with the supervision of health within the limits of the home are, frequently, comparatively insignificant; but the social and economic problems which must be solred in every home, before the greatest benefit may be secured through the application of the lessons learned from recent advances in the field of preventive medicine, are such that the services of a trained public health nurse are almost essential. This is especially true among the poorer classes.

If there has been one single factor more than another which has made for general improvement in health conditions in the larger cities during the last quarter century, that factor is without doubt the rapid spread of public health nursing. Actual services during illness represent only a small part of the nurses' work. Education of the bedside attendants in proper methods of caring for the sick, education of the patients as to the necessity of early treatment, and education of the public as to the importance of cleanliness and sanitatation are all considered a part of her duties. It is the general concensus of opinion that no program for the betterment of community health will be satisfactory unless the public nurse plays a major part in its execution. 


\section{CHAPTER VI}

\section{THE CAMPAIGN FOR BETTER HEALTH}

In outlining a plan for the improvement of community health it is necessary to consider the problem as a whole and outline a plan of action much as a general plans his action against an enemy force. The information which is gained from health surveys, from vital statistics, and from community records, corresponds to the army officer's map of the terrain; the methods and practice of modern scientific medicine are in a sense, the ammunition to be used; the co-operation of the citizens, physicians, civil authorities and workers is represented by the morale of the troops; and the success of the campaign depends upon the intelligent use of all these factors by a keen administrator.

Back of the battle lines there must be a dependable source of supply, and in the same manner back of every community health effort there must be adequate and available funds supplied either by public authority or private individuals. Unlimited funds are practically never available and it consequently becomes the duty of the administration to accomplish the greatest possible result with the least practicable expenditure.

\section{HEALTH ADMINISTRATION}

If there is one element more important than another in the solution of the community health problem it is the question of administration. Enormous amounts have been spent for the benefit of public health which have been wasted because the funds have been poorly administered. Health administration includes not only the expenditure of money but the control of executives as well. It should work for co-operation and 
team work of all existing health agencies and should aim to encourage the interest and enthusiasm of the citizens of the community.

There are sereral different forms of control of health administration. It may be under the control of the state, as would be expected under a purely socialistic or paternalistic form of government. Of this form there is considerable to be said in favor and comparatively little against. From a health viewpoint a paternalistic form of government can accomplish wonders. While sanitary defects cannot be corrected by decree they can be greatly discouraged by laws creating modcrately severe fines for offences against sanitation. Improvement of health conditions under military authority which is, in its essence, patermalistic, has been sufficiently well demonstrated (for example the elimination of typhoid fever during the recent war) to indicate the wide range of its possibilities. Complete socialistic health control will probably never occur in America and there is some doubt as to its success even if it should occur, but a certain measure of socialistic control-using the term in its broadest sense- is inevitable. Indeed our present state health departments are in a sense socialistic forms of governmental control.

The second alternative is the administration of health activities by a private organization such as the Rockefeller Foundation, the Red Cross, or one of the various other welfare organizations which are working for better community health. The disadvantage of private control is that there are usually insufficient funds to reach more than a small part of the population so that financial aid furnished by such organizations must be devoted to only a few localities where experiments may be made and the results demonstrated to the country as a whole.

The third plan of administration presupposes the control by the community itself through representatives elected by its citizens. It is this plan which is being studied in Cincinnati by the National Social Unit Organization. The difficulty associated with such a plan is that members of the community 
rarely have sufficient broadness of vision and experience to visualize the results of better health and that from a practical standpoint, communities up to the present have not made full use of preventive medicine as it exists.

As a matter of fact all these forms of administration are being used today. It is probable that the state will take the initiative in health matters and that in the end they will be administered largely by local authorities under the control of the state or federal government. Private funds should be, and are, nsed to direct research and to demonstrate the value of remedies and preventive measures. Their influence will be felt in concentrating the attention of the community on certain conditions such as infant welfare, pre-natal care, or other similar conditions, which might otherwise be overlooked.

It matters not from whence the administration derives its powers, it must work with the people, not at them. It must have the good will of its executives and must, by unceasing effort, secure and keep the sympathy and understanding of the people or the full measure of success will not be attained.

\section{PREVENTION OF ACCIDENT AND DISEASE}

Health work should start with prevention. While the importance of preventive medicine is well recognized by modern medical science it is difficult for public health authorities to secure adequate appropriations for prevention of disease. The effects of measures for prevention are not always plainly seen and consequently not appreciated. Often it takes the scourge of a widespread epidemic before appropriate measures for the prevention of such diseases as typhoid fever and yellow fever are instituted. The cost of good water, and of efficient sewage disposal are high but not nearly so high as the costs of those diseases caused by the neglect of well-recognized sanitary requirements. This is well known, yet comparatively few communities have appropriated sufficient funds to wipe out entirely typhoid and diarrheal diseases, which are largely carried by a polluted water supply. 
Preventive measures include the prevention of accidents. The enactment of workmen's compensation laws has done more than any other one thing to promote the "Safety First" movement. These laws place the cost of injury directly upon the industry concerned so that it is to the financial advantage of the employer to prevent as many accidents as possible. As a consequence of these laws many devices have been installed to prevent aceidents, and strict rules adopted to prevent employees from "taking chances." It is rather an odd commentary on the operation of the human mind that men will avoid danger because of a factory rule and fear of losing their jobs when they will not aroid the same danger for fear of loss of life or limb.

Statistics show a rapidly increasing number of strcet accidents, especially those due to automobiles. The community can do much to decrease the number of such aceidents both by carefully considered laws, and publicity widely disseminated so as to direct the attention of the publie, both drivers of machines and pedestrians, to the extent of the dangers which exist.

Industrial diseases, such as lead and arsenic poisoning, should be reduced to a minimum. Sufficient testimony is at hand to indicate a method of preventing nearly every form of industrial disease. Education of the public and the inclusion of such diseases under the provisions of compensation laws should be the first moves for prevention.

Diseases spread by social contact-and I use the term in its broadest sense-are much more difficult to deal with than are either industrial diseases or those due to gross sanitary defects. People resent any attempt to control their health by taking away anything which may be considered liberty of action. The enactment of prohibition will no doubt prevent many diseases, but it is looked upon as an affront to personal liberty. Venereal diseases are spread broadcast in nearly every community, but efforts to prevent their spread are met with opposition. Contagious diseases are often disseminated because it is hard to make people observe rules of quarantine. 
The danger of the public drinking cup has long been recog. nized but it required years of education and the passage of state laws before it was discarded.

Two special measures are at our disposal to combat the spread of disease caused by social contact: 1, Education, which is slow but accomplishes results if persistently carried out. 2, Legislation, which must be carefully planned, and enacted only after a period of education.

\section{CURATIVE TREATMENT OF INJURY AND DISEASE}

In every community the question should be asked, "Do the citizens of this community receive adequate medical care?" The establishment of a modern hospital, the location of excellent physicians in the community and the expenditure of money for poor relief do not necessarily constitute adequate community treatment. Investigations must be made to determine whether the money is spent to the best advantage and whether local conditions either in reference to physicians or to hospital service are such as to interfere with the best type of service.

Frequently a community will be found where there are a number of excellent physicians but no facilitics for laboratory or $x$-ray work, thus seriously crippling the medical service. Again where there may be no nursing service, physicians being obliged to devote a large part of their time to this work which could be done better and at less cost by a visiting nurse.

There is a certain amount of lost energy in private practice. Physicians do not limit the area in which they work but spend much of their time traveling from patient to patient, causing thercby a certain amount of duplication of effort. This is due largely to the personal equation, it being regarded as the right and privilege of any sick person to choose his own physician. Thus Doctor A. drives ten miles to see a patient who lives next door to Doctor B. While at the same time Doctor B. may travel the same distance to see his patient who lives near Doctor A. This represents an enor- 
mous waste of time and energy but this right of free choice is zealously guarded by the medical profession, and demanded by the public. It is believed that this demand for free choico is not as important as it appears to be and that if physicians would agree to co-operate, working together for the public good, much of this duplication of effort could be eliminated. It is certain that under the present system physicians have little time to devote to preventive medicine or public health.

Much wasted energy could be avoided and a considerable saving of the physician's time accomplished by a wider use of the visiting nurse in private practice.

The importance of the visiting nurse in the cure of disease cannot be overestimated. It has bcen stated that over 90 per cent. of illness occurs in the home and must be treated there. It is in such cases that the visiting nurse finds her work. Her services should be made available for rich and poor alike, and above all her work should be limited to certain welldefined areas from the start so that duplication of effort may be avoided. If the area in which she practices is limited she will be able to accomplish much more than if required to spend a large part of her time traveling from place to place.

\section{REHABILITATION}

After the storm the salvage of wreckage must begin. After injury or disease there is nearly always a more or less prolonged period of partial disability which calls for rehabilitation. In the mildest cases, disability can be overcome by a few weeks' trip to the country or a short stay in a convalescent home. In some cases the disability may last for months or years and, in such cases, idleness is neither good for the patient nor the community. In many cases there is left behind a permanent disability which forever prevents return to the former vocation.

The workman who has had pneumonia, unless he is warned against it, is apt to return to some form of laborious occupation which, following pneumonia, may result in permanent 
injury to the heart. It is not enough to advise such a man against hard work. He must be guided toward other work for which he is better adlapted. The cripple, who has lost an arm, easily becomes a permanent object of eharity unless he is taught another form of occupation which he is able to earry on in spite of his disability. The man who has been a skilled workman and lost his arm is apt to feel that he has lost his chance and will never again be able to support his family. The change in his mental attitude toward the world is remarkable when he finds that he may be trained for another position, which will not alone make him self supporting, but will enable him to earn as much or more than before his injury. The Institute for Crippled and Disabled Men in New York City makes a specialty of rehabilitation of disabled men.

The Ford Motor Company boasts that a man is never discharged from their employ because of physical disability. If he is unfit for his former occupation he is trained for another. The entire plant was studied with this in view and it was found that, in a comparatively short time, the man with a handicap could be trained for some form of work for which his physical condition fitted him. In 1918 it is said that in the Ford factory there were over 9,000 men at work all of whom had some form of physical disability. On the pay roll were men without one or both feet, men blind of both eyes, men with one or both hands missing, and men with arms or legs hopelessly crippled. Not a few cripples but literally thousands of them.

It is stated that, in the Ford factory, this is not done as a work of charity but as a business proposition and that it pays. Even patients with tuberculosis when unsuitable for sanitarium treatment are kept at work in the factory under medical supervision. These patients work in a specially constructed building, and are able to support their families while they are taking the cure.

There is probably no other large corporation which has followed this plan as extensively as the Ford Company but the 
Federal Board for Vocational Training which has charge of the rehabilitation of disabled soldiers is extending the work along somewhat similar lines. The work of vocational training for industrial cripples, of whom there are an enormous number, has received a tremendous impetus through the efforts of the Federal Board. Congress has appropriated a sum of money for the purpose of encouraging state activities in this line. This money is available to states, in order to encourage the institution of rocational training, on the condition that the state appropriate an equal amount for the same purpose.

\section{CARE OF THE TOTALLY DISABLED}

There will remain even under the best conditions of medical care a certain number of the inhabitants of every community who are totally disabled as far as any gainful oceupation is concerned and hopelessly invalided according to the present state of medical knowledge. I say "according to the present state of medical knowledge" advisedly because there are hundreds, previously considered incurable, now easily cured by well recognized methods of medical and surgical treatment.

The totally disabled includes the insane, certain classes of epileptics, persons in the advanced stages of tuberculosis and inoperable cancer, and a few others. The community must recognize that these persons must be considered a charge on the community as a whole and not merely on their nearest relatives or their acquaintances.

How shall we care for this group of so-called "incurables"? A few may be left in their home surroundings, especially when this course assures reasonably good care. It is reasonable to presume that when necessary the state might pay for the maintenance of such persons in their loomes rather than undertake the expense of institutional care. However, the larger part of the totally disabled, especially the insane, should be treated in institutions. The concentration of various types of chronic mental and physical disorders in a large institution 
permits of their treatment at comparatively low cost and gives promise of the discovery of some form of cure for at least a part of the diseases under treatment. It has been only a few years since cretinism was considered incurable and patients with this disorder spent their lives in asylums. Now the disease is recognized as a clisorder of the thy roid gland and easily cured by appropriate thyroid treatment. As much may pos. sibly be accomplished in the future for other discases now considered incurable.

There is another very potent reason for institutional care of the so-called incurables. Nlost of them do much better when removed from the excitement of modern life and in institutions arrangements can be made so that many of the unfortunates may be kept busy with some form of light occupation which keeps the mind busy and body healthy.

\section{LINES OF ENDEAVOR}

In attacking the problem of community health there are certain lines of endeavor along which efforts for better health may be carried out. Most of these have been already studied with great care and as a result of the experience of others there is considerable cumulative information available. Along some of the lines which will be mentioned there are already national organizations with many branches. Others have been developed by the state or local departments of health or local welfare organizations.

In the organization of any form of community health movement it is well to divide the work so that various workers have their duties definitely outlined. In large communities a separate committee can be appointed, if thought desirable, for each separate health problem.

The prevention of accidents, both industrial and nonindustrial has recently been emphasized by the "Safety First" movement. Much may be accomplished by a study of the accidents occurring during a given period, and by legal measures adopted to diminish such accidents. Closely related to acci- 
dent prevention is the prevention of industrial disease. If a survey of industry clearly slows the prevalence of diseases caused by working conditions it should be a comparatively simple measure to institute reforms leading to their correction.

The prevention of infection through the transmission of food and water-borne diseases is ordinarily considered annong the duties of the loeal board of health. If such diseases are occurring to a greater degree than in other similar communities popular appreciation of the fact will lead to action by the local authorities.

Pre-natal care, maternity care and infant welfare work may well be associated. There is a strikingly large number of stillbirths, and deaths during the first month of life, in the United States. Too many by far, in view of the fact that it has been shown that by proper eare this number can be greatly decreased. The records of the Henry Street Settlement showing the effects of district nursing upon infant mortality rates have been most instructive. Is your community doing all that it should do for expectant mothers and for newly arrived infants?

During the first few years of life, before the school age, is a period which is often neglected. Children as a rule appear bealthy and parents are apt to dismiss signs of illness in the hope that "the child will outgrow it."

Children's welfare during the school period is of extreme importance. This offers an especially favorable occasion to oversee the child's health because children are easily reached in the public schools and many ean be kept under supervision for a comparatively small expense. Mal-nutrition is possibly the most common serious affection which oceurs at this age. Enlarged tonsils and adenoids and defective teeth should be cared for at this time in order to obtain the best results. During the same period the training of crippled children for gainful oceupations should begin.

About the time the child leaves grammar school the war against diseases of venereal origin should be begun. Instruc- 
tion of the ehild as to sex dangers and cther measures to prerent the spread of these diseases should not be neglected. It is not the intention here to ofler a solution of the problem of renereal disease but rather to impress upon the reader that in any community the problem must be met and that a definite poliey, especially adapted to the needs of that particular community, should be rigoronsly earried out. 'The National Social Hygiene Socicty is prepared to give advice and to indicate measures which may be expected to produce results. 'The almost complete climination of this disease in the American Expeditionary Forces would indicate that a solution of the venereal problem is possible. Can we make practical use of the same solution in a given civilian community?

Tuberculosis we have always with us. It is cstimated that about one death in ten in the United States is due to pulmonary tuberculosis. Worse than this is the fact that most of the deaths occur in young adults. While a cure is in many cases possible it is a tedious procedure and, for economic reasons, difficult to accomplish. It is not enough to tell the sufferer that he must move to a "high, dry climate," or the arrested case that he must secure "light out-door work" and then to dismiss the subject. Every case of tuberculosis is a potential source of infection and the problem is a community problem and must be met as such. The National Tuberculosis Association is ready to furnish almost unlimited information on the care of these cases and can render valuable assistance in fighting the disease. The Metropolitan Life Insurance Company has been making a three-year experiment on community control of pulmonary tubereulosis at Framingham, Mass., where results would indicate that there are scveral unrecognized cases of the disease for every one which ordinarily comes under treatment. The work of the Ford Company in taking an active interest in such patients and putting them in employment commensurate with their physical ability has already been mentioned. The experiment will bear watehing. 


\section{HOSPITAL AND HOME CARE}

The hospital eare of acute illness has been fairly well worked out, especially in the larger eities. In rural districts and smaller cities hospital care for the poor is often unobtainable.

The home care of the seriously ill is much less satisfactory if we consider the community as a whole. Visiting nursing can accomplish a great deal to make for better treatment. It is said that even under the best conditions nine persons are cared for in the home to each one taken to a hospital. Look through the homes of the poor and see if they receive even reasonably good care. Question the self-supporting wage earner and see if he is taking advantage of the benefits of modern scientific medicine. See how much moncy he spends for medical care and medicines and stop and figure if he actually gets full value for his money. I have no figures available for the amount spent annually for patent medicines, which seldom do good and often cause serious injury, but I am sure the total must be enormous.

It has seemed to me that routine medical and dental care, that is, the care required by the individual for most of the minor ills which flesh is heir to, has been better met in certain up-to-date industrial communities than under the charity dispensary system of our large cities. The Endicott-Johnson Company, of Binghamton, N. Y., the Standard Oil Company of New Jersey, Cheney Brothers, of Manchester, Conn., and many others have undertaken almost complete care of their employees apparently with excellent results and at a minimum cost for the service rendered. Health Insurance undertakes the same daily care of the sick and has worked fairly well in Germany and England. It has not been tried as yet in the United States although several commissions in various states have been appointed to study the question and health insurance acts in some form have been introduced in the legislatures of several states. 
Another question which must be met and which is at present receiving comparatively little attention is the placing of indiriduals seriously handicapped by disease in gainful occupations. War cripples are being trained, industrial cripples are soon to be trained, but persons handicapped by chronic diseases are seldom giren the attention, with reference to industrial classification, which the seriousness of their condition surely deserves.

In mapping out the lines of endearor as outlined above, no attempt has been made to cover the entire field. An indication of certain well-marked paths, which have been more or less successfully followed in the past should be sufficient as a working basis for a start in any form of health movement. The broadening out of the scope of the work will become self evident once the movement has been started. When funds and personnel are limited it is better to choose one aspect of the health problem and seek for improvement by intensive effort in a limited field rather than to spread the effort over too much territory and accomplish few if any tangible results. 


\section{CHAPTER VII}

\section{WORKMEN'S COMPENSATION INSURANCE}

During recent years there has been a rapid development throughout the United States, of what in this country is a new principle, the state control of compensation for industrial injuries. Since April, 1911, when the first general state compensation law went into effect, the movement has steadily spread from state to state so that, today, there are only six states which have no statutory provision for workmen's compensation. In addition, the federal government has enacted a comprehensive compensation law for the protection of its civilian employecs.

Briefly, workmen's compensation legislation is a legal measure to compel industry to repay, in terms of cash benefits, physical losses sustained by workmen in pursuit of their vocations. In other words, it is the recognition by the State of the responsibility of industry for the wear and tear of the human machine.

For many years it has been the custom in every wellmanaged industrial organization to charge off a certain per centage of income for repairs and depreciation of buildings and equipment, but, until the advent of compensation, employers were not compelled to suffer any loss for broken and injured human machinery. The erippled workman, who because of an injury was unable to continue his work, could be tossed into the discard if the employer so desired, even if the injury had arisen as a direct consequence of a hazardous occupation.

\section{LIABILITY LAWS}

It is not strictly true that there was absolutely no redress for industrial accidents before the enactment of compensation 
laws. There was, it is true, the principle of liability for accident under which the workman might bring legal action to recover damages. Howerer, in most states it was required that in order to collect damages the employee must show that there had been negligence on the part of the employer.

This was, as a rule, difficult to prove and often required years of litigation before the workman received a verdict. Meantime during the course of the trial he had been put to considerable expense of both time and money. Few employees had sufficient funds to carry through such prolonged litigation and, as a consequence, they were usually forced by circumstances to employ a lawyer who would finance the case from his own pocket in the hope of a favorable verdict. Naturally the legal fees were very high. Under such conditions there developed a group of so-called "ambulance chasers," unscrupulous lawyers who were anxious to exploit the injured workman for their own bencfit. Fees of fifty per cent. of the total were common; and fees and expenses equivalent to eighty per cent., or more, were not rare. The result of this was that the injured workman had slight incentive to appeal to law and it often happened that he preferred to shoulder his loss without attempting to recover for either the loss of his time or for his physical disability.

The sum total was that the companies were obliged to spend large sums for liability insurance, the courts were crowded with accident cases, the surgical care of the injured workman was thrown on medical charity and the patient became a charge on the community. No one benefited except certain members of the legal profession. In all fairness to the legal profession it should be said that, as a whole, they strongly objected to such a condition and legislation for its correction was urged.

Some of the larger employers, to their credit, accepted the responsibility and voluntarily took every measure to prevent accidents and compensate injured workers. However, in the main, conditions may be said to have been almost uniformly bad. 


\section{WHAT COMPENSATION ACCOMPLISHED}

At one stroke the compensation acts did much to abolish these abuses. The difficulty of determining responsibility for accidents was recognized and consequently every accident was made compensable even in those eases in which it could be shown that there had been contributory negligence on the part of the employee. The law recognized the "ambulance chaser" nuisance and made the compensation act the only law applicable to industrial accidents, even, in some states, forbidding the payment of a fee for legal services in connection with compensation eases, unless it was clearly evident that such legal adrice was required. The burden of disability was remored from the community and placed upon industry where it belonged. The disabled worker, instead of being an object of eharity, became a pensioner of the industry which had crippled him.

As a rule compensation includes medical and surgical care, medical supplies and a cash benefit during the period of disability. In case of death there is a funeral benefit and a pension for the widow and dependent children.

\section{MEDICAL ATTENTION}

All the compensation laws except those of Alaska, Arizona and New Hampshire provide for medical attention. Most states require the employer to furnish in addition medical supplies and hospital services when needed. There is, however, considerable variation in the service supplied, some states limiting the amount to be spent and others limiting the period during which treatment is to be paid for. Aside from the humanitarian standpoint, the limitation of treatment to two or three weeks, as is the legal requirement in some states, is economically bad because it prevents adequate treatment in the eases which need it most. There is the same objection to the limitation of medical fees to a comparatively small amount, such as fifty or a hundred dol- 
lars, for this tends to prevent sufficient and adequate treatment for the severe injuries. Unlimited treatment is apt to lead to abuse of the privilege, but medical eare for at least two months should be given with additional treatment optional upon the decision of the accident board. The medical fees should be suflicient to insure adequate and skillful care. Excessive fees may be guarded against by careful regulations.

\section{CASH BENEFITS}

By far the best method of compensation for wage loss is a cash benefit up to a certain percentage of the weekly wage. For practical purposes this benefit las been fixed in most states at $66-2 / 3$ per cent. during the period of total disability, continuing as long as the total disability exists. The cash compensation should always be considerably less than the weekly wage in order to discourage malingering and, in a sense, in order to compensate for the fact that contributory negligence on the part of the employee does not deny him the right to eompensation.

For partial disability the workman should, theoretically, receive a part of the reward proportioned to the extent of his disability as measured by the wage loss, but from a practical standpoint this loss is very difficult to estimate. In many cases compensation for partial disability-the loss of a finger or hand for example-is made by the payment of a lump sum.

Death benefits payable to the widow or other dependents are usually figured at 35 per cent. of the decedent's wages at the time of death. To the widow the payments are kept up for life or until remarriage. The widow reeeives two years compensation in a lump sum on remarriage. Compensation is also paid to dependent ehildren and certain other dependents up to a weekly total of $66-2 / 3$ per eent. of the wage at the time of death. 


\section{EMPLOTMIENTS INCLUDED}

When the compensation laws were first introduced efforts were concentrated upon what are known as the "hazardous" employments and in most states the acts as finally passed included only this class of employees. In many states, however, the law has been broadened to include all employees except farm and domestic labor. In some states the principle is applied according to the number of employees, those employers of less than a certain number, usually from two to ten, being exempted from the provision of the act.

In some states casual labor, that is libor employed only for a few hours or a day or so at a time, has not been included in the act. This is because from an administrative standpoint it would be impracticable for employers to insure such cases, but when a firm habitually employs casual labor they should carry insurance to cover the group employed. If the principle of the act is a good one, and there be no doubt on this point, there can be no objection to the inclusion of all employees, even domestic and farm labor. The difficulties arise more from the complexities of the execution of such a law when applied to small employers than from any failure of the principle of compensation in all cases.

\section{ADMINISTRATION}

Most compensation laws are administered by a commission appointed by the Governor. In some cases the commission has power to increase or decrease the amount of compensation and the period and cost of medical care. In others, their powers are limited to a considerable extent either by state laws or regulations.

It is important that such a board or commission shall be composed of men who devote their entire time to the work and that the personnel include men of clear vision and keen understanding of modern social problems. As a rule, the findings of the accident boards are final and cannot be reviewed by the courts. 


\section{INSURANCE CARRIERS}

Insurance may be carried by a state fund, by a mutual insurance fund, by commercial insurance carriers or by rarious combinations. In some states corporations are allowed to maintain their own insurance fund subject to the approval of the proper administrative authorities.

In most states, insurance in a commercial company is permitted but this should be, and generally is, subject to restrictions and rigid supervision, in order to prevent insolvency.

State insurance funds have been started in New York, Ohio, California and many other states. In general they have worked fairly well and are rapidly extending. Mutual insurance associations are permitted in many states. They have perhaps worked better than state funds not being confined so closely by laws and regulations. They should, of course, be carefully supervised by the state insurance authorities.

\section{INDESTRIAL DISEASES}

As a rule industrial diseases have not been considered as injuries within the meaning of the various compensation acts. Thus, if a man contracts lead poisoning while at work as a painter he is awarded compensation in only four states; Cailfornia, Connecticut, Massachusetts and Wisconsin.*

There can be no doubt that all industrial diseases should be compensated for, just as are injuries, but the difficulty has been that, from a practical standpoint, it is very hard to say just when a man contracts a given disease. If a man finally contracts a chronic industrial disease, such as lead poisoning, after several years of work at his trade as a painter, it is probable that he has been absorbing small quantities of lead for many years and that the disease is the result of this process long continued which has finally resulted in disability.

- Since the abore was written the New York State Compensation Act has been amended to include diseases of industrial origln. 
It seems hardly fair that his last employer should suffer the entire loss.

Many diseases may arise either from industry or from other unrelated causes. In such cases it is extremcly difficult to make the distinction. From a theoretical standpoint there is no doubt that industry should bear the costs of industrial diseases. From a practical standpoint it has been difficult to formulate satisfactory regulations to accomplish this result.

\section{COMPENSATION HAS BEEN A SUCCESS}

There can be no doubt that the compensation laws have been successful, which is not to say that there has not been a great deal of dissatisfaction with the methods adopted in the execution of the various compensation acts.

In some states, the provision for medical care is inadequate with the result that the medical profession fecls imposed upon and physicians are consequently not inclined to give their best efforts to make the law a success; in certain states insurance companies have apparently taken advantage of technicalities of the law thereby diminishing the compensation and medical benefits in direct opposition to the spirit of the act; and, worst of all, in some states there have been evidences of petty graft which has acted to deprive injured workers of their just rewards. Minor office holders have induced injured and ignorant workmen to promise them a percentage of the award on the false presumption that their influence would be required to secure a settlement, and other similar petty dishonesties have been occasionally practised.

In almost every state there were misunderstandings and delays due to untrained personnel which, at first, caused a great deal of dissatisfaction among workmen, employers and physicians. However, as experience increases, delays and misunderstandings are lessened and the law works more smoothly.

On the whole the principle of compensation has been a success. The injured workman, today, receives, as a rule, 
better medical care than he received previously, together with al cash benefit which has no taint of eharity. The legal conflicts, with the consequent bad feeling on both sides, previously exceedingly common, are now extremely rare. This in turn eauses him to be more loyal to his employer and a better eitizen in the community at large.

New laws and modifieations of the present laws should be carefully drafted so as to prevent injustice to any of the parties concerned. They should deal liberally with the employee, fairly with the employer, and justly with the state and the community.

\section{THE USE OF SAFETY DEVICES INCREASED}

While compensation insurance is of too recent origin in this country to demonstrate fully, in all details, its value for the prevention of accidents, the rapid increase in the use of safety devices on all forms of dangerous machinery clearly indicates the tendency in this direction. Both the employer and the insurance carrier have a direct financial interest in the prevention of injury and this fact, together with the careful records which are now kept, has led to the adoption of many new and original forms of machinery safeguards. In certain cases the employer may obtain a lower insurance rate if he introduces approved forms of guards against accidents and, in many states, industrial commissions have ruled that extra hazardous machinery must be equipped with safeguards of a design approved by the commission. 


\section{CHAPTER VIII}

\section{COMPULSORY HEALTH INSURANCE}

With the introduction of Workmen's Compensation Insurance in this country, a new conception of community responsibility for health spread rapidly over the United States. What had been apparent to students of sociology and human welfare for many years suddenly became apparent to all. It was recognized that losses due to injuries arising as a result of a particular occupation should be borne by industry as a part of the costs of operation, and not by the individual, and it was further recognized that it was the duty of the various states to protect the worker against such losses by means of well considered constructive legislation.

Reasoning along similar lines the conclusion is soon reached that as all sickness arises from causes found either in the individual, or his work, or in the community at large, the costs of sickness, as a logical consequence, should be met not by the individual alone but by a common fund made up from equitable contributions of all concerned.

Knowing that the sum total of disability is not large and that the expense of treatment can be easily met if the loss is distributed among all workers, whereas the cost of sickness is frequently overwhelming to the individual wage earner, the modern method of insurance against loss at once suggests itself. Consequently compulsory health insurance, or co-operative sickness insurance as it is sometimes called, has been advanced as the solution of the problem of untreated disease, and as a remedy for the relief of economic loss due to physical disability.

Health insurance while new in the United States has been successfully earried out for many years in various European 
countries. It was introduced orer thirty years ago in Germany and spread rapidly. In England, health insurance was introduced in 1911 but, because of the beginning of the World War in 1914, confusion has arisen in its administration so that it is now undergoing considerable re-organization in order that it may function smoothly on a peace basis.

In 1916, the American Association of Labor Legislation, after careful study of the health of the wage earner and of methods for the correction of poverty due to injury and discase, formulated a tentative draft of an act which would make the benefits of health insurance arailable to all wage earners. Legislative action based upon this tentative draft has been instituted in several states but up to the present no state has actually passed any form of law for the introduction of health insurance. Several state commissions have been appointed to investigate the need of such a law, and in general, the reports of these commissions have confirmed the premises assumed by the originators of the tentative draft, namely that there is an immense amount of untreated illness and that a considerable number of cases of poverty arise primarily as a result of economic loss due to physical disability. In spite of these findings legislatures have failed to act, not as a rule, because the need was not apparent, but because they were uncertain as to the ability of health insurance measures favorably to influence existing conditions.

\section{WHAT HEALTH INSURANCE MEANS}

Health insurance as it has been advocated in this country includes three benefits: A cash benefit (based upon the worker's salary) during the period of disability; a death benefit which is usually a fixed sum; and medical and nursing care for all illness whether incapacitating or not.

To these benefits have been added, in some drafts of the act, a maternity benefit for insured women workers or for the wives of insured male workers and a pension benefit for dependents of insured persons who become totally disabled. 
In some cases plans for insurance lave been extended to include not only the worker but his family as well.

The cost of health insurance is to be met by premiums paid in part by the insured, in part by the employer and in part by the State. The figures frequently quoted are 40 per cent. by the wage earner, 40 per cent. by the employer, and 20 per cent. by the State, but there is no fixed rule for the division of the premium.

The insurance may be carried either by: (1) The State; (2) Approved societies as in England; (3) Mutual associations as in Germany. $\Lambda$ s a rule the American plan has disregarded the commercial insurance earriers.

The cash benefit is usually limited to twenty-six wecks in any one year and medieal and surgical supplies are furnished within certain prescribed limits. The maternity benefit includes medical care and a weekly eash benefit for eight weeks. Hospital treatment and laboratory examinations are to be furnished when necessary.

In order to prevent malingering or prolongation of disability among those who find that "it pays to be sick" there is usually a waiting period of several days before the cash benefit begins and the amount of the cash benefit is fixed so as not to exceed two-thirds of the weekly salary. Medical treatment is given freely however at all times without regard to other benefits.

The death benefit is usually a fixed amount, say $\$ 200$, although this can be made to vary according to the size of the family if it is thought desirable.

Administration is ordinarily left under the control of the organizations carrying the insurance but the expenditures are supervised by state authorities.

\section{WHY INSURANCE?}

It is hardly necessary to bring forth arguments for insurance as a protection against economic losses due to sickness. Insurance against fire, insurance against death, and insurance 
against other losses are so firmly fixed in the American mind that no argument is required to sustain the soundness of the principle.

It should be, theoretically, easy to compute the premiums. We know for example that the rorking man will on the arerage lose about nine days every year on account of sickness' and that from 20 to 30 per cent. of the workers will be sick every year. We know that 65 per cent. of those ill more than a week will be back at work within four weeks, that about half the balance will be back at work before the eighth week, that only about 10 per cent. will be sick more than three months and that only about three per cent. will be ill longer than six months. From an insurance standpoint, leaving out of consideration the human equation, the losses should be easily calculated. Practically, this being a new form of insurance in this country, the calculated premium would probably require considerable modification.

It has been claimed that health insurance will favor malingering and that the loss will be greatly increased by pretended illness. This is of course possible and will no doubt, to a certain extent, increase expenditures, but to expect this tendency to be so prevalent as to nullify the insurance principle is to lose faith in the bulk of the American people. Houses have been burned down to collect insurance and ships have been sunk for the sarne purpose but neither fire nor marine insurance has been considered theoretically at fault because of isolated instances of the abuse of the insurance privilege.

\section{WHY COMPOLSORY INSURANCE?}

The word compulsory has been used in connection with health insurance and has given offense to many. The opponents of this form of health movement say that compulsion is out of keeping with American ideals, that Americans will not submit to it, and that while voluntary insurance may be all right compulsory insurance is objectionable. Yet we 
have compulsory education, compulsory taxes and compulsion in the execution of our laws.

Voluntary health insurance, unlike life insurance, has never been widely successful. Wage earners during carly life do not take out voluntary sickness insurance so that most commercial insurance of this type is written for people over forty years of age, during the period in which sickness is most common. Moreover the cost of any form of commercial voluntary health insurance is very high, being increased largely because of commissions and overhead expenses. As a result, for the premium paid the benefits derived are comparatively small in this form of voluntary insurance. Under the plans presented in this country for compulsory insurance the premiums would be collected directly from the employer so that the cost of collection would be greatly decreased; all workers would be included, thereby making the premium comparatively small; and administration would be in the hands of mutual organizations thus making the per capita overhead cost almost negligible.

\section{THE ATTITUDN OF THE PIIYSICIAN}

The vast majority of all physicians are opposed to health insurance. While certain physicians of wide experience have advocated its adoption, mast oppose it in any form. It is claimed that it will make all physicians government employees, that they will be obliged to work for less than a living wage and that it will stifle personal initiative and hinder medical progress.

Under health insurance the sick must of necessity be cared for by the body of the medical profession as it now exists. Medical attendance may be secured in one of thrce ways: (1) By free choice of physicians; (2) By a panel system such as is under trial in England; (3) By salaried physicians in the employ of the State.

The physicians have stood firmly for "free choice" and this 
proriso was introduced into the Darenport Bill which was passed by the New York Senate in 1919. There is much to be said in favor of free choice and a great deal against it. If a patient is allowed to choose his plysician from among all practising physicians who are willing to treat him he will have more confidence in his treatment than if he is forced to go to a special doctor or clinic. On the other hand free choice will put a premium on the advertising doctor. It will cause a considerable amount of so-called medical shopping. Patients will travel from physician to physician in order to secure a diagnosis which suits their own conrenience. It will vastly complicate the keeping of records and tend to increase expenses.

In the panel system all physicians who are willing to practise under the health insurance act are placed on a panel and the workmen must choose a panel physician to care for him for a definite period-usually a year. The physician is paid a certain fixed sum per capita. The disadvantage of this system is found in the fact that the physician is required, for a limited fee, to give unlimited personal service, and service under such conditions is rarely found to be satisfactory either to the physician or the patient.

There is the same objection to the salaried physician if his services are secured by contract. However if the salaried physician is made a state employee, given an adequate salary with a chance for promotion and a career as a public health official the objection is less potent and under such conditions many very able physicians might be induced to devote their services to the public.

However, at the present time, most physicians prefer to be independent and to work out their futures according to their individual desires and, for this reason, they strongly oppose the introduction of health insurance in any form. On the other hand there are a few among the medical profession who, seeing the vast amount of untreated sickness and preventable disease, belicve that health insurance offers a practical remedy and urge its adoption. 


\section{THE ATTITUDE OF THE PUBLIC}

Insurance against illness has been sponsored by welfare organizations and by many individusls but in the main the public has been unresponsive.

Certain labor organizations have been impressed by the large amount of idleness due to plysical disability and in New York the State Federation of Labor went on record as in favor of the introduction of health insurance legislation.

'The sick and the needy, those who would be benefited, are not in a position to make their desires known. The healthy workman is not inclined to worry about sickness in the future and the so-called middle classes are not particularly touched by the problem of untreated disease and its consequences.

The daily newspapers, which do much to influence public opinion, are, as might be expected, somewhat divided in opinion. However it may be stated without fear of contradiction that a part at least of the editorial opinion in the larger cities has come out unqualifiedly in favor of insurance of this type.

In industrial plants, where a modified type of health insurance has been instituted voluntarily by the employer, the employees have been almost universally in favor of this method of caring for all cases of injury and discase.

In every great movement whether for better government, better sanitation, or better health there is usually a period of education before there may be said to be a general public demand. We have just seen that this was true in regard to suffrage and prohibition and it may be expected to apply equally in questions having to do with public health. The fact that there is no wide public demand for health insurance is not a legitimate argument against it.

\section{POBLIC HeALTH A FCYCTION OH THE state}

There can be no question as to the responsibility of the 'ommunity for the health of its citizens. While the extent of this responsibility may be debatable the fact remains that, 
to a certain degree, the health of the individual is dependent upon community conditions which ean be influenced only by public control. If this has in the past been met satisfactorily and in its fullest extent by the activities of the rarious public health authorities then there is less necessity for any form of health insurance. If on the other hand, the community has failed properly to safeguard the health of the public, or if it has failed to make arailable to its citizens a reasonably adequate medical service for the eare of injury and disease, then insurance against illness should be seriously considered as a means of securing better community health.

Any form of health insurance must be closely related to our present public health administration, increasing its facilities and broadening its field of action. In a sense every physician working under a system of health insurance should be a health officer working to diminish the sum total of preventable disease. He should consider himself a public official working to increase public welfare in the community and the State.

We have no definite data as to the costs of health insurance in the United States so that, to a certain extent at least, it would have to be begun with a tentative premium which could be easily changed as required by experience.

In the consideration of insurance against sickness the following points must be constantly borne in mind: (1) The cash benefit must be smaller than the average weekly wage. There must of necessity be no premium placed upon idleness; (2) It must include a large group of workers so that the overlead expenses will be reduced to a minimum; (3) It must contain provisions for adequate pay for both physicians and nurses, so that the best professional talent will be drawn to the service; (4) The medical section must contain provisions for hospital treatment and for the services of specialists; (5) It must be wisely administered and efficiently carried out so that delay in payment of premium will be avoided and there will be no question as to the ability or probity of the officials or salaried employees. 
If state officials, physicians, nurses and others concerned in the execution of a reasonably satisfactory form of health insurance have sufficient vision and strength of purpose to cooperate and work for the best interests of the public welfare, it is believed that such an act will be successful, and will represent an immense force for community betterment. If, on the other hand, any of the above group see in health insurance only a means for personal gain and self aggrandizement, failure is almost certain to result. 


\section{CHAPTER IX}

\section{INDUSTRIAL MEDICINE}

Industrial medicine has been defined as the interpretation of the productive capacity of an industrial plant in terms of the health of the workers. It is the science which treats of the prevention and cure of industrial injury and disease, increasing productivity through the promotion of better health.

Twenty years ago the science of industrial medicine as it is known today was almost undreamed of. There were, it is true, a few firms who employed a "company doctor," who was on call for emergencies and who devoted only a small part of his time to the company work. In most cases when an accident occurred the patient was sent to the city hospital and the responsibility of the employer ceased. Most employers kept no record of absence because of sickness and little or no knowledge was available as to the cost of illness either to the employer or employee. Men were accepted after a personal interview and little or no attempt was made to determine the physical qualifications of the applicants for the particular job.

With the derelopment of the larger corporations which necessitated a more complete system of records it became evident that the company had an investment in every one of its employees which would be lost in the event of disability. It was shown that there was a certain definite cost, which could be expressed in dollars and cents, associated with the training of every new employee. It was also found that the mere absence of a skilled employee from work even for a few days 
slowed down production and caused a certain financial loss. In large corporations it was found that in the course of a year their losses reached enormous proportions.

\section{NEW METHODS NEEDED}

Some of the more progressive organizations such as the United States Steel Company, turned to the medical profession for relief. It was realized that the old form of company doctor had. not been a success and it was also realized that employers as well as other's had failed to grasp the full significance of the. importance of industrial health work. Physicians' salaries were inadequate, their offices were small and inaccessible, and the company physician had little official standing in the corporation.

The attempt to correct such conditions gave rise to the new conception of industrial medicine in which the physician is well paid, is recognized as a company official, and devotes his time chiefly to prevention of injury and disease rather than cure. The medical offices should be commodious, centrally located and fully equipped for modern scientific methods. The industrial surgeon must be able to analyze the cause of accidents and indicate the need for modification of dangerous machines or mechanical processes; he must study his case records and indicate necessary public health measures for the correction of sanitary defects; he must study the employees and the positions to be filled and attempt to make the man fit the job, thus increasing production.

It may be said to the credit of the medical profession that they have fully demonstrated the value of industrial medicine from a business standpoint. Medical departments begun as experiments are being continued as paying investments. While the movement has spread rapidly during the last few years it may be said to have only just beguin. Only comparatively few of the larger corporations have introduced what may be considered a truly comprehensive system of health protection. 
However during the last few years the introduction of the principle of compensation for industrial accidents has done much to impress upon business men the importance of early and efficient medical care. Companies were obliged by law to insure under the workmen's compensation acts and those having an unduc percentage of accidents found their premiums raised beyond the average for the industry. Insurance companies found that their costs mounted alarmingly when no provision was made for medical care. This led to the establishment of surgical first-aid stations in large plants with the employment of full time physicians and nurses. From such a nucleus a large number of more or less well developed industrial health centers have been developed.

\section{EXPENSES PAID BY INDUSTRY}

The essential feature of the industrial health movement, in contradistinction to other forms of health activity, is that the expenses are paid in the main by the industry concerned. This means of course that the community pays the bills in the end, for the employer spends on health measures the money which might have been devoted to extra wages. But it has been found that the increase in wages equivalent to the expenditures for health promotion does not materially increase either community health or company production. Health expenditures by industrial organizations must be eompared to taxes for good roads or better water supply which reduce the individual income but act positively for the good of the community.

The per capita cost of industrial medicine varies greatly according to the work done and the character of the industry. It includes part of the premium for compensation insurance and in addition whatever the cmployer may decide voluntarily to spend for the improvement of the health of the employee. Premiums for insurance under the rarious compensation acts vary in the different states and in the various occupations. In New York the rates for moderately hazardous occupations 
run from five to twenty per cent. of the annual payroll. For non-hazardous occupations the rates may be as low as two or three per ccnt. These charges include a part of cost of any system of industrial medicine.

Figures from a large number of corporations show that the per capita cost of health work varies from less than two dollars per year up to fifteen or twenty dollars per year, or even higher, the variation being due largely to the difference in the service furnished.

\section{INDUSTRIAL HEALTII CENTER}

If, as a result of the study of varions existing medical departments in large corporations, we attempt to make a composite picture of industrial health activities we note at once that the health center forms a conspicuous part of every plan. Sometimes it is called the dispensary, sometimes the clinic and sometimes merely the doctor's office, but in all it is essentially the same, the headquarters for the medical work of the plant.

Here the medical director should have his office and records; here should be located the examining rooms; and close by should be the office of the visiting nurses. A drug room, a laboratory, an x-ray room and a record room should all form part of this central group.

In some plants it is desirable to establish branch first-aid stations in buildings located some distance from the center. Many large plants go one step further and place a first-aid cabinet in every department so that it is immediately available in case of accident.

In connection with the health center, arrangements may be made for hospital facilities, convalescent accommodations, home treatment through a visiting nurse service, conservation of children's health through day nurseries and other similar measures, and for co-operation with the local public health organization. 


\section{PHYSICAL EXAMINATIONS}

Physical examinations should be made of all applicants for employment. The examination should be thorough in detail and should indieate the physical condition of the applicant and the neeessity of treatment of physieal defeets, if any. It is execedingly important that physieal examinations be made by physicians who are tactful and understanding and who undertake to help the applicant to find a suitable position, avoiding carcfully any action which would tend to antagonize the worker. The physician should take advantage of this opportunity to emphasize his sympathetic eo-operation with the worker and to increase the mutual personal understanding between the applicant and an official of the company.

It becomes more and more evident that few should be disqualified because of physical disability. First, those who have contagious disease and are dangerous to other workers must of course be excluded. Seeond, those who are suffering from disease of such character as to render any sort of work dangerous to their health must be turned amay. But further than this there should be few disqualifications. The old idea of disqualifying a man because of the loss of one leg, or a simple hernia, or deafness, or some other similar disability, should be discarded. It should be part of the duty of the examining physician to indicate the kind of work for which the workman with a physical handicap is best fitted and to make every effort to connect the man and the position.

This has been done in a large automobile company in Detroit with rreat success. Nearly a third of all their workmen liave some form of disability. The employment director and the surgeon make a careful survey of the plant and indicate, for example, what positions may be filled hy one-legged men. Similar investigations lead to the classification of all positions according to the physical requirements with the result that the lame, the halt and the blind are actuallv placed in selfsupporting employment. 


\section{MTEDICAL CARE OF EMPLOYEEB}

The treatment rooms should be open during the regular business hours and, in plants which are large enough, a physician should always be in attendance. It is of importance to the employer that every patient secure prompt and efficient treatment and return to work as soon as possible. In minor injuries a small dressing and light bandage which will not interfere with work may be applied. In cases of slight indisposition a half hour rest will often be sufficient for complete recovery.

In complicated cases, $x$-ray and laboratory examinations should be made and, if necessary, the services of a specialist should be provided. When there are several surgeons on the staff they may divide the work so that one may specialize in surgery, another specializes in diseases of the nose and throat, while others specialize in some of the other special departments of inedicine.

A nursing service is a necessary adjunct in the active medical care of the workers. A visiting nurse should visit all workers who report sick and the medical director should base his action upon the nurses' report. Many patients may be safely cared for at home with the aid of an efficient visiting nursing service.

Dental care should also be a part of the medical service and the periodical examination of the teeth should be encouraged. Simple fillings may be made without charge and more complicated bridge-work given for cost.

Shall the treatment be made compulsory? Many workers object to compulsory treatment and it is much better not to insist upon it. The essential factor is that all workers in the plant must be included in the health plan. Medical advice must be made available to them all but there is no necessity of insisting upon treatment for this is apt to antagonize some employees. If the physicians are tactful and show sympathy with the worker there will be little difficulty. Most employees will be glad to accept treatment and it will soon 
become apparent to them that they not only secure free treatment at the plant but that the treatment is, as a rule, at least as good as that secured from private sources.

\section{CONTRIBUTES TO WELFARE}

Industrial medicine is today closely linked to industry. It . is recognized as a factor in continuous employment and production. It makes for community welfare and tends to prerent dissatisfaction and unrest.

It is closely related to the community health movement and, when seen at its best, has seemed to come nearest to representing a practical form of sickness prevention and health control applicable with slight modification to the entire community. Its main disadvantage is that it is difficult to adapt it to the needs of the small employer. As a rule at least 500 employees are required to justify the formation of a medical department. However, if industry has shown us how much can be accomplished along health lines by a business-like medical service, it should be possible for the rest of us to find some way of adapting a similar service to the needs of the general community.

\section{INSURANCE}

In many cases industrial organizations have made sickness and life insurance available for their employees at a low price. This is accomplished through what is known as group insurance. In insurance of this type a large number of employees are insured in a group at a flat rate. The premiums may be paid entirely by the employer, or entirely by the employee, or they may share the expense. In any event the employer makes the actual payment of the premium in a lump sum calculated from the pay roll. This reduces the charges for collection so that insurance of this type can be sold very much cheaper than when sold to individuals.

Life insurance is issued in policies of from one to five thousand dollars, the larger amounts being carried by 
employees of several years service. Sickness insurance with a weekly benefit is usually written for a fixed period of from 13 to 52 weeks. However in some cases the insurance may be based upon the salary, payable over a period of several years. It is ordinarily payable only during complete disability.

The Metropolitan Life Insurance Company insures its own employees against sickness disability practically for life. For the first twenty-six weeks' illness, two-thirds of the salary is paid. From the twenty-seventh week until the end of the fifth year one-half of the original benefit is paid and from this time until the employee reaches the age of 65 , he receives one-quarter of the original benefit.

The same company in its annual report on welfare work makes the following statement:

"The company feels that it is conducting a social laboratory in the care that should be given working people. It has felt furthermore that if it could show the value of its efforts to other employers it would benefit its millions of poliey-holders at present engaged in industries of all kinds. If it could emphasize to the employers of these policy-holders the value of proper working conditions it would be able to secure for all workers longer lives and increased health."

This insurance company which has had a long experience in industrial insurance, and close contact with industrial workers, has found that welfare work among its own employees pays and it advises other employers to adopt similar measures. But it points out that health and welfare work must be given in addition to wages and not a substitute for them; that welfare work is not a substitute for opportunities for development and advancement; and that it must not interfere with the right of the employee to live his or her life without undue interference. 


\section{CHAPTER X}

\section{STATE MEDICINE}

For years many clear thinkers have insisted that the coming of a state medical service was incvitable. In England progress toward this end has been more rapid than in America. Some twenty odd years ago Havelock Ellis in his book, "The Nationalization of Health," suggested the need of national supervision of health with a well organized medieal service based upon community needs and under national control.

In 1917 he repeated his earlier view as to the inadequacy of the present system of private practice and roiced the need of a different form of medical service as follows: "It is inevitable" he says "that we should some day have to face the problem of medical reorganization on a social basis. Along many lines social progress has led to the initiation of movements for the improvement of public health. But they are still incomplete and imperfectly co-ordinated. We have never realized that the great question of health cannot be left to municipal tinkering and to the patronage of Bumbledom. The result is chaos and a terrible waste, not only of what we call 'hard cash' but also of sensitive flesh and blood. Health, there cannot be the slightest doubt, is a vastly more fundamental and important matter than education, to say nothing of such minor matters as the post office or telephone system. Yet we have nationalized these before eren giving a thought to the nationalization of health."

In 1913, England introduced a comprehensive system of health insurance and recently there has been organized a Ministry of Health. If anything, the trend toward a state 
medical service has been inereased rather than diminished during the war.

In America an sttempt which was made scveral years ago to establish a Federal Department of Health with a Secretary of Hcalth at the head was unsuccessful and up to the present none of the states has adopted the prineiple of health insurance or other form of state controlled medicine.

America is proceeding more slowly and conservatively than is England in matters which have to do with public health. Possibly an explanation for this is found in comparison of the living conditions of the two countries. Health is largely influenced by living conditions and such conditions are apt to become less and less sanitary as the population increases. In cities the complexity of all problems of sanitation is greatly increased and the evil effects of high disease rates are more plainly evident than in rural communities. Moreover the close relation of employer and employce in industrial communities tends to emphasize the money loss caused by physical disability. As a conscquence, in a country like England, which contains many large industrial cities where there is much overcrowling, the health problem looma much larger than it does in the United States whore there is less crowding and less evidence of defective sanitation.

In rural communities. the evil effects of disease are not so apparent as in the larger cities so that, even in the United States, public health efforts have, as a rule, been much better developed in large municipalities than in the outlying districts.

\section{STATE MEDICINE AND PRIVATE PRACTICE}

It has been stated that the system under which the private practice of medicine is now carried on is out of date, and that it fails to answer the needs of our time. This statement is substantiated by a varicty of reasons which are slowly becoming more apparent to all.

Medicine today has outgrown the capacity of the private 
practitioner. In order to give his patient reasonably adequato medical treatment according to modern standards, the physician must not only have a general knowledge of medicine but must be qualified as an expert in a number of specialties as mell. He must not only acquire this knowledge by years of effort, but he should also have the elaborate mechanical equipment which is now necessary for efficient diagnosis and treatment. Such equipment may be found in great hospitals, where it is available for the benefit of the joor but it is far beyond the means of the average practitioner. Failing such expert knowledge and elaborate equipment, if he desires to give the best to his patient, the physician must refer a large proportion of his practice to specialists. As a result of the gradual disappearance of his practice the ambitious physician soon specializes himself so that he may feel qualified in at least one subject and, as a result, the general practitioner disappears.

But the most weighty rcason for the adrance of the national idea in medicine in contradistinction to the further development of individual practice is that the present system is based upon the cure of disease rather than its prevention. The total spent for the cure of disease is enormous; the money spent for prevention is, in comparison, a sum of insignificant proportions.

Today the student receives better instruction in the science of medicine than erer before. Magnificently equipped institutions are endowed so that medical education may be secured at a minimum expense, and educational requirements have -increased so that a medical degree is obtained only after years of arduous training. When the young physician fresh from college tries to apply his science to practice he finds that the expense involved in the care of disease deprives a great number of people of the benefits of modern treatment.

The question which arises in the mind of the recent graduate is whether there is not some method whereby the benefits of modern treatment could be made available to all 
at a cost within the limits of reason. In answer to this query those who adrocate the complete socialization of medicine point to the slow increase of the powers and activities of the public health authorities, to the enactment of the Workmen's Compensation $\Lambda$ ct, to the agitation for health insurance in some form, and to the establishment of a Ministry of Health in England, as evidences of a gradual change which is taking place leading eventually to state medicine.

State medicine, as the term is ordinarily used, indicates the complete control of health of the individual by governmental authorities. In practice such a system would probably work out along the same general lines as education. Every citizen would be entitled to free treatment if he desired it. Hospitals and sanitoria would be conveniently established and physicians would be either directly or indirectly in the employ of the government. Treatment would not be compulsory, except, as at present for contagious diseases, and patients desiring extra personal attention would be treated just as at present, by private physicians.

\section{PLAN FOR UNIVERSAL STATE SERVICE}

If, in the United States, there were organized a truly comprehensive system of state medicine, along what lines would such an organization develop and of what would it consist?

In the first place there would be required a United States Department of Health with a Secretary of Public Health. This department would include the present United States Public Health Service, now under the Treasury Department, the Board for Child Welfare now under the Department of Labor, the Indian Medical Service now under the Department of the Interior and the various other medical activities under the Federal Government. The duties of such a department would include the care of medical problems which arise in connection with national needs, all questions which have to do with immigration or emigration and the health aspects of interstate commerce. In addition the Federal 
Department of Health would act to correlate the lealth work of the various states.

State medicine, as organized within state limits, would be divided according to the nature of its work somewhat as follows:

(a) A division of prerentive medicine.

(b) A division of hospitalization.

(c) A division of medical treatment.

(d) A research division.

(e) A division of medical education.

Of course such a classification is entirely arbitrary and would be subject to considerable rariation. Sanitation, child welfare, the prevention of accidents, social hygiene and many other similar subjects would fall naturally into one or the other of the above divisions.

A state system would pre-suppose a headquarters and administration office in one of the larger cities of the state, which would control the general policy of the state medical service just as the Surgeon-General's office controls the policies of the Medical Department in the United States Army. There would be established in various localities of not more than 25,000 inhabitants a medical center with facilities for hospitalization, laboratory examinations and consultations with specialists. Possibly, for purposes of administration, it might be desirable to group several of these centers into a single administrative unit. Physicians would be constantly in attendance at these centers and visiting nurses would be arailable for work in the district. The services of the physicians and nurses would be available for rich and poor alike. All divisions of the State Department of Health would of course be represented at each center and each center should be made as nearly as possibly an autonomous unit.

Such a center would require from ten to twenty physicians, including specialists, with possibly, an equal number of nurses and there would be in the entire state of New York possibly in the neighborhood of three hundred such centers. 
Physicians practicing the various specialties would be arailable at each center and patients treated in their homes would be cared for by physicians assisted by visiting nurses. A clerical force would be available to relieve the professional staff of most of the purely clerical duties.

\section{PERSONNEL}

The personnel of such a system would of necessity be recruited from the physicians and nurses practicing in the state. It is claimed by many that the better class of physicians would not enter into any such scheme and that as a consequence it would surely result in failure. Without the enthusiasm and co-operation of the physicians and surgeons who would practice under such a system the service would be greatly handicapped but it is the conviction of the advoeates of state medicine that, if the service were made attractive, if the salaries were adequate, and if the physicians were offered a career as public health officials, a satisfactory medical service could be furnished to the inhabitants of the state as a whole at a cost considerably less than under the prescnt system.

The question might reasonably be asked as to the ultimate effect of such a system on private practice. There is no doubt that private practice would be somewhat decreased but it is doubtful if the decrease would be appreciable at first. In spite of the fact that all persons would be entitled to free treatment, the rich, and to a certain extent those moderately well-to-do, would continue to employ private phrsicians and specialists as heretofore. The man who could afford the expense would probably ehoose to occupy a private room in the hospital, and many persons would prefer not to accept free treatment from the State. The ultimate result would depend upon the quality of service offered and possibly in time private practice of medieine would deerease, but it is improbable that the time would ever come when there would not be a large number of persons who preferred to pay for medical 
attention. State medicine is not an attempt to secure proper treatment for the rich. It is intended primariiy for the prevention of disease and for the benefit of those who are unable to pay for treatment under the present system.

To the best of my knowledge and belief, a state medical service as outlined above has never been earried out on a large scale. Health insurance as it is seen in some of the European countries is under government control and closely approaches state medicine, but could not properly be called public medicine in the same sense in which we use the term in referring to public education.

Military medicine somewhat approaches the ordinary conception of a state system of medicine, and any contemplated state service might gain a considerable amount of information by a study of the organization and administration of the Army Medieal Department, but there are too many other factors in military medicine, such as mobility of medical units, transportation, battle casualties, etc., to make it applicable to civilian needs without extensive changes.

What is needed today is the scientific application to the problems of civilian life of what the physician has already learned by military experience. Competition in the practice of medicine has no place in military service and should have little if any place in civilian practice. Co-operation whether it be for education, public welfare or better health will accomplish more for the citizens of a community than can possibly be expected from any system based largely upon individual competition. 


\section{CHAPTER XI}

\section{HEALTH CENTERS}

During recent years, activated largely by the growing interest in community health an effort has been made, in widely scattered localities, to increase the efficiency of the various local health agencies through the organization of community health centers. The development of the health center idea has bcen gradual and more or less spontaneous, originating coincidently in several widely separated communities at approximately the same period. Health centers were of prewar origin but their growth was greatly accelerated during the war period, due largely to the cnforced concentration of effort in order to overcome so far as possible the shortage of medical service, a result of the absence from the community of a large number of practicing physicians.

It is not improbable that health centers were the natural outgrowth of the dispensary and that they were originally formed in cities too small for the establishment of elaborate dispensaries and public health laboratories, being instituted in an effort to afford relief and treatment for certain needy members of the community, especially the tuberculous.

\section{RED CROSS HEALTH CENTERS}

After the war the American Red Cross undertook the establishment of health centers as a peace-time activity. They describe a health center as "a physical center of some productive form of co-ordination of the health agencies and activities of a community." The plan as announced was not the introduction of a new organization but the establishment of a central agency by means of which team work could be secured.

In a preliminary survey made by the Red Cross during the latter part of 1919 there were secured records of 79 existing 
health centers scattered over the United States.* In seren of the cities there was more than one center. so that, in all, forty-nine communities were represented. This number is, no l.oubt, very incomplete because many centers, being more or less spontaneous in origin, are not on record as such and, in some places, the functions of a health center are taken on, in part at least, by existing institutions such as hospitals or dispensaries, and are so classified. In addition to the cxisting health eenters, the Red Cross found that there were thirty-three new centers definitely started in twentyeight communities, and nuny others planned for early development. The Social Unit experiment, which is fully deseribed in another chapter, is in many respects a form of health center. In New York City the Department of Health has established tuberculosis, industrial, and child welfare clinics, which represent in a somewhat modified form health centers for certain districts of the city.

Analysis of the existing and proposed centers studied by the Red Cross shows that at the time of the report, (published in Narch 1920) thirty-three were administered entirely by the public authorities, twenty-seven were under private control and sixteen were under combined public and private control. The Red Cross was concerned in nineteen instances.

There was considerable variance in the work and aims of the existing health centers. In forty communitics having health centers in operation, thirty-seven contain clinics of some type, thirty-four do visiting nursing, twenty-nine do child welfare work and twenty-seren do anti-tuberculosis work. Twenty-two have venereal clinics, fourteen have dental clinics and eleven have eye, ear, nose and throat clinics. In only ten are there laboratories and in only nine milk stations.

\section{WIAT IS MEANT BI A HEALTH CENTER}

It is evident from the above that the health center does

-Tohey, James A.: The Ilealth Center MIovement in the United States. The Modern Hospitai, March, 1920. 
not represent a fixed plan for the improvement of health but varies considerably according to the needs of the community, the available funds, and the ideas of its originators. In general, it mears a building, or portion of a building, centrally located where various more or less closely related welfare and health activities are carried out. The grouping together of various health activities may be expected to make for better co-ordination and to prevent duplication of effort.*

In some cases the term "health center" is used to apply to two or more municipal hospitals and laboratorics located in a group and under the control of the public health authorities. This is not, however, the sense in which the word is ordinarily used in speaking of the health center movement.

In New York State the health center movement is expanding rapidly. In general, the plan in the smaller cities has been, apparently, to secure a building where the local health officer could have his headquarters, and to house in the same building the visiting nursing service, and various other health organizations located in the community.

Theoretically two forms of health centers are possible, depending upon the extent of medical treatment, which may be limited or unlimited. The first, and the one which is most commonly seen under present conditions, would possibly include: The public health workers; the Red Cross; the district nurses; and all charitable organizations interested in public welfare. Physicians may hold clinics, limiting treatment at the center to those patients unable to pay for the

- Health Centers are described by the American Red Cross in a speclas circular of information as follows: " $\Lambda$ health center is the physlcal headquarters for the public health work of a community. As such, it is the practlcal and concrete expression of the interest of the community in the health of its inhabitants. 1t constitutes a business-like way of associating health activities, both public and private, under one roof, in daily touch and in complete mutual understanding. The health center thus represents the latest step in the erolution of community health work, and answers the demand for efficient conservation of effort in bringing together important but hitherto independent health campaigns, such as those for the prevention of tuberculosis, venereal diseases, mental disnases. industrial disenses, and above all the vitally necessary modern effort for the conservation of child life. In turn, it offers new posslbilities of properly relating these volunteer activities to the offlial health work of the city, county, state, and Federal authorities." (A, R. C. Clrcular 1000, September, 1919.) 
services of a private physician. The work would consist largely in diseaso prevention and education. In the second plan the health center will represent the medical center of the community for the unlimited treatment of disease as well as for prevention and education. Under such a plan physicians would be on duty at all times, the services of specialists would be available when required, and every patient applying would be entitled to treatment whether "able to pay" or not. Laboratory facilities and $x$-ray apparatus should be a part of the equipment and there might be a staff of physicians and visiting nurses to care for patients in their homes.*

How a health center is to be financed is a difficult question. One carved out according to the second plan is based essentially upon what has come to be known as "group medicine" which is acknowledged as more scientific and efficient than the general run of private practice. Such a health center might function either under the public health authorities, health insurance, industrial medicine, or under one of the various local or national voluntary organizations.

Any form of health center which does not take into consideration the care of the large number of cases of sickness which now receive inadequate treatment, will fall short of accomplishing the maximum benefit for public health.**.

\section{INDESTRIAL CENTERS}

So far as is known none of the centers at present in existence give complete medical service to all members of the community. The nearest approach to such a plan is found in certain industrial communities where a large industry has established an industrial health clinic for the care of its employees. In some cases industrial clinics have reached a high

* A plan which closely approaches this has been proposed for New Tork and $\mathrm{a}$ bill to this end was introduced in the 1920 session of the State Legislature.

* Since the abore was written a plan has been proposed to divide medical service in England into groups of "primary health centers", under the control of local physicians and "secondnry health centers" where treatment by specialists will be arailable. It is stated that if this plan is carried out it will completely revolutionize medical practice. 
degree of derelopment, with well equipped offices and several physicians (including specialists) on duty. Visiting nurses are employed and complete records are kept of illness occurring among employees.

The work of the industrial physician is divided between preventive and curative medicine. Prevention of accidents as well as industrial discases is included in his duties. IIe must also include in preventive medicine the elimination of those more or less ill defincd conditions which are caused by monotony and fatigue. He watches not only the sick rate but bonus rate and, where bonuses are persistently not earned, he must search for a physical reason for this failure. He must assist the man with a physical or mental disability to secure proper employment; he must weed out the misfits; ho must properly interpret the effects of ill health upon production; and he must interest himsclf generally in the welfare of the employees.

Under curative medicine the industrial physician is required to treat injury and disease from the standpoint of economic loss to the individual and industry, as well as from the standpoint of scientific medicine. He must realize that a healthy body is necessary for efficient manual labor and that health is one of the most valuable assets of the community. (See also Chap. IX, p. 84.)

In the best type of modern industrial health center the community health problem has been met practically by the following provisions: (a) Medical care both at home and in the shop; (b) Visiting nursing service; (c) Hospital care either at the company hospital or a nearby general hospital; (d) Insurance benefits for disability and death; (e) Reconstruction and rehabilitation of cripples; (f) Prevention of accident and disease-industrial, personal and social; (g) Welfare-including housing, child welfare, amusements, exercise, etc.

Industrial health centers, unlike some other health activi. ties, are not largely theory with little or no practice. They are 
practical from beginning to end. They are started not as charity but because they pay and, inasmuch as they arise because of community needs, they must be paid for entirely by the combined resources of the employer and employee, thus in the end being paid for by the community which they serve. They represent excellent examples for other communities to follow, for it is a sclf evident fact that in the end every health activity should be supported by the community it serves. Temporary help may be given by the Red Cross, by private charity or by the Federal or state government but such help is only a sort of demonstration, a try-out. In a wide movement for better health every representative community must be, to a large extent at least, self-supporting.

\section{HOSPITALS}

Health centers, whether industrial, public, or private in origin, may be affiliated with the conmunity lospital and patients discharged from hospitals may be kept under professional observation by the staff of the health center. Every effort should be made to co-ordinate the work of the center and the hospital so that expenditure of the least energy will secure the greatest results. In many cases a community hospital may be made a part of the health center and this is especially true in villages and the smaller cities.

\section{ALAMEDA COONTT HEALTH CENTER}

One of the best equipped of the recently established health centers is located in Alameda County, California. The local committee have set forth their conception of the aims of a health center and the reasons for its existence as follows:*

"The health center is defined as an institution which coordinates the public health work of the community in a centrally located building available to every man, woman and child. It conducts elinies-surgical, medical and dentalwith the aim of making hospital care unnecessary. It pro-

- Abstracted in the American Journal of Public Health, March, 1920. 
vides health instruction in personal hygiene to both children and adults by means of popular lectures, lantern slides and the distribution of literature. It offers instruction in maternity and child-welfare, thus reducing infant mortality. It serves as a clearing house for all public health information, thus eflecting a closer co-operation among hospitals. It divides the community into health districts, each with a definite health organization which can instantly be mobilized in' case of threatened epidemic. It prevents overlapping, duplication and waste because it co-ordinates all health and relief organizations."

From the same source we are given ten reasons why every. community should establish and support a health center. They are: (1) It promotes community health; your own safety depends on healthful surroundings. (2) It reduces loss of income caused by sickness; carning power rests on health. (3) It decreases infant mortality. (4) It fosters health education; one school child out of two is defective; three out of four have defective teeth. (5) It reduces labor turn-orer, making fewer hands to train. (6) It mobilizes the forces of public health and welfare. (7) It increases wealth. A healthy community is a good banking community. (8) It prevents epidemics. (9) It protects the home; a healthy home produces a more efficient worker, a more contented citizen. (10) Public health is purchasable; a community to a large extent can detcrmine its own death rate.

It is understood that the Alameda County Board of Supervisors have made a liberal appropriation to carry out the health program. More than two thousand cases a month have been treated since the cstablishment of the center and the experiment gives every promise of suecess.

- In 1920, legislative action was started in New York for the state-wide application of the health center principle. This movement had the endorsements of the State Charities Aid Association and the State Commissioner of Health. The bill. known as the Sage-Machold bill, proposed, in bricf, a health 
center in every community consisting of a hospital, a laboratory, and a dispensary, under the control of a local health board with the advice and approval of the state board of health. A full time medical director and paid attending physicians and nurses were to furnish medical care at a reasonable cost, or free, when necessary, to all members of the community. State aid in the form of fifty per cent. cash grants for buildings, a cash allowance for the treatment of free patients, together with certain allowances toward maintenance, were to be furnished to all communities fulfilling the requirements of the State Department of Health.*

\section{THE RED CROSS PROGRAM}

The plan for the extension of the health center movement by the American Red Cross may be best described by the official statement distributed from National Headquarters.** After discussing the program for the extension of public health nursing the plan for health centers is outlined as follows:

"The time has come for the announcement of the second definite step in the Red Cross health program. This is to be the mobilization of Red Cross interest and influence for the establishment of health centers in every community where conditions make this desirable and possible. These modern community stations of health and social service not only promise greater efficiency in the public and volunteer activities in this field but offer a particular opportunity for effective Red Cross participation. In many communities, particularly those without a health organization and where the Red Cross is now the only organized social agency, the health center may conceivably begin and continue as a purely Red Cross operation. In larger cities, with their well-established volunteer associations and committces and their more highly

- For further detalls of the New York bill see State Charities Ald Association Nems, April, 1920. This bill was introduced, but not acted upon, during the 1920 session.

* American Red Cross Circular 1000, Sept. 29, 1919. 
organized official public health services, the health eenter may mean the practical physical means to bring about better co-ordination of these activities. In this case the Red Cross may initiate the movement or mercly participate as one among other agencies, publie and private. Indeed the health center idea is in itself capable of elastic definition to meet the circumstances and capacities of the smallest as well as the largest Chapters. A handbook will be issued later from National Headquarters covering the subject in fuller detail; the present statement is intended to describe briefly the nature and purpose of health centers and to suggest in a preliminary way how the Red Cross may best prcmote their establishment." 


\section{CHAPTER XII}

\section{THE SOCIAL UNIT EXPERIMENT}

Those who accept the idea that there is a community health problem and believe that it is to a large extent capable of solution will find interesting and instructive reading in the reports of the Social Unit experiment at Cincinnati, Ohio.

The Social Unit Organization has been described briefly as a "nation-wide organization of people who have come together for the purpose of finding some way to increase health, happiness and the other good things of the earth, and of helping to do away with porerty, misery, disease and preventable death."

The National Social Unit Organization was formed in April, 1916, with headquarters in New York City. The purpose of the organization is stated to be "to promote the type of democratic community organization through which the citizenship as a whole can participate directly in the control of community affairs, while at the same time making constant use of the highest technical skill available."

After some deliberation, the Mohawk-Brighton districe of Cincinnati was chosen for the purpose of carrying out a Social Unit community experiment on a large scale and a sum of money was appropriated by the national organization for this purpose.

\section{THE SOCIAL UNIT PLAN}

The Social Unit plan aims to combine the citizens of a community into groups, the members of which will develop the activities of their own particular group for the benefit of the community organization as a whole. Thus the physicians and nurses of the district work for public health; the 
employers and trade unionists are industrial cxperts; social workers form a committee on publie welfare; teachers represent the Board of Elueation, ete.

Decision as to various health measures is left largely to representatives of the people living in or employed in the district, but the exeeution of the suggested solutions of the health problems is referred to the Physicians Council, the Nurses Council, and the Social Workers Couneil.

In an evaluation of the Mohawk-Brighton experiment made by Dr. Haven Emerson, former Commissioner of Health for New York City, the following statement is made: "Inquiry develops the practical unanimity of opinion of physicians in the district that the medical needs of the distriet have been better met than before, that medieal practice had benefitedthese are questions that I asked specifically of the doctors who were in service in the district and those outside the working group who had taken part at one time or another in the actions of the Medical Council-that the medical needs of the district had been better met than before, that medical practice had benefited and that if all taint of donation of services were removed by the assumption of costs by those who were served, there would be no further reservation in the willingness to praise and approve the organization and its results."

While the population is too small and the duration $o_{1}$ the experiment too short to permit statistical conelusion based on morbidity records, certain very valuable results have been obtained, aceording to Dr. Emerson's report, and these results stand as tangible evidence of improvement in health conditions of the unit area.

In the first place a very high percentage of expectant mothers were reached and pre-natal advice and treatment given when necessary. In addition early and continuous supervision of all babies born in the district was secured and adequate care given the mothers during the period immediately following confinement.

Children of pre-school age were examined and many physi- 
cal defects discorered and corrected before the child entered school. It has been said that all children are entitled to education. It might be added that all children are entitled to begin education with the minimum degree of physical handicap. In the Mohawk-Brighton District many of the physical defects were discovered in early life and corrected by appropriate treatment either by private or public medical agencies.

\section{SOCIAL UNIT NURSING}

Nursing in the district was largely carried out by the community organization along lines similar to the district nursing plan. When the patient was able to pay from his own resources private nurses were employed. In most cases, however, visiting nurses were supplied without a fee. The nursing service is divided into maternity, infant, pre-natal, preschool, tuberculosis, and general bedside services. Much of the work done by the nursing staff, as might be expected, was educational in character. The aim was education in personal hygiene througn siilied nursing care for the ill and instructive service for others. During the first year of the experiment Social Unit nurses reached and kept under observation for varying periods 65 per cent. of all children under two years of age in the district, and it is claimed that 100 per cent. of all children having serious physical defects received nursing supervision.

During the influenza epidemic of 1918 more than 3000 visits were made by the nursing service within the district, and more than 350 outside of the district limits.

Miss Zoe La Forge of the Federal Children's Bureau, in a report on the nursing situation, says," "The number of persons who have been reached compared with the number who might have been reached shows a completeness which is extraordinary in public health nursing organizations. This fact

- La Forge, Miss Zoe: The Social Unit and Public Health Nursing. Report of Social Unit Conference. National Social Unit Organ. New York, 1919. 
is even more impressive in riew of the short time in which these results were obtained."

\section{TUBERCULOSIS ACTIVITIES}

Work in the field of tuberculosis was begun in May, 1918, in co-operation with the Anti-Tuberculosis League of Cincinnati. Nurses were assigned to the district and it is probable that most cases of active pulmonary tuberculosis were discovered and brought under treatment. Of 179 new cases reported during the year 103 were located by those working within the unit itself. A large part of this increase was without doubt due to the general good will of the people toward the unitworkers combined with the ability of the block-workers to win the confidence of their families. Many cases of pulmonary tubcrculosis were discovered during the carly stage and as a result were suitable for sanitarium treatment. Arrested cases remained at home under expert medical and nursing supervision.

\section{MEDICAL CARE}

The medical services of the unit are directed by the Medical Council which is composed of 32 of the 38 physicians living or practising within the district. Sixteen of these physicians are employed on part time at $\$ 3$ per hour in professional work at the center, chiefly examining children or adults. Treatment at the center is giren by these physicians only in emergencies. When the need of medical treatment arises patients are referred to their own physicians, or to the free dispensary or hospital. When needy patients require treatment at home the service is rendered by a physician from the City Health Department. Medical service in the homes is not considered to be within the prorince of the health activities so far called for by the Citizens' Council. 'The family physician is informed of the need for treatment and the patient notified that medical care is required. The free choice of physicians is encouraged. 


\section{BENEFITS OF HEALTH SERVICE}

The benefit derired from periodical examinations and medical supervision cannot be orerestimated. As a result of this serrice combined with nursing service and the health educational actirities of the center, physical defects receive early attention by both patients and physicians. The relation between patient and physician is not disturbed but is as a rule greatly improved. The physician is stimulated to do his best work and the patient is taught just what he may expect from a given remedial measure so that there is considerably less criticism of the methods employed, when illness results unfarorably, than is the case in ordinary private practice. Exploitation of the sick by unscrupulous physicians is reduced to a minimum.

As a whole the health serrice may be said to be divided into three sections.

(a) Medical Service furnished in part by private physicians with the co-operation of private and public hospitals and the Department of Health. This part of the service is no different from that of any other section of the city. The only new element in the unit experiment is medical supervision by a medical council.

(b) Nursing service furnished on the district nursing plan free to all who will accept it.

(c) Public health service furnished in part by the citizens themselves, in part by the public health authorities, in part by welfare workers of the Social Unit, and in part by certain other ontside organizations.

The health service indicated certain gross sanitary defects which were corrected through co-operative action of citizens, landlords and tenants. The education of the mass of the population in health matters, having led apparently to a desire for general sanitary cleanliness combined with an understanding of the relation of health to their own and their children's welfare, was an important factor in securing prompt action leading to the correction of sanitary defects. 
Among the citizens themselres the results have been excellent. 'The public las been elucated in the possibilities of increased happiness through increased health and especial emphasis has been placed upon the firm establishment of the belief that reasonable efforts spent for the improvement of health are not wasted but bring results out of all proportion to the expense incurred.

\section{CRITICISAI OF THE SOCIAL UNIT PLAN}

The Social Unit experiment has been severely criticised. While its critics admit that it has done much good they contend that this has only been accomplished because the unit has been experimental and that all parties, citizens, executives and workers are working largely on the enthusiasm of new ideas and novel conceptions of public welfare. They believe that over a large territory, lacking this enthusiasm and the inspiration of a unique experiment, the workers would lose interest and the results would consequently be negligible. It is claimed by some that the Social Unit is revolutionary and represents a dangerous competitor to existing political institutions.

Others, notably the inhabitants of the Mohawk-Brighton District, favor the experiment. Welfare workers as a rule favor the project and believe that actral results obtained have been amazing.

Besides being a health experiment the Social Unit is distinctly a social experiment. Social and health activities are based largely upon decisions of the citizens themselves acting through their councils and executives. There is no disputing the fact that some remarkable results have been obtained. Whether another group of citizens would do as well is possibly debatable.

At all events a reasonably satisfactory partial solution of the community health problem has been obtained. Whether this is the result of the Social Unit plan of community government or whether it is largely due to the intelligence and 


\section{THE COMMUNITY HEALTH PROBLEM}

energy of the executives sent to Cincinnati by the National Social Unit Organization is at present undetermined. Every community is entitled to health conditions at least as good as those in the Mohawk-Brighton District. Possibly community organization is the only way to obtain it.

The residents of this district in the face of a newspaper criticism by the Mayor of Cincinnati, recorded their desire that the Social Unit should continue its work by a vote of 4434 to 120 . 


\section{CHAPTER XIII}

\section{TUBERCULOSIS}

Tuberculosis has been ealled the burden of modern eivilization. It is without doubt the most widespread of all major illnesses. Coming as it does during an carly period in life, attacking members of every strata of society and causing a tremendous annmal loss of life, it presents the most important menace to community health which modern society must face.

Approximately 150 individuals in every 100,000 die annually from pulmonary tuberculosis. In some of the larger cities this number is increased to 200 or even higher. When we consider that tuberculosis is a disease of several years' duration and that many persons suffering from the disease are, except during the later stagcs, usually up and about attending to their normal occupations, together with the fact that comparatively few cases are reported to the public health authorities during the early stage, it becomes at once evident that there must be a large number of untreated and unsuspected cases in erery community. It is ordinarily estimated that there are at least nine active cases for erery death from the disease.

\section{DISTRIBUTION OF TUBERCLI: BACILLI}

The distribution of the tuhercle bacilli is almost unircrsal. Pathologists tell us that practically 100 per cent of all adults dying from accident show evidences of tuberculosis. The signs of the discase, it is true, are in most cases only minor lesions and have little or no elinical significance except for the fact that they point to the wide distribution of the causa- 
tire organism. From a medical standpoint such cases are not considered clinically as tuberculosis. Only when the disease becomes progressive, or when the growth of the organism tends to orercome the resistance of the individual do we speak of the condition as tuberculosis.

We know the cause of tuberculosis, we lnow how the disease is spread, and we know that it can frequently be arrested. We have therefore a condition which should be peculiarly susceptible to control, and to a degree we may say that efforts to this end have been fairly successful. In the registration area of the United States there has been an almost constant decline in the tuberculosis mortality rates from 200.7 per 100,000 in 1904 to 146.4 per 100,000 in 1917. This decrease has been due largely to existing public and private agencies for the control of tuberculosis and to improvement in the social and medical treatment of patients suffering from the disease.

\section{THE CONTROL OF TUBERCULOSIS}

In attempting to control tuberculosis one of two alternatives may be adopted. .We may discard the existing agencies and with a new broom make a clean sweep of all society, attempting the complete removal of all infectious individuals from their surroundings and starting anew with the remainder to create a new civilization. Such a plan has been proposed, including the complete isolation of the tuberculous and legal restrictions against marriage, but fortunately for the peace of the world the attempt has never been made to put this proposed plan into execution. The other alternative is to continue what we have been doing, only expanding our encrgies so that what we already know may be carried to every corner of the country; so that every individual will have placed before him the best that our present knowledge has to offer, while at the same time we make every effort to improve our methods, to correct our mistakes and develop a 
spirit of co-operation between the scientist, the physician, the patient, the legislator and the man on the street.

Much that is said of the control of tubereulosis may be said of almost any health problem in the community. The campaign against this discase in the past has been, and is apt to continue, unler the joint control of the state, or municipal, authorities and various private organizations. Each has its own part to play and none could function adequately to the exclusion of the others.

Private organizations should be devoted largely to research, experimentation, education and observation. They should be depended upun to stimulate interest, to point out new fields and to indicate methods of procedure. Governmental activities should be devoted largely to the execution of plans previously initiated by privatc organizations.

The following is the general plan of a tubereulosis program which has been outlined hy Dr. Donald B. Armstrong:*

1. Organization: Lay and professional organizations, interest, co-ordination, education, public service, ideals.

2. Legislation: Sanitary, cpidemological, institutional provision and appropriations.

3. Sanitation: Cleanliness, respiratory hygiene, food protection, control of spitting, etc.

4. Disease Detection: Reporting of disease by physicians and clinies, the establishment of new elinic facilities, infant welfare and school hygiene, special consultation service, etc.

5. Classification: The standardization of reports and classifications.

6. Treatment: (A) Home treatment including nursing, relief, etc.; (B) Institutional treatment, including sanitoria, day camps, etc.

7. Subsequent observation: Follow-up work with economic adjustment and the conservation of health.

8. Prevention: By sanitary hygiene, education, by the pre-

-Armstrong, Donala b.: Journal of Outdoor Life, Jan., 1020. 
vention of the spread of infection, and by general efforts to increase resistance.

9. Research and Demonstration: The derelopment of a scientific inquiry into the methods of prevention and cure, and into social questions combined with the demonstration of methods.

A program such as the abore can, with slight modification, be adapted to many other diseases. In a community where health work is being started from the beginning, and especially where there are only limited funds available, it is sometimes desirable to limit the work temporarily to measures to combat tuberculosis. This disease lends itself particularly to welfare work because: (1) The discase is chronic; (2) A large amount of preliminary work has been done so that there need be little lost energy; (3) There is a flourishing national organization willing and anxious to furnish assistance and guidance.

In carrying out a tuberculosis program there will be discovered a tremendous number of other diseases which, because they undermine the general health, predispose to tuberculosis. By concentrating on tuberculosis in the beginning the other unfavorable conditions are soon brought to light.

In the treatment of the tuberculosis problem there arise many closely related problems of sanitation and general health which in many cases are capable of casy solution but which in most communities are being handled indifferently or not at aii.

\section{THE DISCOVERY OF EVERY CASE}

The most important phase of the tuberculosis problem has to do with the discovery of all existing cases, that is, the bringing of all tuberculous individuals and all suspects under competent medical care.

The experience of Dr. Donald B. Armstrong in Framingham, Mass., a city of about 17,000 inhabitants, has been 
interesting as showing how many cases may be brought to light by a careful medical survey. On January 1, 1917, there were, according to the official records, 27 cases under observation in the city. On November 15, 1918, as a result of the survey, there were under observation 181 cases and 69 suspects. During this period there were 29 deaths and 32 patients moved to other localities. The source of the 242 positive cases was as follows:

TABLE OF ORIGIN OF TUBERCULOSIS CASES*

Prerionsly known 27

Medical examination drives

96

Draft

Consultation

53

Private physicians' reports

School medical work

Factory medical work

From the above table it is crident that a careful medical survey may demonstrate, at a very conservative estimate, at least one undiscovered case of tuberculosis for every reported case in a typical American community. It is probable that this estimate errs on the side of conservatism and that in fact, there are nearer two undiscovered cases for every reported case.

\section{MEDICAL CARE FOR THE TUBERCULOUS}

The next major problem has to do with the securing of treatment for every active case of pulmonary tuberculosis. Let us suppose that every case has been discovered, how then are we going to sccure the maximum benefit of treatment for each and every patient? 'This becomes at once an economic,

-Armstrong. Donald B.: Tuberculosis Findings, Framingham Monograpb No. 5, March, 1919. 
as well as a social and medical problem. A certain percentage of the patients will be able to continue their old occupations and will require a minimum of medical attention. A somewhat larger proportion will not improve in their present occupations, but will improve if they are placed in more favorable surroundings. Many will be unable to do any work and must be either treated at home or sent to a sanitorium. The economic problem becomes most acute when the bread winner is attacked and unable to support his family. It is useless to tell such a man that he must "get away and take a long rest." Unless provision is made for his family he will be unable to stop work until the disease has progressed so far as to render him physically unfit. At this stage the disease is, of course, unfavorable for treatment.

\section{AFTER-CARE OF THE TUBERCULOUS}

The third phase of the problem has to do with the care of the arrested case. It is customary in such cases to tell the patient that he may now return home and "to secure some form of light out-door work." For the average man such advice is worse than useless. Those who have tried say that light out-door work practically is non-existent. The chief out-door occupation is farming which is far from a light occupation. If an arrested case is allowed to go back to hard manual labor immediately upon discharge from the sanitorium a relapse of the disease is almost certain to occur and the results of treatment are completely counteracted, thereby causing economic loss both to the man and the community.

The problem has been solved in a large way only in a few communities. Certain industrial organizations, notably the Ford Company, have established special work rooms for arrested cases of tuberculosis where they are given light work in hygienic surroundings, under the care of a physician. The results of this plan have been most successful and the future of what might be called "occupational therapy" for incipient and inactive tuberculosis in carefully selected cases is most promising. 
The U. S. Public Iealth Service has outlined a program* for 1920 which includes: (a) Stringent provisions for the proper reporting of cases of tuberculosis; (b) Adequate. instruction of families and patients, especially in families where there is an adranced case; (c) Hospitalization of cases, wherever practicable, either through city institutions, or by arrangements with state and district tuberculosis hospitals; (d) Co-operation with national societies and agencies having for their object the prevention of tuberculosis or the improvement of economic conditions; (e) Improvement of industrial conditions predisposing to tuberculosis, such as dusty occupations, defective ventilation, ete.

For the average community where it is desired to make a beginning in constructive liealth work the campaign may often be centered about the tuberculosis problem. So many welfare measures, such as better housing, child welfare, nutrition, etc., are so intimately connected with the control of tuberculosis that activities undertaken with the aim to prevent the spread of this discase serve to direct attention to community sickncss, and at the same time, tend to improve general community health.

-Annual Report, 1919, ర. S. Public Health Service, Washington, D. C. 


\section{CHAPTER XIV}

\section{SOCIAL HYGIENE IN ITS RELATION TO COMMUNITY HEALTH}

/ In every community there is what has come to be known as a "social hygiene" problem, meaning thereby a problem which has to do, in part, with the prevention of renereal diseases. In many of the smaller communities the presence of sex diseases may be denied but if a careful search be made, in every group containing several thousand persons, evidence of sex disease, either past or present, will almost certainly be found in a fairly definite proportion of the total.

No plan of health improrement can be considered complete unless the question of social hygiene receives due consideration. The prevention of sexual diseases has been frequently attempted and for the most part attempts have met with little or no success. The problem is so complicated by personal habits, social institutions, and by community and national customs that the medical aspects of the question become obscured by the sociological and economic problems which present themselves.

\section{MEDICAL CONTROL POSSIBLE}

As far as the science of medicine is concerned there is no mystery in any of the various sex diseases. They are all of them transmitted only by direct contact, they are all more or less easily curable and their transmission from onc person to another is comparatively difficult. They are not spread by air currents as are measles and smallpox,* they are not disseminated through infected water or food as are typhoid

- The spread of measles and smallpox by air currents is not definitely proven. Some writers deny that this can occur. Howerer, infection does occur from very slight contact in both of these diseases, possibly carrled. in some cases at least, in minute droplets of molsture expelled in coughing or sneezing. 
and dysentery, and they are not carried by insects as are malaria and typhus. Moreover the micro-organisms are not 'scattered broadcast as are the germs of pus-forming infections but, in practically every case, the disease must be spread directly from person to person and the contact must be intimate and prolonged.

Even when such is the case an abrasion or wound of the surface is in certain cases necessary for the introduction of the infective material.

Here then from a medical standpoint we have disease which should be very easily controlled. All that is necessary is to quarantine every case during the infectious stage, and the disease will disappear. But this is more easily said than done. In the first place venercal diseases exist to such an extent that quarantine is impracticable. In the next place the social disgrace of sexual infection is so great that many persons will do their utmost to prevent the discovery of the fact that they are suffering from such disease. And last, and in my opinion most important of all, is the fact that these diseases are often so mild as to escape the knowledge of the patient himself or at least so mild as to permit him to deludo himself into believing that his disease is not serious. If venereal diseases oceurred in acute attacks, as severe as typhoid fever or smallpox, detection would be easy, all cases would come under treatment, the spread of infection would auto. matically stop, and the venereal disease problem would soon become comparatively insignificant.

\section{MILITARY CONTROL OF SEX DISEASES}

In a military community where all the members of the community are under strict control sexual diseases may be reduced to a minimum. This has been frequently proven in the United States, and was demonstrated on a tremendous scale in the American Expeditionary Forces where the venereal admission rate was extremely low. However the 
methods which were used in the Army are for many reasons considered impracticable in civil life.

Nevertheless the study of social hygiere received a great stimulus during the war period. It was realized that here was a live problem which must be recognized and faced before conditions could be bettered. In the past there has always been a strong tendency to deny what was considered objectionable and, in America especially, many persons considered that it was immoral even to admit that such diseases existed.

For some years the American Social Hygiene $\Lambda$ ssociation, the U. S. Public Health Service, the American Red Cross, and various city and state health departments have been attempting to stimulate interest in the problem of social hygiene in order to diminish all forms of veneral disease, without however meeting with any great amount of co-operation from either the public or the medical profession.

\section{PUBLIC HEALTH SERVICE CAJPAIGN}

During the war however the United States Public Health Service outlined a nationwide campaign against venereal diseases to be carried out in co-operation with state and local health authorities and various welfare organizations. In July, 1918, the Chamberlain-Kahn bill was passed by Congress establishing a Division of Venereal Diseases in the Public Health Service and an Interdepartmental Social Hygiene Board. The Surgeon-General of the Public Health Service characterized the bill as the most important public health legislation ever enaeted by law.

The duties of the Division of Venereal Diseases were outlined as follows:

1. "To study and investigate the cause, treatment and prevention of venereal diseases;"

2. "To co-operate with State Boards of Health for the prevention and control of such diseases within the states; and"

- Plerce, C. C.: The Public Health Campalgn agalnst Venereal Diseaser, Social $1 \mathrm{y}$ giene, October, 1019. 
3. "To control and prevent the spread of these diseases in interstate traffic."

In addition to interstate quarantine regulations which forbid interstate travel of persons infected with venereal disease except under a permit of the local health officer, a bill was introduced to make certain United States appropriations available to local health authorities who would co-operate with the Public Health Service for the prevention of venereal discase. Definite minimum requirements were established which must be met before such appropriations are available for local or state health activities. The minimum requirements are, briefly, as follows:

(a) "Venereal diseases must be reported to the local health authorities in accordance with state regulations approved by the United States Public Health Service."

(b) "Penalty to be imposed upon plyysicians or others required to report renereal infections for failure to do so."

(c) "Cases to be investigated, so far as practicable to discover and control sources of infection."

(d) "The spread of venereal disease should be declared unlawful."

(e) "Provision to be made for the control of infected persons who do not co-operate in protecting others from infection."

(f) "The travel of venereally infected persons within the state to be controlled through state boards of health by definite regulations that will conform in general with the interstate regulations to be established."

(g) "Patients to be given a printed circular of instructions informing them of the necessity of measures to prevent the spread of infection, and the importance of continuing treatment."

\section{TREATMENT SHOULD BE MADE ATAILABLE}

From a medical viewpoint every case should have the oppor. tunity of securing expert treatment at a moderate price. 


\section{$1: 6$

There has been a tremendous amount of exploitation of patients by the so-called "advertising specialists." It is even argued by certain conservative physicians that, because men develop these diseases mainly as a result of their own misconduct, they should be made to pay high fees. Many private practitioncrs take little interest in such cases and prefer to send them elsewhere for treatment. This together with the stigma of disgrace which is attached to venereal infection has driven many men to the advertising specialist for treat. ment or has resulted in self medication. Drug manufacturers have become enormously rich from dividends derived from the sale of patent medicines for the cure of sex diseases.

It is most important that every community recognize that it is better to treat these diseases at the expense of the public than to allow them to remain untreated. This is best accomplished by the establishment of a dispensary where treatment can be had for the asking for a nominal charge, or for no fee at all if requested.

In general the campaign should be laid out along the following lines: (a) Education; (b) Treatment; (c) Legislation; (d) Recreation. If the need is recognized and advantage is taken of efforts of the Publie Health Service, and the various local and state health authorities, a great deal may be accomplished. If on the other hand, the presence of a venereal problem is denied or if the subject is shelved because it is considered indecent and immoral, and consequently unfit for discussion, the contagion will continue and the coming generation will pay the price. Still-births, blindness, paralysis, insanity, and many chronic partially-ineapacitating diseases frequently follow untreated veneral diseases. Such bad results ean nearly always be prevented by early and efficient treatment. Social ostracism as a thereapeutic measure in the cure of venereal disease has always been, and always will be, a failure. It is in line with modern social progress to divorce entirely the moral from the medical in the treatment of disease. It is impossible to deny the presence of venereal diseases in the community; it is criminal to ignore them. 
Various other measures for the control of venereal diseases, such as the elimination of the so-called "red light district," the segregation of prostitutes, compulsory quarantine during the infectious stage, and other similar measures which have been adrocated from time to time are not considered within the scope of this chapter. For a further discussion of this question, especially in its social and economic aspects, the reader is referred to the various publications of the American Social Uygiene $\Lambda$ ssociation. 


\section{CHAPTER XV}

\section{REHABILITATION OF THE DISABLED}

It is self evident that the soldier who has done his duty in military service and returned to his home wounded and permanently disabled must not be allowed to resign himself to a life of idleness, depending solely upon his government pension for support. Such a procedure is demoralizing both to the discharged soldier and to the community.

Neither should he be eneouraged to depend upon irregular work of an unskilled nature if he has within him capabilities of something better.

Following the activities of the war and the long period of idleness in the Army hospitals there is often a period of depression. The wounded soldier is apt to decide that he is a "has been," that he is seriously handicapped, and cannot hope to compete with the physically fit and that he will be unable to earn a satisfactory living. He feels that there is nothing left to do except resign himself to the ineritable. This mental condition is, in some cases, a state of depression, so marked that it causes the man to aroid his friends and acquaintances, to become morose and to be considered moody and unfriendly by those with whom he is brought in contact. Place this same man in a gainful occupation, make it possible for him to support a family, let him feel that he has a place in the community, and immediately his whole character changes, he is able to look his fellow in the eye without a feeling of humiliation and, as a consequence, when at work he often makes faster progress and does better work than his uninjured co-workers.

Douglas C. McMurtrie has pointed out that, throughout history, the disabled and deformed man has been a castaway 
of society, that the tribes of aneient India turned out their deformed members to wander in the wilderness, and that the ancient Hebrews banished cripples and forced them to beg at the roadside. Ridicule and suspicion were frequently directed against the deformed, and at one time it was widely believed that some evil power rested in the deformed or erippled body.* During the last century however there has been a rapid change for the better, beginning with pension laws and toward the end expanding, with the broadening conception of the responsibility of the eommunity, through the enactment of compensation laws and laws for vocational training.

It is to be hoped that the problem of the disabled soldier is not to be a permanent one and that the splendid efforts which have been made by the Federal Government will not soon again be required for those injured in war. The lesson once learned, however, must not be forgotten and the obvious advantages of rocational training for the war cripple must be adapted to civilian problems and made available for the cripples of industry of whom there are an enormous number.

\section{MANY CRIPPLES FROM INDUSTRIAL ACCIDENTS}

It is stated that in eighteen states, from which we have complete statistics, there are injured in industry 750,000 persons per year, orer 35,000 of these accidents representing disability either partial or total; and in the course of the year, there are more than 28,000 amputations as a result of accidents in the entire country. No solution of the community health problem is complete unless it takes into consideration the training of disabled men, whether such disability is a result of injury or disease. This problem must of necessity vary in different localities.

There being, unfortunately, comparatively little information arailable for the use of the civilian community which plans the rehabilitation of the industrial cripple, it becomes necessary to study what has been done for the disabled

-McMurtrie, Douglas C.: The Disabled Soldier, New York, 1918. 
soldier and to make use of this information in the care of the civilian cripples.

The beginning of the morement for the training of soldiers was definitely established by the organization of the first training school for invalided soldiers in Iyons, France, in December, 1914. It is said that Edward Herriot, Mayor of Lyons, noted that in the streets of the city there were a large number of strong and rugged appearing soldiers who, except for a specific injury, appeared physically sound. While these men sat about and sunned themselves in the streets of the city the nation cried for munition workers to man the nearby factories. When Mayor Herriot examined into tho question of employing these men, many of whom had been skilled mechanies, he found that they were unable to resume their former occupations because of physical handicaps. It was necessary to teach them new occupations before they could be employed. As a result of his efforts a school was opened at Lyons in December, 1914, with three pupils. In a few months it became nccessary to turn applicants away.

With the example of the French before them the morement soon spread to England, Belgium and other allied countries.

Before the entry of the United States into the war there had been comparatively little study of the vocational training of cripples in this country. While the need had long been recognized, practically no serious effort had been made to meet the need and very little information as to the character of the work being done in France, Great Britain and Italy was available.

The first scrious effort made in America was inaugurated by the Institute for Crippled and Disabled Men which was started by the American Red Cross in New York City during the summer of 191\%. This was nearly a year before the provision for the training of disabled soldiers, sailors and marines became a law (June 27, 1918). Vocational training in the United States was placed under the supervision of the 
already existing Federal Board of Vocational Education, a new division of which was created for this purpose and termed the Division of Rehabilitation.

The Board cstablished oflices throughout the country and an attempt was made to secure contact with all injured soldiers, and to approve for training those who were handicapped for their old occupations, and who would benefit by a course of vocational training. Unfortunately there was a great deal of delay, due largely to the fact that the Federal Board was handling an enormous work and that it was practically impossible to secure for the divisional offices, employees who had been trained in work of this sort. Consequently the training of many disabled men was delayed for weeks or months through no fault of their own.

\section{EARLT TRAINING NECESSARY}

Training should start before the patient is discharged from the hospital. This is very important and is too often neglected. During the long period of convalescence the soldier becomes tired of the monotonous existence he is forced to undergo. He smokes too much, is apt to drink too freely and is generally at odds with his surroundings. Healthful daily occupation not only aids in dispelling ennui but actually hastens healing. This part of the work must necessarily be undertaken in an institution where teaching facilities for a large number of pupils can be easily secured. Medical attention must also be available so that, when dressings are required, only a small amount of time need be lost. It is not necessary for all the men to live at the institution, many can live at home and take the daily trip back and forth for medical care and instruction. Only in very exceptional cases should men be permitted to cnter ordinary schools until the maximum benefit from medical treatment has been obtained.

The United States law failed to insist upon hospital training, so that, as a consequence, after the patient left the hospital there was a grievous delay before vocational training 
could be started. This was iargely due to the overwhelming of the Federal Board with more cases than they could possibly handle, and to other causes which apparently are inherent in government undertakings. The Medical Department of the Army, or Navy, discharged the man, when in the opinion of the surgeons the maximum benefit had been attained. He then had to apply to the War Risk Insurance Bureau for a pension and to the Federal Board for vocational training. This required applications, proofs of identity, repeated medical examinations and, as a consequence, long delays in many cases. This has caused much criticism of the Federal Board. The discharged soldier felt, not without reason, that he was not receiving a square deal. When he was asked to go over the top and risk his life it was not necessary to wait for a special communication from Washington. Why should there be so much delay when the country was asked to repay the debt? As the work has progressed the machinery of the law is acting more smoothly and there has been less cause for complaint.

\section{PHYSICIAN PLATS IMPORTANT PART}

The role of the physician in the training of the war cripple is an important one.* In the first place the physician must pass on the physical condition of the applicant, to decide if he has actually obtained the maximum benefit from treatment. If no further treatment is required it is necessary to decide whether his disability actually disqualifies him for following his old occupation. It is not enough to conclude that he may, by extra effort, continue in his old employment. The questions must be asked, "If this man returns to his old occupation will he be handicapped as compared with the normal worker?" and "Will this man, if he returns to his old work, be able to carry on as long as the normal worker?"

\footnotetext{
- The anthor has discussed this phase of the subject more in detall in an article entitled Rehabilitation in its Relation to the Physician, Modern Mediclne, February, 1020.
} 
If he compares unfavorably with the normal worker it is necessary to give the man some form of training so that, by his skill, he may be able to compete with the normal worker on equal or nearly equal terms. Thus, a mechanic may be taught special mechanical processes which require special technic, thus making it easy for him to secure employment in spite of a wooden leg or a partially crippled arm. That is, the man may be given additional training in his old oceupation if this is considered practicable. This is, however, not almays possible. A policeman who had both feet frozen was found no longer fit for his old occupation and consequently it was necessary to train him in an entirely new line of work. $\mathrm{He}$ became a wireless operator. A physician became stone deaf as a result of a shell explosion which left him otherwise uninjured. This disability made it impossible for him to continue private practice but he was trained as a laboratory worker, and was able to take full charge of a hospital laboratory.

In the choice of a vocation, the man consults with the vocational advisor and between them they come to an understanding which is based upon the man's previous education and training, his desires, the openings available and the opinion of the advisor as to the man's aptitudc and capabilities. After the choice is made the man is sent to the medical adrisor to decide whether there is any objection from a physical standpoint to the proposed course of training.

In the United States every disability, whether due to injury or disease, which arose from, or was increased by military service, is to be considered from a rocational viewpoint. The handicap from a vocational standpoint is classified either as major, minor or negligible. If there is a major handicap, according to the Act, the man recelves training and an allowance for expenses varying from $\$ 80$ to $\$ 115$ monthly, ${ }^{*}$ depending upon the number of dependents who look to him for support. A minor handicap entitles a man to

- This amount is sometimes increased by the Federal Board. 
training, but to no allowance, and a negligible handicap entitles him to placement in a position but no allowance and no training.

\section{CLASSIFICATION OF HANDICAP}

The instructions issued by the Fcderal Board on this point are as follows:

(a) "Major Handicap" includes cases in which, from the point of view of the entry in question, the disability will be a real and permanent handicap in the occupation such as to effect employability and earning power.

(b) "Minor Handicap" includes cases in which, from the point of view of the entry in question, disability involves some inconvenience that does not interfere in any real way with the employability or earning power and that frequently may become negligible after a brief experience in the vocation.

(c) "Negligible Handicap" includes cases in which, from the point of view of the entry in question, the disability may be disregarded in considering the man's employability and earning power.

In some cases the question of handicap presents a difficult problem. Especially is this so of those who complain of disability with indefinite or ill defined symptoms. In such cases the District Medical Officer may send the man to a specialist for consultation, to a radiographer for an X-ray or to a laboratory for a special analysis. Here the physician has at his command all the methods required by modern practice for the diagnosis of disease. For example, a man complains of weakness in his hand following a gunshot wound of the arm. A neurological examination shows that he has a partial paralysis of one of the nerves of the arm and that his disability is probably permanent. Such a man will be classed as a major handicap. Another complains of pain in the elbow when the elbow is bent, following an old fracture. An X-ray 
of the elbow shows a small spicule of bone projecting into the joint. Operation is not considered advisable and the man is given a "inajor handicap, probably permanent."

\section{MEDICAL ATTENTION NECESSARY DORING TRAINING}

Any plan for rocational training should include medical attention for the man during the period of training. Under the plan adopted in this country this care is given by the U. S. Public Health Service. This has not worked very well because the applicant is not in touch with the Public Health Service, as a rule, and the physicians of this service are, in turn, not in close touch with the Federal Board. It is a question if better results would not have been obtained if the entire work had been undertaken by a medical organization such as the Medical Department of the Army or the U. S. Public Health Service, instead of dividing the medical care and educational supervision between the Public Health Service, on the one hand, and the Federal Board, on the other. At present there is considerable duplication of effort. Many of the difficulties of the Federal Board arise because of this duplication and because of the enormous amount of work which it handles. With untried methods and inexperienced employees, many mistakes were certain to occur in the rush of applicants, beginning directly after the armistice, which would not occur in a community effort on a small scale.

There is a problem of considerable human interest in the examination of applicants for training. There may be seen some of the terrible results of war, met with a spirit of bravery and heroism worthy of the cause. Some men appear determined to belittle their disability and have to be argied into accepting training. Such men succed with a small amount of help and guidance. On the other hand, cases are seen in which a simple injury with no apparent disability has so unsettled the soldier's mind that he is unable to undertake any form of vocational education. These latter are the hard- 
est cases to deal with, the men being mentally unsettled and not to be depended upon. It is hoped that in time they will find themselves and become useful citizens.

The following three cases are typical:

F. B. 24 rears-Sergt. Field Artillery. Irish parentage. Enllsted April 19, 1917. Discharged Oct. 7. 1919. Diagnosis: Old scar following mastoid operation. left side. In hospital $\mathbf{9}$ months. Discharged from hospital oct. 7, 1919. Disability: Deafness left ear. Previous occupation: Student, self supporting. Unable to continue course for lack of runds. In this case the handicap is considered as 25 per cent. If this man is allowed to complete his course in electrical engineering, he will be able to overcome his handicap. Recommended for course in Massachusetts Institute of Technology.

E. W. 24 rears-Serbian parentage. Enlisted in Infantry, December. 1917. Wounded-July, 1015. In U. S. Army hospitals eleven months. Discharged June, 1919. War Risk Bureau gires disability as 75 per cent. Previous occupation-laborer. Examination shows multiple gunshot wounds completely healed. Complete hlindness right eye, following wound of temple. Deformity of right band following $G$. S. W. Is nnable to use hand for finer movements but has strong grip and will be able to do heary work. New occupation advised-vulcanizlng. This man will be sent to a tratle scliool to learn vnleanizing. As a skilled worker he should receive more pay than previously and be able to overcome his handicap. As a laborer he would probably end by becoming a chargo on the community.

R. S. G. 26 years-American-First-class seaman. Enlisted Norember. 1917. Served as armed guard on commercial liner. Discharged Jannary, 1919. Old occupation-machinist's helper. Diagnosis (Feb., 1919): Nephritls, chronic parenchymatous. Disability complete, unable to perform any work. Referred to Marine Hospital, Staten Island, for treat. ment. Oct. $S$, 1919: Man has been in hospital for nearly elght months. Returns anxious to go to work. Examination shows that he is stili suffering from nephritis and able to do only rery light work. If this man does hard work his trouble will be aggrarated and he will become a charge on the community. He should be sent away where he can do light work and be under medical supervision.

When the work of the Federal Board is finished an enormons amount of statistical data will be available both from a medical and a vocational standpoint. In instituting rocational training for industrial cripples the experience of the Federal Board should be made use of, mistakes being aroided by a careful study of methods employed by the board and of the experiences of foreign countries in the same field.

For those who are interested in this phase of social welfare work the government publishes a monthly magazine, the Vocational Summary, which may be secured by application to the Federal Board of Vocational Education, Washington, D. C.

* The case histories and a part of this chapter, dealing especially with the medical aspects of the work of the Federal Board, are reprinted, by permission, from an article by the author in Iodern Medicine, Feb., 1920. 


\section{REHABILITATION OF THE CIVILIAN CRIPPLE}

While the training of the disabled soldier has been carefully worked out the training of the crippled civilian is passing through the formative period, so that it is difficult or impossible to outline its present status. What is true at the time this is written may be changed before it appears in print. It is therefore impossible to make definite statements in reference to the details of the movenient.

In general, the Federal Government plans to encourage the development of re-education for industrial cripples through an appropriation, a part of which is made available to the various states upon the condition that they appropriate a similar amount and carry out the details of the work in accordance with definite standards established by the Federal Board. Many states are co-operating in this work but the methods of procedure have not yet been worked out.

It is the opinion of the writer that civilian methods of vocational re-education can be most suceessfully developed in the various states, through the grouping of the disabled workers in certain definite localities for training. This will permit the grouping of students and instructors in an institution and will thus allow for a more direct contact between the student and the trained instructor. In other words it is believed that one or more schools should be established in appropriate locations in each state, rather than to attempt to provide instruction in various already existing industrial establishments, where, in many cases, as has been shown by experience, the training of disabled workmen has become sidetracked by the pressure of rontine work.

Each institution should provide facilities both for funetional re-education, that is the training of the muscles to overcome as far as possible the physical handicap, and vocational re-education or the training of the disabled worker for a new vocation. Functional re-education falls naturally under the supervision of an orthopedic surgeon, while vocational training would be under the control of those skilled in voca- 
tional subjects. Often these two forms of re-education may be carried on at the same time.

After the institutional training has been completed, the student may be profitably sent out for a period of practical field experience.

Until statewide plans are carefully worked out, communities may attempt to secure training for industrial cripples in various local industries. In a few cases this has been very successful but, in the main, if there is a school available for this purpose within the state, much better results may be expected to follow the institutional plan of training than can. be hoped for under any form of local community effort. 


\section{CHAPER XVI}

\section{ENDOWED HEALTH DEMONSTRATIONS}

The methods employed by the Rockefeller Foundation are of interest to students of community health because the enormous financial resources of the organization permit it to make experiments in health control which for economic reasons could seldom be attempted by the average community.

As expressed in its charter the purpose of the Rockefeller Foundation is the promotion of "the welfare of mankind throughout the world." 'This is a big undertaking even for an organization with an endowment fund of over one hundred million dollars and a yearly income which, including gifts, amounted to $\$ 8,609,710.86$ in 1918 .

In order to secure the greatest benefit from this income the trustees of the Foundation have followed a program of education and diffusion of knowledge so that each country may "contribute its best achievements to a common fund from which all lands may draw." In the report for 1918 it is stated that, "in this commerce of culture, science, sympathy and idealism, the Rockefeller Foundation desires to put its policies, personnel and resources at the service of the world."

The Rockefeller Foundation bears the same relation to public health as a state anricultural college does to farming. The Foundation may indicate methods for health improvement, and even actually put such methods into practice in certain selected communities, but in the main it has always been the desire of this organization to withdraw irom the field when adequate methods, whether for prevention or cure, are once established on a firm working basis by local authorities.

During the year 1918 large amounts were expended for

- The statistics in thls chapter were taken in part from the Annual lieports of the Rockefeller Foundation. 1917 and 1918. 
war relief largely through the American Red Cross, and the United War Work Fund of the Young Men's Christian Association. These two organizations receired over $\$ 9,500,000$ during the war and about $\$ 1,000,000$ in addition was deroted to other organizations. During the same year approximately $\$ 350,000$ was appropriated for medical research and relief in connection with war activities.

In spite of this tremendous sum which was spent for war relief, the regular expenditures for public health, medical education and research amounting to $\$ 3,600,000$ were continued.

From the standpoint of community health the greatest interest is found in the work of the campaign against tuberculosis in France, the work of the International Health Board, and the researches of the Rockefeller Institute of Medical Research.

\section{THE FRENCH CAMPAIGN AGAINST TOBERCULOSIS}

The campaign against tuberculosis in France, as has been pointed out by Dr. George E. Vincent, President of the Foundation, was not undertaken because the French are less skilled in the treatment of tuberculosis or because the scientific knowledge of the disease in France is second to any other country. It was found that in France there were sanitoria which, as regards buildings, scientific equipment, personnel and surroundings, were as good if not better than anything to be found in America. The Leon Bourgeois Dispensary in Paris was found well organized, with visiting nurses, trained physieians, free public lectures, and everything that goes to make up a modern scientific dispensary.

If Ameriea had anything to contribute to the French it was a demonstration of organized team work. In France ideas do not spread so rapidly as they do in this country, possibly because there are few national organizations which ean quickly inform each community what is being done in every other. 
There has been, in France, a rapidly increasing interest in the question of public health since the work was begun. Clever advertisements were read by all and, partly because of the adrertisements themselves and, partly because the advertising of public health was a new idea which originated with "les Américains," the movement created great interest. Work was begun intensively in two eommunities and gradually increased until, at the end of 1918 , the campaign had been extended to twenty-seven departments. French visiting nurses, les visiteuses d'hygicne, were trained at the various dispensaries and arrangements made to bring a group of physicians to the United States to give them an opportunity to study American institutions and methods. In the yearly report the following statement is made in reference to the campaign against tuberculosis in France: "Within a reasonable time, therefore, the Foundation expects to withdraw, confident that the work will go on until a nationwide system of combating tuberculosis bas become a permanent part of the policy of France."

The method of handling this campaign is typical of much of the work done by the Rockefeller Foundation. To move in, to create interest, to demonstrate what can be done by a reasonable expenditure of time and money, and then to withdraw and leave the work to be carried on by local organizations apparently is the general policy.

\section{THE HEALTH CAMPAIGN IN FORTH CAROLINA}

This policy is also seen in the work done in North Carolina in conjunction with the State Department of Health. A three-year program was laid out, the appropriations gradually decreasing during the period. North Carolina was the first state in the South to attempt to meet its rural health problems by effective organization on a county basis. Campaigns have been carried out against typhoid fever, hookworm, dysentery and many other diseases. Child welfare, the prevention of tuberculosis and the medical inspection of school children are all included in the plan. The State Board 
of Health is in charge, the local work is largely done by the county health authorities and the expenses are met by the state, the counties, and the Rockefeller Foundation. After three years the Foundation is to withdraw and the program is to be continued by the counties and the state.

This experiment in North Carolina will bear further watching. It is proposed to see that every child attending school receives any necessary medical treatment which may be required. Trips are made to out of the way districts so that all eases may receive treatment and the effort gives promise of excellent results.

The experience in the prevention of typhoid fever has been most instructive. "In nine counties of North Carolina, during the four year period from 1914 to 1917 the total deaths from typhoid fever were 478. This is a yearly average of 119.5 deaths, or 35.3 deaths per hundred thousand. During 1918 as a result of a crusade against soil pollution in these nine counties, a total of 6,480 fly-proof privies were erected. Typhoid ferer statistics for the year 1918 show that out of an aggregate population of 305,016 in these counties there were only 24 deaths from this disease, a rate of 7.8 per hundred thousand.

It is possible that North Carolina will actually solve some of the more troublesome problems of community health while the northern states are still discussing them. The experiment is one of widening influence of the state in the domain of health and approaches state medicine. So far, in North Carolina at least, the venture has been most successful.

The Rockefeller Foundation is using its influence to advance medical education. The School of Hygiene and Public Health at Johns Hopkins was organized largely through its efforts and a similar school has been organized in connection with the medical university at San Paulo, Brazil. Students from Brazil, China and France have been granted fellowships in order to study in the United States and members of the medical staff of the Foundation are granted "study leave" in 
order to pursue special courses in public health at leading American or foreign institutions. In China a medical school is now in course of construction.

\section{HOOKWORM INFECTION}

For several years experiments have been conducted in an effort to combat hookworm infection. This disease, widely prevalent in our southern states, has been found to be of almost worldwide oceurrence. Hookworm disease exists wherever the larva of the worm find favorable soil conditions. They require shade, moisture and warmth for their propagation and growth such as found in tropical or subtropical countries. They are not found in cold countries or in very dry countries, such as Arizona or northern Mexico.

In India, Brazil, the West Indies, Central America and Australia, widespread infection has been demonstrated by the work of the International Health Board. In many of the areas studied, between 80 and 100 per cent. of all inhabitants were found infected. Work done by U. S. Army surgeons during the recent war indicated that a large percentage of southern troops, both white and colored, were suffering from hookworm infection of more or less pronounced degree.

Hookworm disease results from the presence of hookworms in the human intestine. It begins insidiously and may not make itself felt for several years. For a time the body is able to resist the disease, but the cumulative effect finally becomes evident. The physical strength is slowly sapped by imperceptible degrees, so that there is finally a distinct retardation of physical development and the mental capacity is gradually undermined, the result being that in the later stages the impairment of the intellectual character is plainly evident. Anemia, loss of flesh and strength, and defective mentality are the characteristic symptoms. Persons suffering from the infection although showing few if any symptoms are more susceptible to other infections than are healthy individuals. In Camp Bowie the sickness records from Octo- 
ber, 191\%, to May, 1918, demonstrated that resistance to other diseases was the lowest and mortality rates were the highest in those organizations in which hookworm disease was the most prevalent.

The diagnosis is easily made from the examination of the stools and the cure is simple, being accomplished often by a single treatment with a strong intestinal antiseptic followed by a purge. Yet in spite of this there are huge districts in the United States where no concerted efforts have been made to rid the community of the affliction.

\section{INFECTION SURVEY OF JAMAICA*}

The methods of the International Health Board may be illustrated by the following survey:

The infection survey of the Cayman Islands (a dependency of Jamaica) made during the spring of 1917 , resulted in the Government appropriating approximately $\$ 12,000$ for carrying out a co-operative campaign against hookworm disease in Jamaica proper. As an initial step in the measure of control, an infection survey of the Island was made during June and July, 1918.

The survey indicated that probably two of every three inhabitants of Jamaica hare hookworm disease. High infection rates were also recorded for round worms and thread worms, the former being found in 67.2 per cent. of 10,926 persons examined, and the latter in 35.9 per cent. In the larger towns and cities, which are located along the coast, a beginning has been made toward the proper disposal of the excrement, but in the rural districts soil contamination is practically universal. There are laws requiring a latrine at every home, but no serious attempt has been made to enforce them.

\section{INACGURATION OF CONTROL MEASURES}

The survey is to be followed by a series of demonstrations in cantrol measures. The working arrangement provides that

- From the Appendix of the Report for 1918. Rockefeller Foundation, New York. 
the Government is to share the expense of the initial field posts and to have suitable latrines installed in all areas in advance of examination and treatment. The Government has available approximately $\$ 7,500$ as a first appropriation for this purpose.

It is to be expected that the Foundation will, in a case such as the above, furnish the funds and personnel for the proper demonstration of the control of the disease in one or more sections of the Island, leaving the balance of the Island to be cared for by the Goverument. Complete control of the disease is difficult and the prevention of reinfection is impossible unless modern sanitation is introduced and maintained.

\section{THE CONTROL OF MALARIA}

The Foundation, through the International Health Board, has carried out a series of demonstrations on the control of malaria in various localities. We know that malaria is carried by a certain species of mosquito and we know that if we can climinate the mosquito the spread of the disease will automatically stop. This has been known for many years and yet there are literally thousands of communities which are afflicted with this direase and yet make no concerted effort to be rid of it. It has remained for the Rockefeller Foundation to demonstrate that it is cheaper to be rid of malaria than to have it.

\section{EXPERIMEN'T AT CROSSET, ARKANSAS, 1916*}

The first of the tests was undertaken at Crosset, a lumber town of 2129 inhabitants situated in Ashley County in southeastern Arkansas, about twelve miles north of the Louisiana line. It lies at the edge of the "uplands" in a level, low lying region (elevation 165 feet) with sufficient undulation to proride reasonably good natural drainage. Climatic conditions and abundant breeding places favor the growth of the anopheles mosquito. Malaria in a severe form is widely preva-

-Quoted from the Report for 1918. 
lent as an endemic infection and, according to the estimate of the local physicians, is responsible for about 60 per cent. of all illness throughout the region. Within the town itself the malaria rate was high and was recognized by the lumber corporation and the people as a serious menace to health and working efficiency.

The initial step in the experiment was a survey of the community to determine the malarial incidence, to ascertain the species of mosquitoes responsible for the spread of the infection and to locate the breeding places of these mosquitoes. Brecding places were exhibited on a community map, and an organized effort was centered on their destruction or control. The program of simple measures excluded all major drainage. Shallow ponds were filled or drained; streams were cleared of undergrowth where necessary to let the sunlight in; their margins and beds were cleared of vegetation and obstructions; and they were drained to a narrow channel providing an unobstructed water flow. Artificial containers were removed from premises; water barrels on bridges were treated with nitre cake. All remaining breeding places were regularly treated by removing regetation, opening up shallow margins to give free access to small fish, and spraying once a week by means of automatic drips or a knapsack sprayer. All operations were under the control of a trained lay inspector. Care was exercised to avoid all unnecessary effort, and to sccure, not the elimination of the last mosquito but a reasonably high degree of control at a minimum cost.

The first conspicuous result apparent to every person living in the community was the practical elimination of the mosquito as a pest. The reduction of malaria as shown by a parasitic index taken in Mav, 1916, and again in December of the same year, was 72.33 per cent. The reduction in physicians' calls as compared with the number of calls for the previous year (company's record) was 70.36 per cent. The per capita cost of the work-omitting overhead-was $\$ 1.24$. During the year the lumber company had repeated these 
measures at two of its large logging eamps with results that were convincing as to the soundness of the investment.

At the end of 1916 the community took over the work and for two years has maintained it at its own expense and under its own direction. The same measures have been continued under the supervision of a trained native lay inspector. The following table shows the yearly results and the per capita cost :

\section{PHYSICIANS' CALLS FOR MALARIA}

Population 2129

1915 Calls (Company's records)

1916 “

1917 "

1918 “
"

66

6
2500

741

200

73

Reduction for the three years, 97.1 per cent.

PER CAPITA COST

1916 (omitting overhead)

$\$ 1.24$

1917 (total cost)

.63

1918 (total cost)

.53

These results were confirmed in other localities where similar figures were obtained.

The methods used by the Rockefeller Foundation have been deseribed in some detail in order to give some idea as to what may be accomplished in a community by a concerted effort for better health. It is not to be expected that the Foundation will undertake this work for every community. It can merely demonstrate methods of control, and the various communities may accept them or reject them as they see fit.

The American Red Cross, the American Child Hygiene Association, the National Tuberculosis Association and many other public and semi-public organizations are working along the same general lines as the Rockefeller Foundation. Some are endowed and others sccure their funds largely throngh 
public subscriptions. They should all be looked upon as merely auxiliary organizations and should in no case replace public health activities or community health effort.

The American Red Cross as part of its peace-time program, places special emphasis upon community service for better health. This work is to be in addition to the already established activitics for military and civilian relief and is to supplement them in local comnunities. For this purpose a new department has been organized, the Department of Health Service, the purpose of which is to give national and community service for the development of better health. "The opportunity and responsibility have been brought home to our chapters," says the Red Cross Bulletin,* "by the widespread demands for help along health lines in the sereral communities, as well as by the national conviction that we face an emergency and continuing disaster in the health field not less alarming than the emergency of war."

The health service, briefly, includes: (1) Service for the extension of public education through health lectures, posters, pamphlets and books, together with the collection and distribution of health information and statistics; (2) The establishment of health centers in the effort to co-ordinate official and other health agencies serving the community; (3) The promotion of community health studies; (1) The organization and promotion of classes in first aid and life saving, thereby tending to prevent accidental injury and death.

The Red Cross nursing serrice has already been referred to. The activities of the Department of Nursing have been outlined as follows:- "(1) Providing a public health nurse for your community, if you have none; (2) Conducting class in home care of the sick; (3) Assisting in organizing and supervising any health activity pertaining to nutrition."

The peace-time health program of the Red Cross, as outlined abore, is too recent in origin to permit of conclusions as to its efficacy for community health betterment *January $5,1920$. 
but, if we may judge from past performances, the American Red Cross may be expected to accomplish appreciable results and to play an important part in the movement for better health.

Howerer, it is to be remembered that the Red Cross is not to be considered as a sort of enlarged health department which undertakes to solve the health problems of the world but rather that the health movement is simply an attempt to make the resources of experience and information of this vast organization available to each and every community where the health is appreciated and where serious efforts are being made for its ultimate improvement.

The Russell Sage Foundation is an endowment fund which is devoted in part to the development of public health. The purpose of the Sage Foundation is "the improrement of social and living conditions in the United States of America." The endowment consists of $\$ 10,000,000$ donated by Mrs. Russell Sage. It is apparently the policy of the trustees of the fund to devote the income largely to research, but they have in several instances taken an active part in health morements among which may be mentioned the anti-tuberculosis campaign, medical inspection in schools, and the management of children in institutions. A publication department is maintained and many books and pamphlets on subjects dealing with health and welfare are published.

The New York Department of Health has a slogan to the effect that within limits health is purchasable. Certainly the studies and experiences of these organizations would secm to justify this statement and to show that, in some cases at least, it may be purchased at a comparatively low price. However, in spite of the evidence at hand, it has taken many years and much labor to induce legislatures to adopt a broad conception of the health problem and to appropriate funds for health purposes in amounts sufficient to permit the public authorities to wage most effectively the fight against preventable disease. 


\section{REFERENCES}

\section{A PARTIAL LIST OF RECENT PUBLICATIONS}

Amar, Joles: Physiology of Industrial Organization and the ReEmployment of the Disabled, 1919.

American Red Cross: Health Centers, A Field for Red Cross Acitivity. Booklet, Washington, Sept., 1919.

Andreas, J. MAce: Health Education in Public Schools, 1919.

Ayres, May; Williams, Jesse F.; and Wood, Thomas D.: Healthful Sehools, 1918.

Barton, George Edward: Teaching the Sick. A Manual of Occupational Therapy and Re-Education, 1919.

Best, II Arry: The Blind, Their Condition and the Work Being Done for Them in the United States, 1919.

Bishop, Robert H.: Health Center in a Large City, American Journal of Nursing, July, 1917.

Brainerd, ANNIE M.: Organization of Public Health Nursing, 1919. Brend, W. A.: Health and the State, 1918.

Broadhurst, Jean: Home and Community Hygiene. A Text-book of Personal and Public Health, 1918.

Brington, Margaret F.: What Social Workers Should Know About Their Own Communities, Russell Sage Foundation, 1918.

Caвот, Richard C.: Social Work, Essays on the Meeting Ground of Doctor and Social Worker, 1919.

Camos, Jean: Physical and Occupational Re-Education of Maimed, 1919.

Catrin, Locy Carmelia: The Hospital as a Social Agency in the Community, 1918.

Dawson, Bertrand: The Nation's Welfare. The Future of the Medical Profession (Cavendish Lectures), 1918.

Devine, Edward T.: Disabled Soldiers and Sailors Pensions and Training, 1919.

Doblin, Loois I.: Mortality Statistics of Insured Wage Earners and Their Families. Experience of the Metropolitan Life Insurance Company, Industrial Department, 1911-16.

Everetr, RAY H.: The cost of Venereal Discase to Industry, Jour. of Industrial Hygiene, Sept`mber, 1920.

Faries, John Culbert: The Economic Consequences of Physical Disability, Red Cross Institute for Crippled and Disabled Men, New York, 1918.

Framinaham Community Health and Tuberculosis DemonstraTIONS: Monographs, Community Health Station, Framingham, Mass., 1918-1919.

Goler, Geonge W.: Rochester Bureau of Health Consultation, Public Health Journal, July, 1917.

Harl, Heraert J.: Bedside and Wheel-Chair Occupations, Red Cross Institute for Crippled and Disabled Men, New York, 1919. 
Harris, Garrard: and Billings, Frank: The Redemption of the Disabled. A Study of Programs of Rchabilitation for the Disabled of War and of Industry, 1919.

Horfman, Frederick L.: Industrial Accidents in the United States and Their Relative Frequency in Different Occupations, Prudential Life Insurance Company, 1918.

- A Plan for More Effective Federal and State Health Administration, Prudential Life Insurance Company, 1919.

Hogan, F. B.: Schools for Health Centers, Survey, Dec. 14, 1918.

League of Red Cross Societies Bulletin: The Public Health Program, July, 1920.

Lippite, Louisa C.: Personal Hygiene and Home Nursing, 1919.

MacKenzie, James: The Future of Medicine, 1919.

McDill, Jonn R.: Lessons from the Enemy. How Germany Cares for Her War Disabled, 1918.

McMurtrie, Douglas C.: The Disabled Soldier, 1919.

:- The Evolution of National Systems of Vocational Rehabilitation. Issued by Federal Board, 1918.

Menical Research Committee: National Health Insurance, Third Annual Report, London, 1917.

-: An Inquiry into the Prevalence and Etiology of Tuberculosis Among Industrial Workers, London, 1919.

Meyer, ErNst C.: Hospital Service in Rural Communities, Journal American Medical Association, April 19 and 26, May 3, 10, and 17, 1919.

Mock, Harry E.: Industrial Medicine and Surgery, 1919.

National Industrial Conference Board: Hours of Work as Related to Output and Health of Workers, Boston, 1919.

National Social Unit Organization: Bulletins 1 to 5, New York, 1919.

New York State Department of Healtm: Health Centers, Monthly Bulletin, Aug. and Dec., 1918; Feb. and June, 1919.

Pattison, H. A.: Productive Vocational Workshops for Rehabilitation of the Tuberculous and Other Disabled Soldiers, Federal Board for Vocational Training, 1919.

Peterson, Erwin A.: The Program of the Red Cross, Journal Amer. Med. Assn., Aug. 28, 1920.

Ross, Elizabetr: Health Activities at a Civic Center in a Small Community, American Journal of Nursing, August, 1917.

Schafer, A. C.: Public Health Center Field Work, New York State Journal of Medicine, April, 1917.

Stokes, JonN H.: Today's World Problem in Disease Prevention. A Non-Technical Discussion of Syphilis and Gonorrhoea, U. S. Public Health Service, 1919.

IVriout, Florence Swift: Industrial Nursing, 1919.

Government Documents

Reports and special articles bearing on community health are published by the Children's Bureau and the Labor Statistics Bureau of the Department of Labor; by the Public Health Service of the Treasury Department; and by the Bureau of Education, Department of the Interior. The Federal Board of Vocational Education publishes a monthly magazine and a series of bulletins on rehabilitation. 


\section{N D E X}

Accidents, Prevention of $\ldots \ldots \ldots \ldots \ldots \ldots \ldots \ldots 6,62$

Accidents, Industrial, and Liability Laws ........ 67

Adults, Sick Rates .................... 9

Administration of Compensation Laws .......... $r_{1}$

Alameda County Health Center ............. 104

American Association of Labor Legislation ....... 76

American Red Cross Health Centers ........... 99

American Red Cross, Peace Time Program ....... 148

Appropriations for Public Healtl ............ 35

Bedside Nursing .................. 42

Benefits, of Compensation Acts ............ 70

Benefits, of Health Insurance ............ 82

Board of Health, Appropriations for .......... 35

Board of Health, Local ................. 33

Board of Health, North Carolina ............ 36

Board, International Health . . . . . . . . . . 143

Bureau of Child Hygiene................ 8

Campaign for Better Health ............... 54

Care of Employees ..................... 89

Case Histories, Disabled Soldiers . . . . . . . 136

Cash Benefits of Compensation Laws .......... 70

Center, Maternity .................... 50

Centers, Industrial $\prod_{e a l t h i} \ldots \ldots \ldots \ldots \ldots \ldots \ldots . \ldots 2$

Centers, Health . . . . . . . . . . . . . . . 99

Centers, Red Cross ..................... 99

Children, Examination of School ............ 8

Church Control of Nursing ............... 48

Civilian Cripples, Rehabilitation of .......... 137

Colleges Teaching Public Health Nursing ........ 41

Community Health, The Private Physician and..... 23

Community Nursing .................. 48

Compensation Insurance, Workmen's ......... 6 \%

Compensation Laws, Effect on Use of Safety Devices. 74 


\section{INDEX}

Compulsory Health Insurance $\ldots \ldots \ldots \ldots \ldots \ldots \ldots$ 75

Crippled and Disabled Men, Institute fur......... 60

Crippled Employees of Ford Motor Company....... 60

Cripples, Civilian, Rehabilitation of $\ldots \ldots \ldots \ldots \ldots 137$

Cripples, Industrial ................. 129

Death Benefits Under Compensation Laws......... 70

Defective Children in New York State ......... 8

Demonstration, Framingham Health ......... 10

Demonstration, Health $\ldots \ldots \ldots \ldots \ldots \ldots \ldots \ldots .6 . \ldots$

Departments, Health $\ldots \ldots \ldots \ldots \ldots \ldots \ldots \ldots . . . \ldots$

Departments, Local Healih ............... 34

Departments, State Health ............... 33

Disabled, Rehabilitation of .............61, 128

Disabled Soldiers, Case Histories ............ 136

Disabled Soldiers, Rehabilitation of ........... 61

Disability As Cause of Mental Depression......... 128

Disabled in Selective Draft ................ 4

Disability Insurance for Employces ........... 91

Disability, Percentage in Community .......... 12

Disability, Percentage in Draft Examinations....... 6

Disability Table of Defects Found in Draft....... 5

Disease, Hookworm, Methods Used Against ....... 143

Disease, Prevention of $\ldots \ldots \ldots \ldots \ldots \ldots \ldots \ldots . \quad 56$

Disease, Treatment of $\ldots \ldots \ldots \ldots \ldots \ldots \ldots \ldots \ldots \ldots$

Diseases, Cause of $\ldots \ldots \ldots \ldots \ldots \ldots \ldots \ldots \ldots \ldots \ldots \ldots \ldots$

Diseases, Industrial and Tirkmen's Compensation.... 72

Draft Army, Percentage of Defects in .......... 6

Draft, Disability Discovered by ............... 4

Draft, Table, Disability Discovered by.......... 5

Dumferline Scale .................... 8

Dutchess County Survey ................. 27

Education Influenced by Rockefeller Fuundation.... 142

Employees, Medical Care of .............. 89

Employments Included Under Wor'smen's Compensation 71

Endowed Health Demonstrations .............. 139

Examination of School Children ............

Expenditure for Sickness ................ 17

Expenditures of Local Health 1 Departments ........ 34

Expenditures, Yearly for Sickness ............ 18

Experiment, Social Unit ................. 108

Federal Board of Vocationai Training .......... 131 


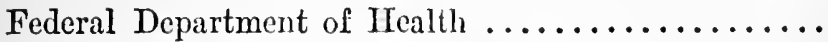
Fees for Public Health Nursing ............... Ford Motor Company and Disabled Employees.......

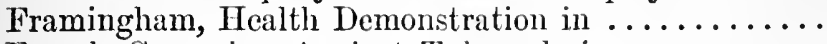
French Campaign Against Tuberculosis .......... Government, Expenditures for Health ............ Government, Federal, and Disabled Soldier ......... Handicap, in Vocational Training . .............. Health Appropriation Per Capita ................ Health Board, International

Health Campaign in North Carolina ............

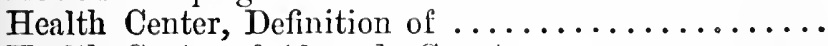
Health Center of Alameda County $\ldots \ldots \ldots \ldots \ldots \ldots \ldots \ldots$
Health Centers $\ldots \ldots \ldots \ldots \ldots \ldots \ldots \ldots \ldots \ldots$

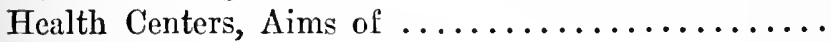

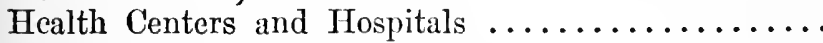
Health Centers, Industrial $\ldots \ldots \ldots \ldots \ldots \ldots \ldots \ldots$ Health Centers, Red Cross Program ............. Health Centers, Sage-Machold Bill for ........... Health Centers, Ten Reasons for $\ldots \ldots \ldots \ldots \ldots \ldots$

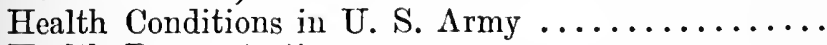

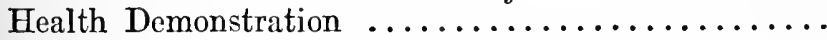

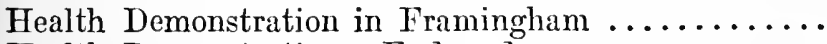
Health Demonstrations, Endowed

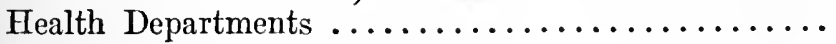

Health Departments, Local

Health Departments, State $\ldots \ldots \ldots \ldots \ldots \ldots \ldots$.

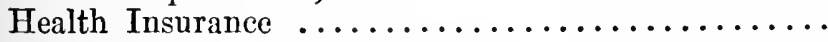

34

33

21

Health Insurance and the Public ............. 81

Health Insurance, Cash Benefits in .......... 82

Health Insurance, Compulsory . .............. 75

Health Insurance for Industrial Workers ......... 90

Health Insurance, Growth of $\ldots \ldots \ldots \ldots \ldots \ldots \ldots .75$

Health Insurance, Meaning of $\ldots \ldots \ldots \ldots \ldots \ldots \ldots$ \% 6

Health Insurance, Medical Care in .......... 79

Health Insurance Premiums ................ is

Health Program of American Red Cross ........... 148

Health Service in Social Unit Experiment ....... 112

Health Study by Metropolitan Life Insurance Co..... 9

Henry Street Settlcment ................ 50

Home Care $. . . \ldots \ldots \ldots \ldots \ldots \ldots \ldots . \ldots \ldots$ 


\section{INDEX}

Hookworm Disease Combated by Rockefeller Founda-

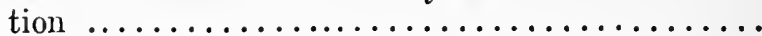

Hookworm Survey in Jamaica .............. 144

Hospital Care ....................... 65

Hospitals and Health Centers .............. 104

Hygiene, Social ..................... 122

Industrial Cripples .................... 129

Industrial Diseases Under Compensation Laws ...... 72

Industrial Health Centers ...............87, 102

Industrial Hygiene in Public Health Service Program 31

Industrial Medicine ................... 84

Industrial Medicine and Home Care ........... 65

Industrial Medicine, Expenses of $\ldots \ldots \ldots \ldots \ldots \ldots 86$

Industrial Medicine, Methods $\ldots \ldots \ldots \ldots \ldots \ldots \ldots$.

Industrial Nursing $\ldots \ldots \ldots \ldots \ldots \ldots \ldots \ldots \ldots \ldots .45$

Industrial Physician, Work of ............. 103

Industry, Physical Examination in ........... 88

Infancy, Disease of, in Public Health Service Program 32

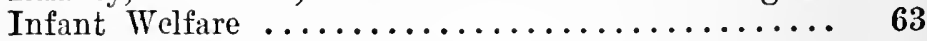

Injury, Treatment of $\ldots \ldots \ldots \ldots \ldots \ldots \ldots \ldots \ldots, 58$

Insurance Carriers for Proposed Health Insurance... 77

Insurance Carriers for Workmen's Compensation In-

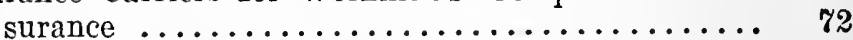

Insurance, Compulsory Health .............. 75

Insurance for Industrial Workers $\ldots \ldots \ldots \ldots \ldots \ldots .96$

Insurance, Health .................... 1 , 72

Insurance Nursing ................... 51

Insurance, Workmen's Compensation .......... 67

Institute for Crippled and Disabled Men........60, 130

International Health Board ............... 143

Jamaica, Hookworm Survey in ............. 144

Kensington Survey ................... 17

Liability Laws and Industrial Accidents........... 67

Life Insurance Nursing .................. 51

Loss of Wages Due to Sickness .............. 17

Major Handicap in Vocational Training ......... 134

Major Ills in Framingham Survey ............ 11

Malaria, Arkansas Experiment ............... 145

Malaria, Control of .................... 145

Malaria, Expenses for Extermination of ........ 19

Mal-nutrition in School Children ............ 8 
Mal-nutrition, Public Health Service Program....... Maternity Care

Maternity Center

Medical Attention During Vocational Training .....

Medical Attention Under Compensation Laws .......

Medical Care in Social Unit Experiment ...........

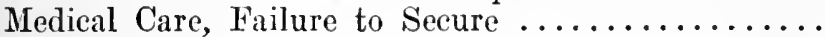

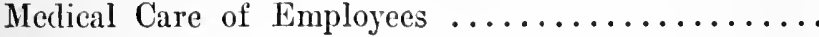

Medicine, Industrial

111

Medicine, State

Mental Depression Caused by Disalility ............

Metropolitan Life Insurance Co., Sickness Surveys by..

Metropolitan Life Insurance Nursing $\ldots . . . . . . .6$

128

Minor Handicap in Vocational Training ............

Minor Ills, Table of

9,26

51

134

Mohawk-Brighton Experiment, Evaluation of .......

National Organization for Public Health Nursing....

109

39

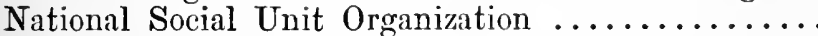

108

Negligible Handicap in Vocational Training ........ 134

New York City, Examination of School Children....

New York City, Mal-nutrition in School Children...

New York State, Physical Condition of School Children

North Carolina Health Campaign ............

Nursing, Community ..................

Nursing Industrial

Nursing in Public Health Work..............

Nursing, Insurance $\ldots . \ldots \ldots \ldots \ldots \ldots \ldots \ldots \ldots$.

Nursing, Public Health $. \ldots \ldots \ldots \ldots \ldots \ldots . . . .$.

Nursing, School

52

51

38

46

Nursing Service for Industrial Workers..........

Organization for Public Health Nursing .............

Organization, Social Unit

100

Percentage of Defects in Draft Army...............

Physical Examination in Industry

Physician, Private in Community Health Work......

Physician, Relation of Visiting Nurse and.........

Physicians and Vocational Training $. . . . . \ldots \ldots . . .6$.

Physicians, Attitude of Toward Health Insurance....

Physician's Calls Influenced by Malarial Control..... Physicians, Under State Medicine ............... 
Porerty and Sickness .................. 15

Premiums of Health Insurance ............ 78

Pre-natal Care ............................6 63

Prevention of Accidents $\ldots \ldots \ldots \ldots \ldots \ldots \ldots \ldots, 56$

Prevention of Discase ................. 56

Private Practice and State Medicine ........... 93

Public Attitude Toward Health Insurance........ 81

Public Health, A Function of the State ......... 81

Public Health Nursing $\ldots \ldots \ldots \ldots \ldots \ldots \ldots \ldots \ldots .638$

Public Health Nursing and Red Cross .......... 40

Public Health Nursing, Fees for ............. 49

Public Health Nursing, Growth of ........... 39

Public Health Nursing in Social Unit .......... 110

Public Health Nursing for Tuberculosis ......... 44

Public Health Nursing, National Organization for... 39

Public Health Nursing, Specialization in ........ 43

Public Health Nursing, Training for .......... 40

Public Health Service ................... 31

Public Health Service Campaign Against Sex Diseases 124

Public Health and Visiting Nursing .......... 52

Red Cross Health Centers ................. 99

Red Cross Program for Health Centers .......... 106

Red Cross Public Health Nursing ............. 40

Rehabilitation ....................... 59

Rehabilitation of Civilian Cripples ........... 137

Rehabilitation of Disabled Soldiers ..........61, 128

Rehabilitation, Origin of $\ldots \ldots \ldots \ldots \ldots \ldots \ldots \ldots \ldots$

Rockefeller Foundation .................. 139

Rockefeller Foundation, Malarial Expenses in Arkansas 19

Rural Hygiene in Public Health Service Program.... 31

Russell Sage Foundation, Influence on Public Health.. 149

Safety Devices Increased by Compensation Laws..... 74

Sage-Machold Bill for Health Centers . .......... 105

Scale, Dumferline .................... 8

School Children, Examinations of $\ldots \ldots \ldots \ldots \ldots \ldots$ 7

School Children, Physical Condition in New York

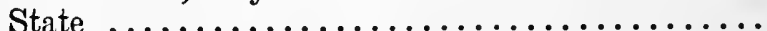

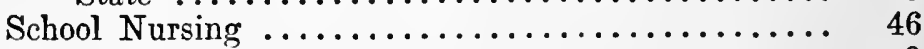

Service, Health ................... 9

Sewage Disposal, Public Health Service Program.... 32

Sex Diseases, Control of $\ldots \ldots \ldots \ldots \ldots \ldots \ldots \ldots . \ldots 123$ 
Sex Diseases, Public Health Service Campaign Against 124 Sex Diseases, Treatment of ............... 125 Sick, Percentage in Community ............. 12 Sick Rates for Adults ................... 9 Sickness As a Cause of Wage Loss.............. 17 Sickness, Expenditure for ............... 17 Sickness, Responsibility for $\ldots \ldots \ldots \ldots \ldots \ldots \ldots \ldots . \ldots$ Sickness Surveys ..................... 6 Sickness Survey, by Metropolitan Life Insurance Co.. 26 Sickness, Yearly Expcnditures .............. 18 Social Hygiene $\ldots \ldots \ldots \ldots \ldots \ldots \ldots \ldots \ldots 4,122$ Social Hygiene, Medical Control ............ 122 Social Hygiene, Military Control ............ 123 Social Unit Experiment .................. 108 Social Unit Experiment, Medical Care .......... 111 Social Unit Experiment, Tuberculosis Activities in.. 111 Social Unit Nursing ................... 110 Social Unit Plan ..................... 108 Social Unit Plan, Criticism of ............. 113 Soldiers, Disabled, Rehabilitation of $\ldots \ldots \ldots \ldots \ldots .61$ Specialization in Public Health Nursing ......... 43 State Health Departments ................ 33 State Medical Service .................. 95

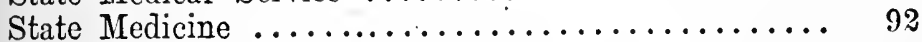
State Medicine and Private Practice ............ 93 State, Public Health a Function of............. 81 Study of Mal-nutrition $\ldots \ldots \ldots \ldots \ldots \ldots \ldots \ldots \ldots$. Surgeon General's Report of Draft Defects........ 5 Survey, Dutchess County ................. 27 Survey, in Framingham, Mass. .............. 11 Survey, in Jamaica ................... 144 Survey, Kensington ................... 17 Surreys, Sickness ..................... 6 Totally Disabled, Care of $\ldots \ldots \ldots \ldots \ldots \ldots \ldots \ldots .61$ Training, Vocational .................... 130 Treatment of Disease $\ldots \ldots \ldots \ldots \ldots \ldots \ldots \ldots \ldots, 58$ Treatment of Injury $\ldots \ldots \ldots \ldots \ldots \ldots \ldots \ldots \ldots, 58$ Tubercle Bacilli, Distribution of $\ldots \ldots \ldots \ldots \ldots \ldots, 115$

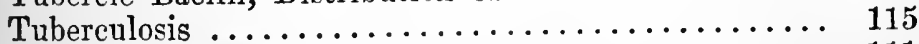
Tuberculosis Activities in Social Unit........... 111 Tuberculosis, Control of $\ldots \ldots \ldots \ldots \ldots \ldots \ldots \ldots 116$ 


$$
645560
$$





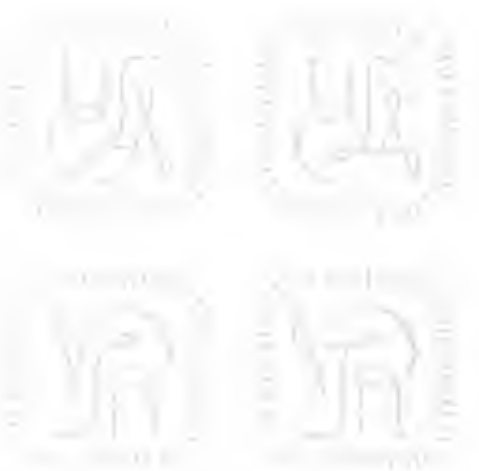



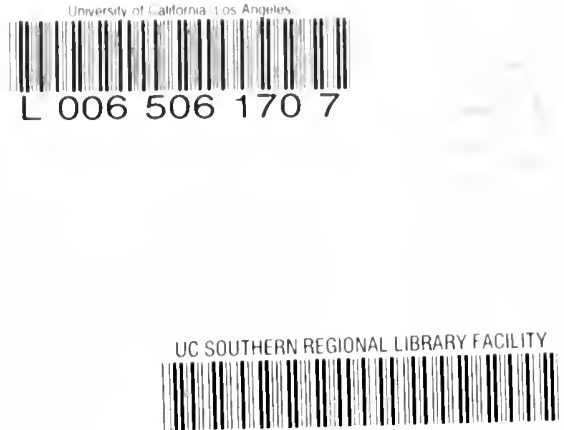

AA $000681200 \quad 2$ 
